\title{
Skills and the employability of university graduates
}

Citation for published version (APA):

Humburg, M. (2014). Skills and the employability of university graduates. [Doctoral Thesis, Maastricht University]. ROA. https://doi.org/10.26481/dis.20141002mh

Document status and date:

Published: 01/01/2014

DOI:

10.26481/dis.20141002mh

Document Version:

Publisher's PDF, also known as Version of record

\section{Please check the document version of this publication:}

- A submitted manuscript is the version of the article upon submission and before peer-review. There can be important differences between the submitted version and the official published version of record.

People interested in the research are advised to contact the author for the final version of the publication, or visit the DOI to the publisher's website.

- The final author version and the galley proof are versions of the publication after peer review.

- The final published version features the final layout of the paper including the volume, issue and page numbers.

Link to publication

\footnotetext{
General rights rights.

- You may freely distribute the URL identifying the publication in the public portal. please follow below link for the End User Agreement:

www.umlib.nl/taverne-license

Take down policy

If you believe that this document breaches copyright please contact us at:

repository@maastrichtuniversity.nl

providing details and we will investigate your claim.
}

Copyright and moral rights for the publications made accessible in the public portal are retained by the authors and/or other copyright owners and it is a condition of accessing publications that users recognise and abide by the legal requirements associated with these

- Users may download and print one copy of any publication from the public portal for the purpose of private study or research.

- You may not further distribute the material or use it for any profit-making activity or commercial gain

If the publication is distributed under the terms of Article $25 \mathrm{fa}$ of the Dutch Copyright Act, indicated by the "Taverne" license above, 
SKILLS AND THE EMPLOYABILITY

OF UNIVERSITY GRADUATES 
(c) Martin Humburg, Maastricht 2014

All rights reserved. No part of this publication may be reproduced, stored in a retrieval system, or transmitted in any form, or by any means, electronic, mechanical, photocopying, recording, or otherwise, without the prior permission in writing, from the author.

Published by ROA

Postbus 616

6200 MD Maastricht

ISBN: 978-90-5321-529-6

Printed in the Netherlands by Océ Business Services 


\title{
SKILLS AND THE EMPLOYABILITY OF UNIVERSITY GRADUATES
}

\author{
Proefschrift \\ ter verkrijging van de graad van doctor aan \\ de Universiteit Maastricht, \\ op gezag van de Rector Magnificus, \\ Prof. dr. L.L.G. Soete \\ volgens het besluit van het College van Decanen, \\ in het openbaar te verdedigen op \\ donderdag 2 oktober 2014 om 10.00 uur \\ door \\ Martin Humburg
}




\section{Promotoren}

Prof. dr. A. de Grip

Prof. dr. R.K.W. van der Velden

\section{Beoordelingscommissie}

Prof. dr. L. Borghans (voorzitter)

Prof. dr. P. Elias

Prof. dr. W. Gijselaers 


\section{ACKNOWLEDGEMENTS}

Finishing my dissertation feels good. Not because writing it has been a cumbersome process or because I am glad it is over. On the contrary: I very much enjoyed the past five and a half years working towards obtaining my PhD. It was exactly what I wanted to be doing and I felt at home at ROA and in the academic atmosphere at Maastricht University.

I would like to express a sincere word of gratitude to many people who made this dissertation possible and who made the past five and a half years such a productive time and a pleasant experience. First of all, I am greatly indebted to my supervisor Rolf van der Velden. It was he who hired me as his research assistant in March 2008 after receiving an e-mail explaining that some German guy needed any kind of job in Maastricht because his girlfriend lived here and because he needed to finance his part-time $\mathrm{PhD}$ project. There are not many people who would have taken this e-mail seriously and I am thankful that Rolf had the curiosity to invite me for a talk.

I am grateful to Rolf and to Andries de Grip, my other supervisor, for supporting my successful application for a Maastricht University METEOR grant in September 2008, and for providing guidance, support and invaluable comments throughout the entire $\mathrm{PhD}$ project. Another important word of thanks goes to Jim Allen, for countless inspiring discussions on my research and for thousands of ROA hallway meters we have walked together to the coffee machine discussing movies and tennis. I feel bad about not letting Jim be part of the Corona on the day of my defence, but I prefer to have him stand behind me as my paranymph.

A special thanks to my first roommates Sander Dijksman and Timo Huijgen for making me feel welcome at ROA, for encouraging me to practice my Dutch on them, and for cycling through the beautiful hills of Limburg with me. I wish to thank my second roommate Charlotte Büchner for many much-valued discussions and, most importantly, lots of laughs. The (former) post-docs Eric Bonsang and Olivier Marie, whom I consulted at least once a day on econometric matters, deserve special mention. I thank Eric for being my third roommate, and for the deep conversations we had about science and life. Many thanks to Olivier for not being resentful when Germany eliminated France and Brazil in this year's Football World Cup.

Annemarie Künn-Nelen, Raymond Montizaan and Jan Sauermann were excellent PhD candidates to follow and seek advice from. It was a stroke of luck that Achmed Elsayed, Jan Feld, Roxanne Korthals, Nicolas Salamanca, Olga Skriabikova, Maria Zumbühl and me all started writing our dissertations at around the same time, enabling us to share experiences and to discuss each other's work.

During the past six years, I have had countless pleasant conversations and chats with my dear colleagues. The School of Business and Economics, and in particular the people working at $\mathrm{ROA}$, provided me with a productive environment many other $\mathrm{PhD}$ candidates can only dream of. I would like to express special thanks to Willeke Klein, Mariëlle Retz and Esther Soudant for editing my thesis and for making it ready for publication. Joyce Gruijthuijsen deserves a special word of appreciation for her hospitality during the first days at ROA and for her great assistance in administrative matters ever after. 
Finally, I am most grateful to my family and friends, in particular my wife Laura and my two daughters Ema and Paula, for making my life such a happy one. Many people would have become afraid at the thought of starting a family while both parents are writing their PhDs. You, Laura, never had the slightest doubt that it would work out just fine. And, as always, you were right! 


\section{CONTENT}

List of Figures $\quad$ ix

List of Tables $\quad$ x

01 Introduction 1

1.1 Motivation 2

1.2 Aim of the study 3

1.3 Outline of the study 4

02 What is Expected of Higher Education Graduates in the 21st Century? 7

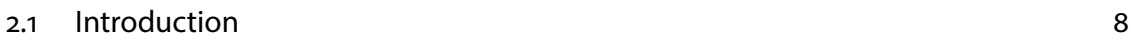

2.2 The trends and related skills 8

2.2.1 The knowledge society and professional expertise 8

$\begin{array}{ll}\text { 2.2.2 Increasing uncertainty and flexibility } & 10\end{array}$

2.2.3 The ICT revolution and innovation and knowledge management 12

2.2.4 The emergence of high performance work places and the mobilization of $\begin{array}{ll}\text { human resources } & 14\end{array}$

2.2.5 Globalization and international orientation $\quad 16$

2.2.6 The change of the economic structure and entrepreneurship 17

$\begin{array}{ll}2.3 \text { Conclusion } & 20\end{array}$

03 Skills and the Graduate Recruitment Process 21

$\begin{array}{ll}3.1 & \text { Introduction } \\ 3.2 & 22\end{array}$

3.2 Literature review and theoretical framework 23

3.3 Data and methodology 25

3.4 Econometric model 30

3.5 The right CV for getting invited to the job interview 32

3.6 Which skills are getting graduates the job? 39

$\begin{array}{ll}3.7 & \text { Conclusions } \\ \end{array}$

04 Personality and Field of Study Choice 51

4.1 Introduction $\quad 52$

4.2 Data and methodology 54

$\begin{array}{lll}4.3 & \text { Results } & 59\end{array}$

$\begin{array}{ll}4.4 \text { Conclusion } & 65\end{array}$ 
05 Which Skills Protect Graduates Against a Slack Labour Market 71

$\begin{array}{lll}5.1 & \text { Introduction } & 72\end{array}$

$\begin{array}{ll}5.2 & \text { Conceptual framework } \\ & 73\end{array}$

$\begin{array}{lll}5.3 & \text { Hypotheses } & 74\end{array}$

$\begin{array}{lll}5.4 & \text { Data } & 77\end{array}$

$\begin{array}{ll}\text { 5.5 Estimation results and discussion } & 79\end{array}$

$\begin{array}{lll}5.6 & \text { Conclusion } & 83\end{array}$

06 Conclusions

6.1 Summary 88

6.1.1 What are the trends that shape the labour market of graduates and how do they affect employers' skill demand? 88

6.1.2 Which skills are most important in the graduate recruitment process? 90

6.1.3 How is students' personality related to their field of study choice? 90

6.1.4 Which skills protect graduates against a slack labour market? 91

$\begin{array}{ll}6.2 \text { Contribution and implications } & 92\end{array}$

$\begin{array}{lr}\text { Valorisation addendum } & 97\end{array}$

$\begin{array}{ll}\text { Bibliography } & 101\end{array}$

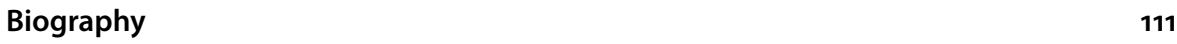

$\begin{array}{ll}\text { ROA Dissertation Series } & 113\end{array}$ 


\section{LIST OF FIGURES}

Figure 1.1: Framework of the thesis 4

Figure 3.1: Choice set example CV attributes $\quad 27$

Figure 3.2: Choice set example skills $\quad 29$

Figure 3.3: Graphical illustration of salary attribute coefficients displayed in Table $3.2 \quad 37$

Figure 3.4: Graphical illustration of salary attribute coefficients displayed in Table $3.4 \quad 43$

Figure 3.5: Concave relationship between productivity and skill level 47

Figure 5.1: Four labour market segments and available jobs for graduates. 76 


\section{LIST OF TABLES}

Table 2.1: Skills and related aspects $\quad 20$

Table 3.1: Sample descriptives $\quad 26$

Table 3.2: Mixed logit model of selecting graduates for a job interview 32

Table 3.3: Employers' willingness to pay for CV attributes 38

Table 3.4: Mixed logit model of selecting graduates for hiring 40

Table 3.5: Employers' willingness to pay for skills 44

$\begin{array}{ll}\text { Table 3.6: } & \text { Proportional frequencies of attributes in choice set and selected } \\ & \text { graduate profile }\end{array}$

Table 4.1: Personality traits and their definitions 53

Table 4.2: Comparison of sample to national distribution 55

Table 4.3: Personality traits and cognitive skills by educational level and gender $\quad 56$

Table 4.4: Personality traits and cognitive skills by field of study in university and gender $\quad 58$

Table 4.5: Average marginal effects of personality traits and cognitive skills on individuals' probability of going to university (ordered probit model) 60

Table 4.6: Average marginal effects of personality traits and cognitive skills on probability of choosing a particular field of study in university, by gender 62

Table 4.7: Detailed field of study categories and six categories used in multinomial logit framework by gender

Table 4.8: Summary statistics of variables used in multinomial logit model of field of study choice

Table 4.9: Mean self-reported hours spent studying per week 70

Table 4.10: Mean self-reported demandingness of study (5 point scale) 70

Table 5.1: Overall unemployment rates and unemployment rates in the occupational domain of particular fields of study per country $\quad 78$

Table 5.2: Probability of being overeducated five years after graduation 81

Table 5.3: Probability of being overeducated for different levels of field-specific skills and unemployment in occupational domain of field of study (other variables fixed at mean)

Table 5.4: Probability of being overeducated for various levels of academic skills and overall unemployment (other variables fixed at mean)

Table 5.5: Probability of being unemployed five years after graduation

Table 5.6: Descriptives of variables used in multivariate analysis (overeducation model)

Table 5.7: Marginal effects of preferred models of overeducation and unemployment 
INTRODUCTION 


\subsection{Motivation}

Young adults commonly see obtaining a university degree as an important step towards a labour market career which is satisfying both in terms of earnings and non-pecuniary job characteristics. On average, graduates earn more than their lower educated counterparts and are employed in jobs which are less dangerous, involve less physically demanding tasks, and at the same time offer greater work autonomy and more task discretion (OECD, 2013a). The fulfilment of young adults' expectations with regard to the advantages of obtaining a university degree is to a large extent contingent upon their ability to find a graduate job after leaving university. This, however, is by no means certain. Unemployment and educational mismatch - being employed in a job which does not formally require a university degree - are common problems among recent graduates: about 10 per cent of European young adults aged 25-29 with a tertiary degree are unemployed, ranging from 3 per cent in Germany and Norway to 24 per cent in Spain and 38 per cent in Greece (Eurostat, 2013). Graduate surveys suggest that the percentage of graduates employed in jobs which do not require a higher education degree is at least as high as the percentage of graduates unemployed (Barone and Ortiz, 2011). Consequently, one out of five European graduates in their twenties - a critical age for gaining first experience in the labour market and developing a professional career - is either unemployed or educationally mismatched. Although unemployment has certainly the most detrimental effect on earnings, it is well documented that also educational mismatch is associated with a substantial earnings penalty and lower job satisfaction compared to graduates who are employed in a graduate job (Groot and Maassen van den Brink, 2000; Hartog, 2000; Chevalier, 2003; Sloane, 2003; Green and Zhu, 2010).

Previous research indicates that graduates' ability to avoid unemployment and educational mismatch is related to the skills they possess. Graduates with higher skill levels are commonly found to have a higher probability of being employed, a lower probability of being educationally mismatched, and to have higher average earnings than their peers with lower skill levels (McGuinness, 2003; Chevalier and Lindley, 2009; Allen and Van der Velden, 2011; Levels, Van der Velden, and Allen, 2013). Skills are a central concept in human capital research and a major driver of labour market success as they increase individuals' productivity (Becker, 1962; Nelson and Phelps, 1966; Schultz, 1975, Bowles and Gintis, 1976). While differences in skill levels are most obvious for individuals with different educational attainment, skills are heterogeneous even within educational levels (Allen and Van der Velden, 2001). Against this background, a substantial part of graduates who are unemployed or employed in jobs which do not require a university degree simply do not possess the skill level required by graduate jobs (Oosterbeek and Leuven, 2011, Chevalier, 2003; Chevalier and Lindley, 2009; Levels, Van der Velden, and Allen, 2013).

Besides the skill level, there is evidence that graduates' employability depends on the types of skills they possess. For example, it has been shown that field-specific skills decrease graduates' probability of becoming unemployed or educationally mismatched whereas other skills, such as flexibility, are unrelated to these outcomes (Allen and Van der Velden, 2011; Verhaest and Van der Velden, 2013). Furthermore, Biesma et al. (2007) find that employers in the occupational field of public health prefer graduates with strong problem solving skills, creativity and interpersonal skills over graduates who are highly flexible and have a lot of 
public health knowledge. Employable graduates are thus graduates who possess the level, but also the types of skills employers need for their productive processes. This points to the challenge of effectively translating higher education into higher skills, and types of skills which are demanded by the labour market.

While unemployment and educational mismatch are serious negative labour market outcomes for individuals, a substantial portion of the costs of higher education is provided by the public, and so the public too has an interest in the returns to higher education to be in accordance with investments made. The increasing participation in higher education makes this more and more important. This is part of the reason why the concept of employability has become popular among policy makers in recent years. In particular, policy makers hope that increasing graduates' employability - i.e. aligning skill supply with skill demand - will lower youth unemployment by solving existing supply shortages and by stimulating economic growth through technological and organizational change and innovation (OECD, 1999; European Commission, 2010; Council of the European Union, 2012; OECD, 2013b).

\subsection{Aim of the study}

The central theme of this thesis is the relationship between skills and graduates' employability. I examine this relationship from three different perspectives: economic and organizational trends, employers' skill demand, and individuals' skill supply. Overall, this thesis attempts to answer the following four questions.

1. What are the trends that shape the labour market of graduates and how do they affect employers' skill demand?

2. Which skills are most important in the graduate recruitment process?

3. How is students' personality related to their field of study choice?

4. Which skills protect graduates against a slack labour market?

The relation of these questions to the perspectives taken in this thesis is depicted in Figure 1.1.

This thesis sets out with chapter 2 which focuses on question 1 and analyses how employers' demand for various types of skills is shaped. Surveying various strands of literature, we attempt to give a comprehensive overview of the trends which affect the labour market of today's graduates and to relate these trends to the demand for particular types of skills. These types of skills are: professional expertise, flexibility, innovation and knowledge management skills, skills with regard to the mobilization of human resources, international orientation, and entrepreneurial skills.

While chapter 2 gives a detailed account of the types of skills which are important for performing typical graduate job tasks, it does not assess their relative importance for graduates' employability. Chapter 3 attempts to answer question 2 and elicits employers' preferences for graduate skills. It tests the relative importance of a selection of the types of skills highlighted in chapter 2 . 
Figure 1.1

Framework of the thesis

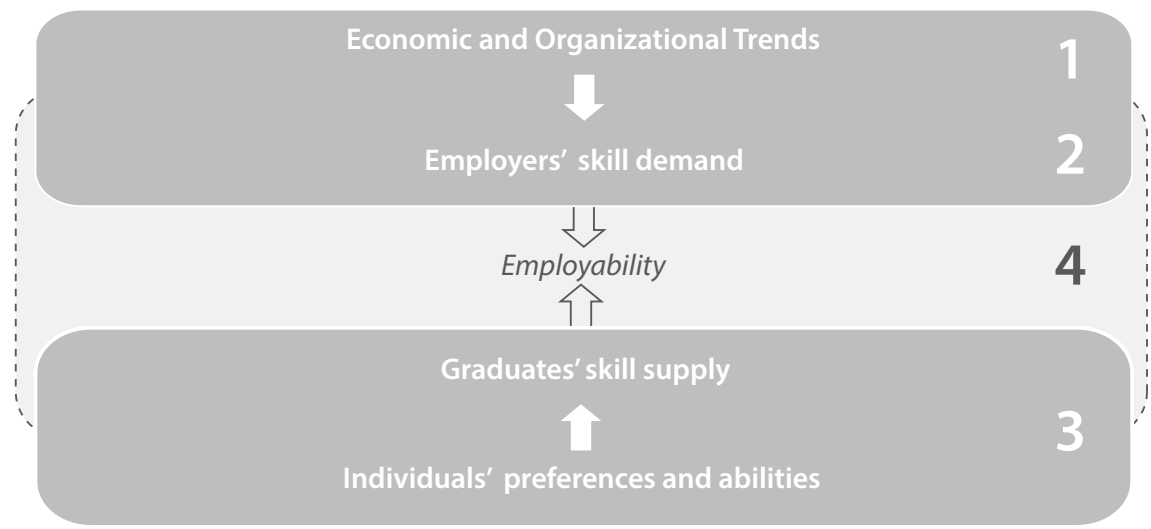

Knowing employers' preferences for skills may help graduates to decide which skills to acquire in order to be successful in the labour market. Against this background, chapter 4 examines how personality influences individuals' field of study choice (question 3). It elaborates on the extent to which individuals' preferences for subject matters and work environments, captured by their personality, are important determinants of individuals' skill profile.

Finally, chapter 5 examines what happens when graduates' skill supply meets employers' skill demand. This chapter focuses on field-specific skills and general academic skills and analyses how proficiency in these skills is related to the probability of being unemployed or employed in a job which does not require a university degree. Moreover, chapter 5 examines how this relationship differs under different degrees of excess labour supply in the overall labour market and in the labour market segment related to the field of study (question 4).

While this thesis considers graduates' skill level in its analysis, one of its major contribution lies in the examination of the relationship between graduates' employability and graduates proficiency in various types of skills. We attempt to shed light on the skill mix employers demand and on how students make educational decisions.

\subsection{Outline of the study}

The structure of this thesis follows the four questions outlined above. Chapter 2 identifies six trends which shape the labour market of today's graduates and analyses how these trends relate to employers' skill demand. Chapter 3 elicits employers' preferences for graduates' skill profiles. Chapter 4 examines how young adults' personality impacts their field of study choice. Chapter 5 explores how graduates' levels of field-specific and academic skills are related to their employability in different labour market segments and under various degrees of excess labour supply. Chapter 6 concludes and discusses the implications of this thesis' findings. 
Chapter 2: What Is Expected of Higher Education Graduates in the $21^{\text {st }}$ Century?

In chapter 2, we reflect on the skills university graduates are expected to have in today's economy. First, we identify six trends which form the basis of the changing role of graduates in economic life. These trends refer to the knowledge society, increasing uncertainty, the ICT revolution, high performance workplaces, globalization, and the change of the economic structure. By changing the nature and range of tasks graduates are expected to fulfil in today's economy, we argue that these trends generate new and intensify traditional skill demands, which we summarize as professional expertise, flexibility, innovation and knowledge management, mobilization of human resources, international orientation, and entrepreneurship. We introduce these six trends knowing that there is no consensus among researchers on the exact number of the drivers of skill demand and how independent these various trends are, let alone how to name and define them. We are aware that in reality these trends are strongly interlinked, with the ICT revolution probably being a main driver of the other trends. However, we are convinced that our categorization of trends and resulting skill demands can serve as a useful tool to examine what is expected of graduates in the $21^{\text {st }}$ century, and what are the drivers of these skill demands.

\section{Chapter 3: Skills and the Graduate Recruitment Process}

In chapter 3, we elicit employers' preferences for a variety of CV attributes and types of skills when recruiting recent university graduates. We are able to show that, when choosing candidates for job interviews, employers attach most value to CV attributes which signal a high stock of occupation-specific human capital and which indicate short adjustment periods and low training costs, such as work experience and a good match between the field of study and the vacancy. In line with this, graduates' professional expertise is one of the major determinants of the probability of being hired in the second stage of the hiring process. However, we also find that interpersonal skills are as important for graduates' employability as professional expertise. Other types and attributes also play a role in the recruitment process but are less important and can therefore not easily compensate for a lack of more occupation-specific human capital and interpersonal skills.

\section{Chapter 4: Personality and Field of Study Choice}

Chapter 4 examines the determinants of field of study choice. While field of study choice relates more to the content of individuals' field-specific skills, analysing its determinants can give important insights into the extent to which individuals react to market signals on skill demand when making decisions concerning their skill profile. In this chapter, I show that individuals' personality substantially influences their field of study choice. The findings of chapter 4 indicate that next to income maximization preferences for subject matters and work environments are important drivers of students' skill acquisition.

\section{Chapter 5: Which skills protect graduates against a slack labour market?}

In chapter 5, we explore the relationship between graduates' skills and the risk of overeducation (educational mismatch) and unemployment in 17 European countries. We distinguish between field-specific and academic skills, and between two labour market segments: the occupational domain of a particular field of study and the overall labour market. In line 
with the predictions of the crowding out hypothesis we find that the level of protection afforded by field-specific skills against the risk of overeducation is higher when the degree of excess labour supply in the occupational domain of the graduate's field of study is higher. Conversely, academic skills afford more protection against the risk of overeducation when excess labour supply in the overall labour market is higher. Field-specific skills also protect graduates against the risk of unemployment, whereas graduates' level of academic skills appears to be unrelated to the risk of becoming unemployed. 


\section{WHAT IS EXPECTED OF HIGHER EDUCATION GRADUATES IN THE 21ST CENTURY?}




\subsection{Introduction}

Expectations towards higher education institutions and their graduates have always been high.' For centuries, universities have been the place where higher order knowledge and skills have been developed, refined and nurtured. Never before, however, have expectations towards higher education and its graduates been so strongly expressed and explicitly defined - in particular by employers.

This chapter examines the skill set graduates are increasingly expected to possess. As we focus on graduates, we also focus on graduate skills. This means that we leave basic skills (basic levels of skills like numeracy, literacy, computer skills) out of the analysis, taking them, in a way, for granted.

We identify six trends which form the basis of the changing role of graduates in economic life. These trends are the knowledge society, increasing uncertainty, the ICT revolution, high performance workplaces, globalization, and the change of the economic structure. By changing the nature and range of tasks graduates are expected to fulfil in today's economy, these trends generate new and intensify traditional skill demands, which we summarize as professional expertise, flexibility, innovation and knowledge management, mobilization of human resources, international orientation, and entrepreneurship.

We introduce these six trends knowing that there is no consensus among researchers on how many independent trends there are, let alone how to name and define them. We also recognize that in reality these trends do not stand isolated but are strongly interlinked, with the ICT revolution probably being the main driver of the others. However, we are convinced that the categorization of trends and resulting skill demands we present here serve the purpose of this chapter best. They should be seen as a useful tool to examine what is expected of graduates in the $21^{\text {st }}$ century, and what are the drivers of these skill demands.

In the next section we elaborate the six trends and related skill demands. The chapter ends with a conclusion.

\subsection{The trends and related skills}

\subsubsection{The knowledge society and professional expertise}

\subsubsection{The knowledge society}

In developed nations, the $20^{\text {th }}$ century has been marked by a transition from an industrial society, characterized by mass production, to a post-industrial one, in which the service sector takes on a prominent role and knowledge becomes a valued form of capital. Bell (1999), who coined and brought forward the term "post-industrial society" in the 1970s, emphasizes the role played by theoretical knowledge in this type of society, particularly as the source of innovation and policy formulation. For Bills (2004, p.100) "the primacy of theoretical knowledge, even more than the shift from goods to services, or the computerization of the

$\overline{1} \quad$ This chapter is a slightly revised version of Humburg and Van der Velden (2013). We thank Jim Allen, John Buchanan, and Didier Fouarge for useful suggestions, and the participants of the Department of Education Public Seminar at Oxford University, 5 November 2012, for their comments on earlier versions of this paper. 
workplace, or any trend toward meritocratic selection, defines the post-industrial society." The transition from a fabricating to a knowledge society has been facilitated by two (other) major trends: globalization and rapid technological change. It is now possible to generate and to gather vast amounts of data, process them into relevant information and communicate them to recipients for decision making. For businesses, knowledge has become a major ingredient in gaining and sustaining competitive advantage (Wickramasinghe and Von Lubitz, 2007), and on a more general level this applies to nations, too. The emergence of the knowledge society increases the demand for knowledge workers (Reich, 1992), whose tasks are complex, non-repetitive and non-routine, and can therefore not be replaced by rule-based information and communication technology (ICT). The demands on knowledge workers are extensive. Clearly, credentialed and cognitively skilled individuals employed in the most information-intense sectors of society are the winners of these changes (Hage and Powers, 1992; Autor, Levy and Murnane, 2003).

\subsubsection{Professional Expertise}

In order to deal with the demands of the knowledge society, graduates need to be equipped with the skills necessary to fulfil tasks which are at the heart of knowledge work. In contrast to the application of more pragmatic and contextual knowledge, knowledge work entails unstructured decision making. Unstructured decisions concern important, novel, non-routine problems for which no established procedure exists for how to solve them. Levy (2010) calls "expert thinking" a collection of specific solution methods which vary with the problem at hand. It does not only entail a specific body of knowledge but also the ability to apply expert thinking. Becoming an expert, however, is time and learning intensive. The important difference between a young professional or recent graduate and an expert is that the expert can deviate from routine solution methods. Here, broad academic skills, such as analytical thinking and reflectiveness, help the expert to know when doing so is appropriate. According to OECD's Definition and Selection of Key Competencies (DeSeCo) project, reflectiveness is the ability of individuals to become the object of their thoughts (Rychen and Salganik, 2003). Thinking reflectively allows individuals to relate a solution method to other aspects of their experiences and to subsequently adapt it to novel problems. It also allows them to see the limitations of their own discipline and to take other perspectives into account. This is especially important as a substantial proportion of today's innovations takes place at the cross-section of disciplines and knowledge workers have to successfully work in teams of professionals from different disciplines. A certain amount of interdisciplinary knowledge supports this process.

All these aspects of professional expertise taken together - a body of knowledge, expert thinking, and broad academic skills - are what enables knowledge workers to adequately execute their profession. However, it requires considerable time and investment to establish and maintain a collection of theoretical knowledge and specific solution methods often complemented by learning how to use professional tools (e.g. drills for dentists or computer-aided design tools for engineers). The time necessary to become an expert in a job is usually estimated to be five to ten years (Hayes, 1981; Ericsson and Crutcher, 1990). 


\subsubsection{Increasing uncertainty and flexibility}

\subsubsection{Increasing uncertainty}

It is widely recognized that the last 40 years have seen a significant shift of the risks and costs associated with economic activity from institutional shareholders and their agents to smaller businesses and workers. While some authors interpret this shift as a gradual return to equilibrium after the exceptionally long boom of the late 1940's, the 1950's and the early $1960^{\prime}{ }^{2}$, others see over-capacity and intensifying international competition in manufacturing, as well as the emergence of financialization and excess liquidity at the core of this development (Brenner, 2006; Froud, Johal, Leaver and Williams, 2006). Brenner, for example, argues that, confronted with international competition of new lower cost market entrants, firms have been successful in putting pressure on labour in order to maintain their rate of profitability in otherwise unprofitable production lines. Froud et al. (2006) do not find evidence for labour shedding in large firms in the US and the UK in the 1980's and 1990's, yet they argue that capital markets use the rhetoric of shareholder value to pressure managers to hold down fixed labour costs and to restructure their firms in times of economic difficulties. Against this background, there is evidence that these risk and costs associated with increased market uncertainty have been passed down unequally onto two main groups of workers. On the one hand, there is a trend towards the emergence of a highly valued core labour force of knowledge workers. This core labour force is increasingly employed in flexible and fluidly defined work settings. Workers are allocated to tasks according to market demand and might even be expected to do a variety of minimally overlapping jobs during their life time, possibly by means of re-training. In these work settings, flexibility is functional and internal. The counterpart of this core labour force is a pool of part-timers, temporary workers, self-employed and high-turnover workers, which has been growing in numbers in most developed economies over the last decades (Castells, 1996) and whose share of the work force approaches $40 \%$ e.g. in the UK.

Although flexibility is increasingly demanded by employers, skills related to flexibility, such as the ability to rapidly acquire new knowledge, are not necessarily rewarded. Allen and Van der Velden (2011) show that professional expertise - not flexibility related skills - is by far the skill that has the strongest positive relationship with earnings and the probability to be employed. If, as Castells hypothesizes, the labour force is indeed composed of a highly valued core of knowledge workers and a pool of flexible "on demand" workers, professional expertise seems to be the entry ticket to the core group.

The emergence of a system which increasingly combines a core labour force with externally flexible workers is often explained by employers' need to react to economic shocks in highly regulated countries. When wages are rigid, firms hire temporary workers or offer workers fixed-term contracts to hedge market uncertainty (DiPrete, Goux, Maurin and Quesnel-Vallee, 2006). Workers with flexible contractual arrangements can then easily be let go when business gets worse. However, flexibility can also relate to new flexible production processes involving networks. Different economic agents organize and come together in networks for specific projects, just to get together in other constellations for the next project.

2 For an overview of interpretations of postwar growth see Crafts and Toniolo (1996). 
Schmid (1998) argues that, next to economic forces, social differentiation and the need to deal with demographic challenges adds to this flexibilization trend. On the one hand, individuals may decide to temporarily reduce working hours or exit the labour force to care for children or parents, or in general embrace non-standard work arrangements in order to find a balance between private and working life that corresponds better to their preferences. On the other hand, employers may offer flexible work arrangements in tight labour markets in order to motivate individuals to participate in the labour force.

As a result of the changing relationship between employers and workers, the latter experience an increasing number of labour market transitions, be they voluntary or involuntary. According to Schmid (1998) it is the responsibility of governments to take account of these developments by combining labour market flexibility and social security in a way that facilitates the creation of nsitional labour markets. He distinguishes five types of transitions: 1) transitions between different kinds of employment (transitions between dependent and self-employment, part-time and full-time employment, or fixed-term and more permanent employment relationships), 2) transitions between unemployment and employment, 3) transitions between education and training and employment, 4) transitions between private and labour market activity, 5) and transitions between employment and retirement. Leaving aside the transition to retirement, in the past the transition from education to employment was the major - and for many the only - transition.

While the state establishes the framework for transitional labour markets, it is the individual workers who have to master these transitions. Today, making one of these transitions is becoming more frequent and common for individuals. Consequently, individuals have to be equipped with the skills necessary to master the level of external flexibility that is expected of them or that they think is most appropriate for their preferred work-life balance.

Of course, graduates - the group of workers we are focussing on in this chapter - have a higher chance of belonging to the valued core labour force than medium or low educated workers (DiPrete et al., 2006). Moreover, further research has to determine whether flexibility is part of a life-long boundaryless career (Stone, 2006) or just a temporary phenomenon in the early stages of the career (Allen, Coenen and Humburg, 2011). At the least, also for graduates becoming a member of this valued core might take a while and therefore they need to be prepared to successfully master periods of increased uncertainty.

\subsubsection{Flexibility}

Flexibility demands a lot from individuals. Remaining flexible may require workers to expect the unexpected, to stay employable, to reskill and retrain, to leave familiar work environments and to get acquainted with new tasks. For some, it might even mean losing expert status. Irrespective of these responsibilities, flexible work arrangements, such as part time work or occasional work, potentially offer workers the opportunity to find a better balance between work and private life. This, however, presupposes a fair amount of voluntariness with regard to belonging to the pool of flexible workers.

Increasing uncertainty demands individuals to incorporate uncertainty and the need to be flexible into their life plans and personal projects. Moreover, flexible workers are increasingly responsible for their own employability. This includes making plans and setting aside time and resources for further training and life-long learning. The ability to deal with 
changes and uncertainty and the ability to learn new things are therefore important aspects of individuals' flexibility and employability. In addition, being and remaining employable demands a substantial level of transition skills. Although flexicurity - the combination of flexibility and security - is mainly seen as a challenge to be resolved at the national level by introducing appropriate labour market institutions (Schmid, 1998; Muffels, 2008), successfully mastering the many possible transitions between education and training and employment, different forms of employment, employment and unemployment, and labour market activity and private activity requires substantial knowledge on how the system works.

\subsubsection{The ICT revolution and innovation and knowledge management}

\subsubsection{The ICT revolution}

Of the six trends we are identifying, we would argue that technological change is probably the one that is interlinked the most with the other trends. Technological change and especially the predominance of ICT is one of the main driving forces behind the emergence of the knowledge society, it has changed markets and contributes to increased levels of market uncertainty, it facilitates and necessitates the emergence of high performance workplaces, and it is a main driver of globalization and changes in the economic structure.

Hage and Powers (1992) draw a distinction between instruments and other machines which are primarily used in production processes. While instruments increase the number of tasks being performed, most machines simply replace labour. ICT can assume both forms and there is widespread consensus that the introduction of ICT into workplaces is skill biased - that it favours higher skilled workers. For repetitive, routine tasks - often performed by low and medium skilled workers - ICT can be seen as labour replacing. ICT is faster and cheaper than people in performing these tasks. With regard to knowledge work and professional expertise, however, ICT is mostly instrumental and complements labour (Autor, Levy, Murnane, 2003; Levy, 2010). Besides being a complement to (mostly skilled) labour, instruments in the form of upgraded equipment make job tasks more complex (Hage and Powers, 1992). The tendency that higher skilled individuals are better suited to use new technologies is therefore often seen as another source of skill bias (Caroli and Van Reenen, 2001; Hujer, Caliendo and Radic, 2002; Greenan, 2003). Organizations in technology rich environments might prefer highly skilled workers as they have higher digital competence and lower training costs.

According to a competing view, the adoption of new technologies by organizations is not exogenous, but a reaction to a large supply of highly skilled workers. Proponents of the endogenous skill biased technological change hypothesis argue that the expansion of higher education in the second half of the $20^{\text {th }}$ century produced a large stock of highly skilled workers, and that this in turn induced the development of new technologies directed at complementing the highly skilled in order to increase productivity and profits (Acemoglu, 1998). A highly skilled workforce may therefore have created its own demand.

Whatever the underlying causal direction of this development, the introduction of ICT has revolutionized the way data and knowledge is generated and diffused. There is today an unprecedented range of resources easily available. In the $21^{\text {st }}$ century, the challenge is not to 
access knowledge, but to manage, integrate and evaluate it. In this regard, graduates play a crucial role within organizations.

\subsubsection{Innovation and knowledge management}

The ICT revolution does not only impact the skills that are directly related to it, but changes the nature and content of most other skills as well. It is hard to conceive of any professional skill that is not affected by ICT in some way. Also so-called 'soft' skills like communication skills have significantly changed in character due to the ICT revolution. And even the most basic skills like literacy and numeracy have been impacted by ICT (OECD, 2012). Although we recognize this broad impact of ICT on all types of skills, we will concentrate here on the skills that are supposed to be more directly related to innovation and knowledge management.

ICT has important implications with regard to the skills necessary to manage knowledge in a way that supports and facilitates innovation. In today's workplaces, innovation and knowledge management are strongly related to ICT skills. The concept of ICT skills, however, is very broad. Van Dijk (2005) distinguishes between operational ICT skills (skills directly related to the development and application of ICT hardware and software), ICT information skills (skills related to searching, selecting and processing information on computers, the internet and other ICT media), and strategic ICT skills (skills related to using ICT to achieve specific or more general goals). Van Dijk's distinction quite clearly extracts the ICT skill dimensions that are of particular importance to the tasks of knowledge workers. These relate primarily to the substantial information skills and strategic ICT skills which knowledge workers require for the purpose of innovation.

Raw data and random information have no value for decision making unless filtered and put into context. Whereas in the past individuals spent considerable amounts of time searching for scarce information, for the first time in history, the predominance of ICT makes for an abundance of data to be readily accessed. Today's challenges do not lie in information gathering, but in establishing a common understanding of information (Levy, 2010). The ability to rapidly separate signals from noise is therefore not novel as a valuable capability in degree, but in type (Dede, 2010).

Filtering information is by no means limited to separating signals from noise. It also involves evaluating content with regard to its reliability and credibility $(O E C D, 2012)$. In sum, successful knowledge management requires workers to use tools interactively, encompassing using language, symbols and text; using knowledge and information; and using technology (Rychen and Salganik, 2003).

Organizations' competitiveness is often largely based on their capacity to introduce entirely new products or processes, or to substantially improve existing ones. To date, the necessary and sufficient conditions for innovation are unknown. However, the availability of knowledge workers with good innovative and creative skills who have the ability to come up with new ideas or the ability to approach problems from a different angle are usually seen as a major ingredient of innovation. Moreover, processed, well managed and systematically communicated information can also play a crucial role. It has been suggested that organizations' innovative capacity depends on diffusion of knowledge to a broad range of key individuals within them (OECD/Eurostat, 2005). Knowledge workers therefore often are assigned the role of receptors and distributors of expert information. This includes the information 
and strategic ICT skills to remain alert to new developments including new technology and codified knowledge in patents, by means of the specialized press and scientific journals as well as good networking skills. Knowledge workers have to be well connected in order to both receive relevant information as well as to spread this information within the organization.

Information which merely flows through the organization is not likely to foster innovation. Ideas, new technology and knowledge have to be absorbed by the organization and find their way into processes at the end of which lie innovation and the introduction of competitive products. Innovation and knowledge management therefore includes the skills to bring an innovation from the 'drawing board' into the organization. These implementation skills relate closely to the strategic, organizational and interpersonal skills that we will discuss in the next section.

\subsubsection{The emergence of high performance work places and the mobilization of human resources}

\subsubsection{The emergence of high performance work places}

The centrality of knowledge work and increasing levels of market uncertainty may require organizational changes within firms. It is widely believed that traditional bureaucratic management stifles innovation and is ill-equipped for optimally using the potential of knowledge workers. Organizations which heavily rely on knowledge workers to increase productivity and competitiveness, and which adapt their organizational structure accordingly, have been labelled "high performance organizations" (OECD, 1999). What distinguishes them from other organizations is that the high performance work places these organizations design involve a broad range of skills and task variety, the extensive use of team work, reduced hierarchical levels, and the delegation of responsibility to individuals and teams (Betcherman, 1997). As it becomes increasingly difficult for managers to keep pace with technological developments, an argument in favour of giving knowledge workers more weight within the organization is to better align strategic decisions with the latest innovations. Moreover, flattening hierarchies potentially increases the speed of decisions in the face of market uncertainty.

Organizations which adopt high performance work practices have been found to have higher productivity and better financial performance (e.g. Appelbaum, Bailey, Berg and Kalleberg, 2000; Bartel 2004; Black and Lynch 2004). High performance organizations engage workers in the broader production process and provide them with comprehensive understandings of organizational goals and priorities (Bills, 2004). The organization supplies knowledge workers with the means to attain agreed goals and gives them autonomy with regard to the path to get there.

This trend towards decentralized decision making has partly been facilitated by technological change. There is a strong relationship between the introduction of high performance workplaces and investment in ICT (Arnal, Ok and Torres, 2001). Autonomous teams are now able to complete whole processes that had earlier been fragmented due to the lack of centralized databases. Not only has ICT changed production processes, it is increasingly a feature of new products, as well. Organizational changes can contribute to the development 
of innovative products by forming teams with complementary expertise (e.g. automotive engineers and electronic engineers). Alternatively, workers may have to be experts in more than one field. As the work places which emerge from this kind of organizational change demand a highly complex set of skills, it is often labelled skill biased organizational change (European Commission, 2008).

Measuring the incidence of high performance work places is difficult. Most surveys rely on questions which ask whether firms have adopted or plan to adopt work practices that are an integral part of high performance work places, such as team work, job rotation and the delegation of responsibility. Further, incidence, and also meaning of these work practices differ between countries. Critics of the literature on high performance work places are therefore sceptical that organizational changes towards more flexible firms present real revolutionary changes (Pollert, 1988; Ramsay, 1996; Bernstein, 1997). Instead, these authors suggest that new work practices could be management "fads", old wine in new bottles.

Although it is difficult to say to what extent high performance work places are ousting traditional work places, there is some evidence that there is an upward trend in their diffusion. The proportion of firms adopting new work practices is on the rise (Arnal et al., 2001) and with it the demand for the skills they require.

\subsubsection{The mobilization of human resources}

The emergence of high performance work places sets high expectations on the mobilization of human resources. If knowledge workers are required to optimally mobilize their own and others' human capital, they need to have interpersonal skills (the ability to work in a team and communicate and cooperate effectively with diverse colleagues and clients), (self)management skills (the ability to work within budget and time constraints, leadership), and strategic-organizational skills (the ability to act strategically towards the achievement of organizational goals).

The importance of interpersonal skills is not unique to the $21^{\text {st }}$ century (Dede, 2010). It is obvious, however, that the skills demanded of workers in settings characterized by autonomous teams with shared decision making differ from those of workers in traditional hierarchical work settings. Traditionally, interpersonal skills are the domain of managers, who have to be effective in getting others to achieve the organizational goals without necessarily being experts themselves. In high performance work places, however, teams and workers are given responsibilities ranging from production, training and product innovation to customer relations and marketing. Organizational goals are attained by teams of workers with complementary professional expertise (Karoly, 2004). This involves a high degree of information-sharing and communication and fundamentally increases the worth of collaborative capacity for non-management level workers. Having to interact in socially heterogeneous groups makes it necessary to relate well to others, to cooperate and to manage and resolve conflict (Rychen and Salganik, 2003). Working in teams and making shared decisions, demands workers to be able to communicate effectively, evaluate their work and the work of others, influence team mates and to seek advice, information and support when appropriate. The importance of these skills for professionals in Europe has been documented by Felstead, Gallie, Green and Zhou (2007), Allen (2011) and Miles and Martinez-Fernandez (2011). 
Reduced hierarchical levels open up opportunities for professional development. The work of knowledge workers is outcome oriented and the employer's capacity to monitor the working process is low. From the employers' perspective, high degrees of autonomy must not result in knowledge workers leading a self-centred, isolated work life within organizations. Rather, knowledge workers should know their position in the organization and should be able to link their work to the tasks of others. In high performance workplaces, being able to set one's task in the greater organizational context become key skills for professional and organizational success. It is therefore in the interest of the employer to employ individuals with strategic-organizational skills, that is, individuals with the ability to direct their actions independently towards attaining the organizational goal. In addition, knowledge workers should have good self-management skills referring to the ability of work within time and budget constraints.

\subsubsection{Globalization and international orientation}

\subsubsection{Globalization}

Globalization - the strengthening and acceleration of world-wide interconnectedness - has certainly been facilitated by the development of ICT. Never before has an economy had the capacity to work as a unit in real time on a planetary scale (Castells, 2000). Globalization affects trade levels, production processes, information flows and the competitive environment in which organizations operate. Globalization is therefore also related to the emergence of the knowledge society, the implementation of high performance work places as well as the flexibilization of the relationship between employers and employees. At this point, however, we would like to highlight the extent to which globalization increases the demand for an international orientation.

Globalization is characterized by fast flows of ideas, financial capital, goods, services and people across national borders. As a result, interaction with people from other cultures and with other linguistic backgrounds becomes more common and is now part of the working life of a substantial proportion of the higher educated workforce. Around one third of European graduates work in organizations whose scope of operation is international (Pavlin and Svetlik, 2011). The same proportion indicates that the ability to speak and write in a foreign language is highly required in their job.

Growing global interdependence is certainly one major driving force behind this development. A substantial proportion of workers' regular customer contact, brainstorming and consultation with colleagues, and decision-making nowadays takes place across national borders or involves groups of people with diverse national backgrounds. At the same time, the flattening of hierarchical levels also impacts the number of individuals who work within culturally heterogeneous groups. This is because decentralizing decision-making not only grants groups of professionals more autonomy. It also shifts large amounts of communication from higher levels of the hierarchy to the working level. Whereas traditionally the managerial level tended to be the recipient and the distributor of information, today the exchange of information increasingly takes place directly between professionals. 


\subsubsection{International orientation}

Almost anybody will have heard some anecdote where intercultural communication has gone completely wrong and where business intention dramatically failed as a result. Working and interacting with individuals of different cultural and linguistic backgrounds, not just in a casual setting but in goal-oriented work settings, presupposes an elevated degree of foreign language skills and cultural sophistication. Naturally, a precondition of any goal-oriented interaction between individuals of diverse national backgrounds is to have a common language foundation. Individuals working in international contexts have to be able to understand spoken messages, to initiate, sustain and conclude conversations and to read, understand and produce texts appropriate to the firm's needs (European Commission, 2007).

Yet even if this pre-condition is fulfilled, management activities, collaborations or negotiation efforts in intercultural settings can suffer significant setbacks when patterns of thought or behaviour of others are misinterpreted. Selling products abroad can fail simply by not adjusting marketing strategies and sometimes the product itself to the particularities of the foreign market (Verluyten, 2001). Today's graduates increasingly have to be able to take a step backwards from self-reference and familiar frameworks and adapt to new cultural contexts. These intercultural skills include knowing - or at least being aware of particular cultures of e.g. negotiation, politeness, decision making, team work or executives, colleagues, partners or clients.

\subsubsection{The change of the economic structure and entrepreneurship}

\subsubsection{The change of the economic structure}

Over the last decades deregulation, technological change and globalization have fundamentally changed the competitive environment in which organizations operate and have resulted in an unprecedented growth of the service sector. At the same time, the relative importance of small and medium sized firms has increased substantially. To give an often cited example, between 1970 and 1996, the share of employment of the 500 largest US firms dropped from 20 per cent to 8.5 per cent (Carlsson, 1992 and 1999). Partly, this can be accounted for by firms' reaction to international competition in the form of organizational changes such as decentralization and vertical disintegration (Loveman and Sengenberger, 1991). In addition, there is evidence that the economic environment after the early 1970's has been most favourable for small and medium sized enterprises. Amongst other factors, technological changes may have reduced optimal firm size and the minimum scale of entry and deregulation of markets may have created opportunities for small and medium sized businesses (Brock and Evans, 1989). Increasing market risk due to international competition as well as the change in consumer preferences towards customized products may have favoured smaller firms as they are often said to be more flexible (Piore and Sabel, 1984; Meredith, 1987; Carlsson, 1989) and innovative (Acs, 1992; Audtretsch and Thurik, 2000; Carree and Thurik, 2003). The superiority of small and medium enterprises with regard to flexibility, innovation and job creation has, however, often been challenged (Williams, Cutler, Williams and Haslam, 1987; Semlinger, 1992; Weimer, 1992; Parker, 2001). Moreover, Brock and Evans (1989) point to the possibility that the growing share of employment in small and medium 
enterprises may be a temporary phenomenon rather than a long-term trend. Whatever the reason for the change in the economic structure, the observed growth of importance of small and medium enterprises for employment in combination with the flattening of hierarchies within firms increases demand for graduates who are comfortable with assuming responsibility and with contributing to the success of the organization through entrepreneurship. Audretsch and Thurik (2000) even point to the centrality of entrepreneurship at the country level. For high-wage countries whose key comparative advantage lies in the generation of knowledge and innovation, entrepreneurship may be one of the main ingredients of global competitiveness. At the firm or within-firm level, entrepreneurship can be understood as "the discovery, evaluation and exploitation of future goods and services" (Eckhardt and Shane, 2003: 336). ${ }^{3}$ At the institutional level, entrepreneurship involves "changing the structure within which economic and other activities take place" (Crouch, 2005: 101). The importance of entrepreneurship is therefore not confined to knowledge workers working in the private sector but is also relevant for the work of institutional entrepreneurs in the public sector.

\subsubsection{Entrepreneurship}

Whenever knowledge workers assume a central role within an organization, they have to be increasingly alert to changes in markets and innovations. This not only includes evaluating how developments affect their own work, but also to draw the consequences for the organization as a whole. The higher the degree of autonomy knowledge workers enjoy within the organization, the more important their ability to independently contribute to the organization's economic and commercial success. This is true for owners of a firm as well as for employees both in the private and the public sector. Having entrepreneurial skills/commercial awareness has two important advantages for graduates. On the one hand, as with the other skill demands, it helps them fulfil the requirements of (potential) employers and to improve their position on the labour market. On the other hand, it provides them with the basis for starting their own businesses and becoming employers themselves.

As shown above, the centrality of knowledge work has led to an increased demand for interpersonal, strategic thinking and innovation skills. To some extent, entrepreneurship and commercial awareness could have been discussed as a part of these skill demands. Yet, it is worthwhile devoting a separate section to them for two reasons. Firstly, it underlines their importance for the survival of organizations and the competitiveness of entire economies. Secondly, it enables us to highlight the facilitating and commercial as opposed to the creative side of innovation.

It is important to note that the importance of entrepreneurial skills is not confined to the private sector. Globalization does not only result in international competition among firms but also between countries and regions. Today, one of governments' main challenge is to create institutions which best unfold creative capacity and innovation and which facilitate economic growth. Against this background, institutional entrepreneurs are actors who purposefully leave existing paths and recombine existing governance mechanisms to create new, innovative institutional environments (Crouch, 2005).

3 According to Eckhardt and Shane, their definition of entrepreneurship follows Venkatamaran (1997). 
At the firm level, the trends we identify contribute to the blurring of the boundaries between entrepreneurs managing their own firm on the one side and knowledge workers fulfilling central tasks within an organization on the other. Boundaries become blurred because an increasing proportion of the workforce is required to possess entrepreneurial skills and commercial awareness. This refers to the ability to perceive changes in the market and to identify competitors as well as commercial risks and opportunities. It also pertains to the awareness of the costs associated with one's activities and costs of decisions. Potentially most importantly, it refers to the ability to recognize the commercial value of an idea and to search for and pursue opportunities to turn them into successful products.

The existence and the characteristics of such opportunities are of major importance for the process of entrepreneurship (Eckhardt and Shane, 2003). However, one central question with regard to the relationship of higher education and entrepreneurship is whether the specificity of education influences graduates' ability to pursue opportunities. Lazear (2005) argues that entrepreneurs need to possess a relatively broad and balanced set of skills which enables them to pursue opportunities they identify in the face of uncertainty and obstacles. For example, next to the conception of the basic product, entrepreneurs are usually involved in hiring the initial team and obtaining some early financing. Entrepreneurs must certainly possess professional expertise, but it is the combination of professional expertise with the ability to perceive market opportunities which really distinguishes them from other experts. As Lazear (2005: 661) puts it: "A technical engineer may be superb at creating a new device, but that device may not have any business value. The innovator who succeeds is the one who can come up with something that is not only technically sound but business relevant as well." Lazear is pointing to the paradox that for business, it might sometimes be advantageous to be able to take a step backwards from technical details in order to concentrate on business value and market relevance. Commercially successful products are not necessarily the most innovative ones. An entrepreneur needs to possess the ability to handle the complex relationship between a product's price, quality and degree of innovation. Studies examining the determinants of entrepreneurship regularly find that business owners and self-employed ${ }^{4}$ have a more balanced, generalist skill set than employees. Lazear (2004, 2005), supported by Wagner $(2003,2006)$, argues that this is the result of a trade-off between professional expertise and entrepreneurship and that individuals intending to become entrepreneurs purposefully acquire more general human capital. Other studies, however, suggest that the generalist profile of entrepreneurs is the outcome of differences in innate ability (Silva, 2007) or a greater taste for variety (Astebro and Thompson, 2011).

Entrepreneurs are conceptually distinct from self-employed individuals offering some kind of well-established services, such as tax counselling. These individuals do not rely on the broad set of skills crucial to entrepreneurs as they do not need to possess the versatility necessary to perceive market opportunities for new products and identify employees suitable for achieving the (new) firm's objectives (Lazear, 2005).

4 This definition of entrepreneurs which ignores employees involved in entrepreneurial activities can be ascribed to a lack of better measures in the data used in these studies. 


\subsection{Conclusion}

In this chapter we brought forward the idea that societal, economic and organizational trends are changing the work environment and the job tasks of graduates. As a result, not only the demanded level of some skills is increasing, but also the character of some skills is changing. We identified six trends which are important drivers of changing skill demand. These trends are the knowledge society, increasing uncertainty, the ICT revolution, high performance workplaces, globalization, and the change of the economic structure. We show how these trends generate new and intensify traditional skill demands, which we summarized as professional expertise, flexibility, innovation and knowledge management, mobilization of human resources, international orientation, and entrepreneurship. Table 2.1 shows how these skills relate to particular skill aspects.

Table 2.1

Skills and related aspects

\begin{tabular}{ll}
\hline \hline Professional expertise & Specific body of knowledge \\
& Ability to apply expert thinking \\
& General academic skills (e.g. analytical thinking, reflectiveness) \\
\hline Flexibility & Ability to deal with changes and uncertainty \\
& Ability to learn new things \\
& Employability skills (e.g. the willingness to invest in further education and training, and \\
& the ability to plan and take responsibility for one's own career) \\
\hline Innovation and knowledge management & Innovative/creative skills (creativity, curiosity) \\
& Networking, information and strategic ICT skills \\
& Implementation skills \\
\hline Mobilization of human resources & Interpersonal skills (communication skills, teamwork skills) \\
& (Self-)management skills (working within budget and time restrictions, leadership) \\
& Strategic-organizational skills \\
\hline International orientation & Foreign language skills \\
& Intercultural skills \\
\hline Entrepreneurship & Ability to identify commercial risks and opportunities \\
& Cost awareness \\
& Ability to turn an idea into a successful product \\
\hline \hline
\end{tabular}


SKILLS AND THE GRADUATE

RECRUITMENT PROCESS 


\subsection{Introduction}

The transition from university to work is a pivotal phase in graduates' lives. ${ }^{5}$ Graduates exchange the known world of education for the less familiar world of work. For most graduates, this is the first time they get reliable information on the labour market value of their credentials. Every time a recent graduate applies for a job he or she gets information on whether investments in skills and the observable attributes mentioned on their curricula vitaes (CVs) were worth it in terms of getting the job they have applied for.

Graduates who are concerned about their labour market success will invest in the skills which will enable them to take advantage of promising job opportunities. Similarly, graduates try to acquire observable characteristics, such as a higher educational degree or work experience, which increase their skills and/or reliably signal the skills they have to employers. Often, the decisions which have to be made by students and graduates involve potential trade-offs. For example, individuals who work alongside their studies to gain work experience may find that they lack the time to get a high grade point average. Others may decide to leave university with a bachelor's degree to get work experience instead of enrolling into a master's programme to get additional education. From a graduate's perspective - but also from a higher education policy perspective - it is important to know which choices increase or decrease graduates' employability from the employers' perspective. Knowing the preferences of employers can inform university students' educational choices and can enable higher education institutions to help graduates acquire the skills they need to be successful in the labour market.

In order to assess the relative importance of observable attributes and types of skills in the recruitment process, we conducted two stated choice experiments among 903 employers in 9 European countries. In the first experiment, respondents were repeatedly presented graduate profiles with information on attributes commonly found on graduate CVs. They were then asked to either choose the profile they would like to invite to a job interview, or to choose none of them. The attributes we focus on in this paper are graduates' degree, the match between their field of study and the job tasks, the amount of relevant work experience they have gained, the study experience abroad they have acquired, their grade point average, and the prestige of their alma mater. We exclude indices such as age, race, or gender as this paper exclusively focuses on attributes which are the outcome of individuals' educational and work-related investments.

In the second experiment, which directly followed the first, we repeatedly presented respondents with hypothetical profiles containing graduates' proficiency in a selection of skill types. Again, respondents were asked to choose a profile (or none); this time, however, the profile they would hire. The types of skills contained on the hypothetical profiles in the second recruitment step were professional expertise, general academic skills, innovative/

$5 \quad$ This chapter is joint work with Rolf van der Velden. We are grateful to Andries de Grip and Raymond Montizaan for their useful comments. This paper and its other versions have also benefited from discussions at the DUHR seminar at Maastricht University, the Employers' Perspective on Graduate Employability in Europe testing seminar at the EU Commission in Brussels, the Advances in Latent Variables conference in Brescia, and the Transitions in Youth conference in Berlin. We would like to express thanks to Annelore Verhagen for her assistance with this study. The project on which this study is based was made possible through financial support from the European Commission. 
creative skills, strategic/organizational skills, interpersonal skills and commercial/ entrepreneurial skills.

On the basis of these experiments we are able to estimate employers' preferences for $\mathrm{CV}$ attributes in the selection of suitable candidates for job interviews, and for various types of skills in the actual hiring decision. In addition, we are able to draw on a large number of in-depth interviews with employers to validate the results and to elicit the rationale behind employers' preferences.

We find that employers prefer hiring graduates with higher levels of professional expertise - content-specific knowledge and skills needed to solve occupation-specific problems. Accordingly, employers' selection of graduates for job interviews is most influenced by $\mathrm{CV}$ attributes signalling a high stock of occupation-specific human capital, such as a good match between the field of study and the job tasks, and relevant work experience. We also find that interpersonal skills are as important to graduates' chances of getting the job as professional expertise.

The contribution of this paper is twofold. First, we are able to shed further light on the recruitment behaviour of employers and the value they attach to various attributes commonly found on applicants' CVs when selecting suitable candidates for job interviews. Second, this paper investigates the relative importance of different types and levels of skills in employers' decision to hire a graduate. We provide important insights with regard to the types of skills which increase graduates' employability.

The remainder of this paper is structured as follows: section 2 reviews the literature on the role of skills in graduates' transition from university to work. Section 3 presents the data and methodology of the study and section 4 the econometric model used to estimate employers' preferences. In section 5 we present the results of the first stated choice experiment, the results of the second stated choice experiment in section 6 . We then draw conclusions in section 7.

\subsection{Literature review and theoretical framework}

Rational, profit-maximizing employers hire graduates on the basis of their human capital. Becker (1962) thinks of human capital as the stock of knowledge and skills which enters individuals' (and firms') production function directly. Others conceptualize it as the capacity to adapt to disequilibrium situations such as technological change (Nelson and Phelps, 1966; Schultz, 1975), or as attitudes towards work and hierarchical settings (Bowles and Gintis, 1976). Both cognitive and non-cognitive skill endowments contribute to individuals' human capital stock and consequently to their productivity (Heckman, Stixrud and Urzua, 2006).

When selecting candidates for job interviews, employers face the challenge that human capital is not perfectly observable. Often, employers must rely on limited information contained on CVs to assess the value of job applicants to the firm. Employers will therefore exploit a correlation between productivity and observable characteristics, such as the degree or grade point average, to make inferences about applicants' productivity. The signalling value of the observable characteristic to employers will depend on their demand for the type of skill associated with the signal, and the differing cost structure between high 
and low skilled graduates (Spence, 1973). The greater the difference of the costs associated with obtaining a particular credential between low and high skilled graduates, the higher the credential's signalling value will be.

Given the very negative social consequences for the groups concerned, a substantial part of the literature on employers' use of observable characteristics as signals in the recruitment process focuses on statistical discrimination against particular groups of applicants, such as older applicants or applicants belonging to particular ethnic or religious minorities (Phelps, 1972; Aigner and Cain, 1977; Van Beek, Koopmans and Van Praag, 1997; Arrow, 1998; Altonji and Pierret, 2001). Our paper deviates from this line of research in that it explores the signalling value of credentials which are the result of individuals' educational or work-related investments. Furthermore, our study focuses only on the labour market of the highly skilled.

Studies based on graduate survey data find that graduates' chances of securing a graduate-level job are indeed associated with observable characteristics such as the degree, work experience, grades or study experience abroad (Allen and Van der Velden, 2001; Mason, Williams and Cranmer, 2009; Allen and Van der Velden, 2011). However, these studies do not provide an analysis of the relative importance of these CV attributes in the recruitment process. To our knowledge, our study is the first which investigates the relative importance of investment-related CV attributes commonly found on graduate CVs from the employer perspective. What is more, by substantiating the results from the experiment with the findings of in-depth interviews with some of the respondents, we are able to shed light on the motivation behind employers' preference for graduates with particular CV attributes.

In addition to examining the signalling value of $C V$ attributes, this paper investigates the relative impact different types and levels of skills have on graduates' chances of getting a graduate-level job. Differences in the importance of types of skills are based on the idea that economically important skills are not unidimensional and that the extent to which skills are productive depends on the match between workers' skills and the requirements of the job (Sattinger, 1993; Hartog, 1992). Graduates' skill profiles differ with respect to their emphasis on particular types of skills, such as interpersonal, commercial or professional skills. Their chances of securing the job they are applying for therefore depend on the importance of particular types of skills for performing the job tasks. In an analysis of the demand for engineering and science graduates in the UK Mason $(1998,1990)$ identifies work readiness - the knowledge, skills and commercial understanding which make graduates deployable soon after hiring - as one of the most important hiring criteria used by employers. In support of this finding Heijke, Meng and Ris (2003) show that a high level of field-specific skills is positively related to graduates' chances of finding a job which matches their field of study. Other studies, however, point to the importance of interpersonal and other transferable skills for graduates' employability. Autor, Levy and Murnane (2003), for example, argue that computers substitute routine analytical and interactive tasks but strongly complement non-routine analytical and interactive tasks. They subsequently show for the US that the declining price of computer capital in recent decades raised the relative demand for workers who have a comparative advantage in the ability to combine analytic and interactive tasks. Moreover, Biesma et al. (2007) show that for Dutch master-level graduates in the field of public health, problem-solving skills, creativity and interpersonal skills are more important 
than flexibility and public health knowledge. For the UK, Felstead et al. (2007) find that problem-solving, communication and persuasion skills are rewarded over and above the premium of education and training. Our study attempts to contribute to the literature by identifying employers' preference for various types of skills in various occupational fields and several European countries.

Besides investigating the relative importance of different types of skills, we also explore the effect of the skill level on graduates' chances of getting hired. Based on the findings of earlier studies which suggest that the occupational production function with respect to individuals' skill level is logistic or concave (Knight, 1979; Borghans and de Grip, 2000; Van der Velden, 2011), we expect decreasing marginal returns to skills with regard to graduates' employability.

We simulate both stages of the graduate recruitment process using two stated choice experiments. The use of stated choice experiments to estimate respondents' preferences originated in market research (Cattin and Wittink, 1982; Carroll and Green, 1995) but is increasingly being applied in various fields of economics such as transport economics, health economics and labour economics (Louviere, Hensher and Swait, 2000; Ryan, 2004; Van Beek, Koopmans and Van Praag, 1997; Biesma, Pavlova, Van Merode and Groot, 2007; Borghans, Romans and Sauermann, 2010; Pouliakas and Theodossiou, 2010; Eriksson, Johansson and Langenskiöld, 2012). The recent increase in the use of stated choice experiments in economics can be attributed in part to recent studies dispelling doubts that stated preferences reliably predict real market behaviour, and showing that parameter estimates based on stated preference data match those based on revealed preference data quite well (Louviere et. al, 2000). With respect to our study, using hypothetical graduate profiles in the experiment enables us to estimate the relative importance of various types of skills without the costly collection of data containing both graduates labour market outcomes and objective measures of skills. Moreover, even if we had objective measures of graduates' skill profile estimation results would be biased if some of the types of skills were not used as selection criteria by employers due to the difficulty of reliably assessing them during job-interviews. By assuming that graduates' proficiency in the types of skills presented on the hypothetical profiles have been assessed equally well, we can estimate the demand for skills regardless of whether these skills can be assessed reliably in real-world job interviews.

\subsection{Data and methodology}

The experiments were conducted in June and July 2012 in nine European countries (Czech Republic, France, Germany, Italy, Poland, Spain, Sweden, The Netherlands and the United Kingdom). Individuals registered on consumer panels of a large international market research organization were invited to participate in the online survey. Filtering questions made sure that only individuals who had been involved in recruiting a higher education graduate in the past five years were eligible to participate in the experiments. In those countries with a binary tertiary education system, 'higher education graduate' was explicitly defined as someone who graduated from a university, and explicitly excluded graduates from universities of applied sciences. 
Our study focuses on the recruitment of graduates in a selected number of occupational fields. In many occupational fields, recruitment is to a large extent governed by legally binding credentials. As we did not want our study to be confounded by legal requirements, we excluded professions in health and welfare as well as education and focused on seven occupational fields where most of the remaining graduates find work: Electro-technology, Engineering, Financial services, ICT, Legal services, Media and Communication, and Policy and Organization. Respondents who had not recruited a graduate to fill positions in one of these occupational fields in the last five years were excluded from the survey. Table 3.1 shows the most important sample descriptives.

Table 3.1

Sample descriptives

\begin{tabular}{|c|c|c|}
\hline & $\mathrm{N}$ & Per cent \\
\hline \multicolumn{3}{|l|}{ Country } \\
\hline Czech Republic & 64 & 7.09 \\
\hline France & 100 & 11.07 \\
\hline Germany & 100 & 11.07 \\
\hline Italy & 100 & 11.07 \\
\hline Netherlands & 147 & 16.28 \\
\hline Poland & 92 & 10.19 \\
\hline Spain & 100 & 11.07 \\
\hline Sweden & 99 & 10.96 \\
\hline United Kingdom & 101 & 11.18 \\
\hline \multicolumn{3}{|l|}{ Occupational field } \\
\hline Electro-technology & 58 & 6.42 \\
\hline Engineering & 186 & 20.6 \\
\hline Financial services & 160 & 17.72 \\
\hline $\mathrm{ICT}$ & 171 & 18.94 \\
\hline Legal Services & 133 & 14.73 \\
\hline Media and Communication & 122 & 13.51 \\
\hline Policy & 73 & 8.08 \\
\hline \multicolumn{3}{|l|}{ Firm size } \\
\hline$<20$ & 301 & 33.33 \\
\hline $20-49$ & 140 & 15.50 \\
\hline $50-99$ & 114 & 12.62 \\
\hline $100-249$ & 137 & 15.17 \\
\hline$>250$ & 211 & 23.37 \\
\hline
\end{tabular}

$20.2 \%$ of the panel members who received an e-mail responded to the invitation to participate in the survey. This number is not a response rate in the usual sense as data collection in each country was halted as soon as 100 employers had completed the survey. $56.8 \%$ of individuals passed the first filter question (involved in recruiting higher education graduates in the past 5 years), and $71.2 \%$ of those passing filter 1 passed filter 2 (involved in recruiting in one of the 7 occupational fields). $68.6 \%$ of those passing all filter questions completed the survey. 
Overall, we collected responses from 903 employers. In each of the two experiments, these 903 employers made 10 choices, so that 9030 choices per experiment were observed.

Before starting the first choice experiment, respondents were asked to imagine a situation in which they recruit a recent higher education graduate in the occupational field they indicated to be recruiting for. Respondents were instructed that the vacancy they are recruiting for in the experiment is a full-time junior position which can be characterized as structural in the sense that it has a longer time horizon and represents an investment for the organization. Seasonal work and short-term replacement positions were excluded. Respondents were told that when choosing the graduate profiles in the experiment they should think of a position in their organization that has these characteristics, and to keep the same position in mind for the entire exercise.

Figure 3.1

Choice set example CV attributes

\begin{tabular}{|c|c|c|c|}
\hline \multicolumn{4}{|c|}{$\begin{array}{l}\text { Of these } 3 \text { candidates, which one would you invite to a job interview? } \\
\text { Remember this is a junior position for a recent higher education graduate }\end{array}$} \\
\hline $\begin{array}{l}\text { Degree: } \\
\text { Bachelor (BA, BSC) }\end{array}$ & $\begin{array}{l}\text { Degree: } \\
\text { Master (MA, MSc) }\end{array}$ & $\begin{array}{l}\text { Degree: } \\
\text { Doctorate }\end{array}$ & \multirow{7}{*}{$\begin{array}{c}\text { None of } \\
\text { these }\end{array}$} \\
\hline $\begin{array}{l}\text { Match of field of study and job } \\
\text { tasks: } \\
\text { Field of study related to job tasks but } \\
\text { no exact match }\end{array}$ & $\begin{array}{l}\text { Match of field of study and job } \\
\text { tasks: } \\
\text { Field of study unrelated to job tasks }\end{array}$ & $\begin{array}{l}\text { Match of field of study and job } \\
\text { tasks: } \\
\text { Field of study matches job tasks } \\
\text { completely }\end{array}$ & \\
\hline $\begin{array}{l}\text { Relevant work experience: } \\
\text { No }\end{array}$ & $\begin{array}{l}\text { Relevant work experience: } \\
2 \text { years }\end{array}$ & $\begin{array}{l}\text { Relevant work experience: } \\
1 \text { year }\end{array}$ & \\
\hline $\begin{array}{l}\text { Study abroad: } \\
\text { No }\end{array}$ & $\begin{array}{l}\text { Study abroad: } \\
\text { Partly }\end{array}$ & $\begin{array}{l}\text { Study abroad: } \\
\text { Entirely }\end{array}$ & \\
\hline $\begin{array}{l}\text { Grade Point Average: } \\
\text { Above average }\end{array}$ & $\begin{array}{l}\text { Grade Point Average: } \\
\text { Average }\end{array}$ & $\begin{array}{l}\text { Grade Point Average: } \\
\text { Below average }\end{array}$ & \\
\hline $\begin{array}{l}\text { Type of university: } \\
\text { Average ranked university }\end{array}$ & $\begin{array}{l}\text { Type of university: } \\
\text { Average ranked university }\end{array}$ & $\begin{array}{l}\text { Type of university: } \\
\text { Top ranked university }\end{array}$ & \\
\hline $\begin{array}{l}\text { Starting Salary: } \\
\text { Average for this position }\end{array}$ & $\begin{array}{l}\text { Starting Salary: } \\
25 \% \text { below average for this position }\end{array}$ & $\begin{array}{l}\text { Starting Salary: } \\
25 \% \text { above average for this position }\end{array}$ & \\
\hline
\end{tabular}

In the first experiment, only CV attributes which are the result of graduates' human capital investment were included, excluding indices such as age, gender, ethnicity, beauty or religion used in other studies (Van Beek et al., 1997; Eriksson et al. 2012).

The following common attributes and their levels are included in the profiles of the first experiment:

1. Degree: Bachelor's degree, Master's degree, Doctorate.

2. The match between the field of study and the job tasks: field of study matches job tasks completely, field of study related to job tasks but no exact match, field of study unrelated to job tasks.

3. Relevant work experience: no, 1 year, 2 years 
4. Study abroad: no, partly, entirely

5. Grade Point Average: below average, average, above average, upper $10 \%$

6. Prestige/reputation of university: average, high

7. Starting salary: $25 \%$ below average, $10 \%$ below average, average for this position, $10 \%$ above average for this position, $25 \%$ above average for this position

We restricted the number of attributes to seven in order to limit the information processing burden on respondents. The degree levels used are the typical levels differentiated in higher education. National equivalents of these levels were used in the various translations of the master questionnaire. The three levels referring to the match between the field of study and the job tasks-attribute resemble those commonly used in graduate surveys, indicating that the match is complete, incomplete or non-existent. We deliberately limited the number of years of work experience to two years, reflecting our intention to measure employers' preferences for recent graduates. Study experience abroad was taken up as this attribute is increasingly common in the European context. Grade point average was included in four levels, whereas we included the upper $10 \%$ level to explore whether there is a return to belonging to the top $10 \%$ of the reference group beyond that of having above average grades. The prestige or reputation of the university was taken up as a two level attribute to see whether enrolling into a university with high prestige or reputation, rather than an average university, has an impact on graduates' chances to get invited to a job interview. Starting salary was taken up as an attribute to have a measure of labour costs in the model which may be used to calculate employers' willingness to pay for CV attributes and their levels.

A shortcut randomized design was used to generate the hypothetical graduate profiles (Sawtooth Software, 2000). With this type of design, profiles are constructed using the least often previously used attribute levels for a particular respondent. As a result, the occurrence of attribute levels is balanced (see table 3.6 in the Appendix).

In the second stage of the survey, we use a discrete choice experiment to elicit employers' preferences for particular skills in the actual hiring decision. We here include six types of skills and the starting salary. Respondents were told that in the first step they had selected and invited a pool of candidates who all seem equally suitable to do the job the respondent was recruiting for, indicating that in this experiment, candidates only differ with regard to the skills included in the profiles. Respondents were instructed that all candidates had been sent to an assessment centre which had thoroughly tested their skills. The information provided on the profile presented the results from this assessment centre, containing the graduates' skill level in the following six domains: ${ }^{6}$

1. Professional expertise: content-specific knowledge and skills needed to solve occupation-specific problems

2. General academic skills: skills which one typically associates with higher education yet which are not occupation-specific, such as analytical thinking and reflectiveness.

6 The selection of these six types of skills is based on a review of the literature on the skills demanded of higher education graduates in today's workplaces performed by Humburg and Van der Velden (2013). 
3. Innovative/creative skills: the ability to come up with new ideas and to approach problems from a different angle

4. Strategic/organizational skills: the capacity to think strategically and act in the interest of their organization.

5. Interpersonal skills: ability to work in a team and to communicate and cooperate effectively with diverse colleagues and clients.

6. Commercial/entrepreneurial skills: ability to identify commercial risks and opportunities and being cost-aware.

The skill levels presented on the profiles were whether graduates belonged 1) to the top $25 \%, 2$ ) to the average, or 3 ) to the bottom $25 \%$ of their reference group. For the purpose of readability and comprehensibility we will refer to these levels as high, average and low skill levels.

Respondents were provided with the definitions of the six types of skills before running the choice experiment. In addition, by scrolling over the skill type, they were able to recall the definition of all types of skills at any time during the experiment. The meaningfulness and appropriateness of these types of skills in the context of the recruitment process had been tested with a small sample of human resources personnel before the study started. The tested individuals confirmed the relevance of these types of skills for this study.

Figure 3.2

Choice set example skills

Of these 3 candidates, which one would you hire?

Remember this is a junior position for a recent higher education graduate

\begin{tabular}{l|l|l|l}
\hline Starting Salary: & Starting Salary: & Starting Salary: & \\
10\% below average for this position & Average for this position & $10 \%$ above average for this position & \\
Professional expertise: & Professional expertise: & Professional expertise: & \\
Bottom 25\% & Average & Top 25\% & \\
General academic skills: & General academic skills: & General academic skills: \\
Top 25\% & Average & Bottom 25\% & \\
Innovative/creative skills: & Innovative/creative skills: & Innovative/creative skills: & None of these \\
Top 25\% & Bottom 25\% & Average & \\
Strategic/organizational skills: & Strategic/organizational skills: & Strategic/organizational skills: & \\
Average & Bottom 25\% & Interpersonal skills: & \\
Interpersonal skills: & Interpersonal skills: & Average & \\
Bottom 25\% & Top 25\% & Commercial/entrepreneurial skills: & \\
Commercial/entrepreneurial skills: & Commercial/entrepreneurial skills: & Top 25\% & \\
Average & Bottom 25\% &
\end{tabular}

In order to be able to examine the heterogeneity of preferences during data analysis the following background information on respondents was collected: respondents' role in the organization (general management, HR, specific recruiter, other), respondents' role with regard to recruitment process (responsible, involved), the occupational field they are recruiting for, the economic sector of the firm, the number of graduates whose recruitment respondents had been responsible for or involved in in the past 5 years, the proportion of 
graduates in the firm, and firm size and the scale of the market the firm is operating on (local, regional, national, international).

A total of 110 in-depth interviews (10 interviews in each of the nine European countries of the online survey plus Estonia, as well as 10 large multinational corporations) were conducted. In the nine countries where the online experiment was conducted, interviewees were recruited from among its participants. In the other two countries and with respect to the 10 large multinational corporations databases of the market research organization were used to recruit interviewees. Each interview lasted about one hour and included a short version of the experiment to learn about the motivation behind employers' choices

\subsection{Econometric model}

We use the mixed logit model to estimate employers' preference for our selection of CV attributes and types of skills. In our discrete choice experiments, the probability of an alternative (a hypothetical graduate) being chosen depends on its characteristics displayed on the profiles shown to respondents, and the difference between its utility and the utilities of the other three alternatives, including the "none of these" option. A conditional logit framework as developed by McFadden (1974) is appropriate for estimating the relative importance of graduate characteristics in these kind of choice settings. The mixed logit model we use in this study is an advanced version of the original conditional logit model. While the mean coefficients estimated by both types of models do not differ qualitatively (not shown here) we apply a mixed logit model as it estimates the standard deviation of the mean coefficients, thereby providing information on the extent to which employers' preferences for particular characteristics differ.

Like any discrete choice model consistent with random utility theory, the mixed logit model assumes that an individual faces a choice amongst $J$ alternatives in each of $T$ choice situations. The model is well explained in Hensher and Greene (2003) and Train (2009), on which the following description is strongly based. In our specification, coefficients that enter utility are treated as varying over individuals but being constant over choice situations for each individual. The utility that individual $\mathrm{n}$ obtains from alternative $j$ in choice situation $t$ can be written as $U_{n j t}=\beta_{n} x_{n j t}+\varepsilon_{n j t^{\prime}}$ where $x_{n j t}$ is the vector of observed variables (in our case attribute levels), coefficient vector $\beta_{n}$ is unobserved for each $n$ and varies in the population with density $f\left(\beta_{n} \mid \theta^{*}\right)$ where $\theta^{*}$ are the true parameters of this distribution, and $\varepsilon_{n j t}$ is an unobserved random term that is distributed iid extreme value over choice situations, individuals, and alternatives. Conditional on $\beta_{n^{\prime}}$ the probability that individual $n$ chooses alternative $i$ in choice situation $t$ is logit:

$$
L_{n i t}\left(\beta_{n}\right)=\frac{e^{\beta_{n}{ }^{\prime} x_{n i t}}}{\sum_{j} e^{\beta_{n}{ }^{\prime} x_{n j t}}} .
$$

The unconditional probability is the integral of the conditional probability over all possible values of $\beta_{n^{\prime}}$ which depends on the parameters of the distribution of $\beta_{n}$. We specify the 
density of $\beta_{n}$ to be normal with mean $b$ and covariance $W$. This allows the coefficients to have positive or negative signs for different decision makers. The choice probability under this density becomes:

$$
Q_{n i t}(b, W)=\int \frac{e^{\beta_{n}{ }^{\prime} x_{n i t}}}{\sum_{j} e^{\beta_{n}{ }^{\prime} x_{n j t}}} \phi\left(\beta_{n} \mid b, W\right) d \beta_{n} .
$$

where $\varphi(\beta n \mid b, W)$ is the normal density with mean $b$ and covariance $W . b$ and $W$ are the parameters of interest to be estimated.

If, as normally the case in stated choice experiments, a sampled individual faces a sequence of choice situations, it is the probability of the sequence of observed choices which matters for maximum likelihood estimation. Let $i(n, t)$ denote the alternative that individual $n$ chose in choice situation $t$. Conditional on $\beta_{n^{\prime}}$ the probability that individual $n$ made this sequence of choices is the product of logit formulas:

$$
S_{n}\left(\beta_{n}\right)=\prod_{t=1}^{T}\left[\frac{e^{\beta_{n}{ }^{\prime} x_{n i(n, t) t}}}{\sum_{j} e^{\beta_{n}{ }^{\prime} x_{n j t}}}\right]
$$

The unconditional probability for the observed sequence of choices is [see Train 2009]:

$$
P_{n}(b, W)=\int \prod_{t=1}^{T}\left[\frac{e^{\beta_{n} x_{n i(n, t) t}}}{\sum_{j} e^{\beta_{n}{ }^{\prime} x_{n j t}}}\right] \phi\left(\beta_{n} \mid b, W\right) d \beta_{n} .
$$

One of the reasons why mixed logit models have only become a promising tool in data analysis recently is that the integral in (4) necessary for exact maximum likelihood estimation cannot be calculated analytically as it does not have a closed form in general. The integral is approximated through simulation and the simulated log-likelihood function is maximized. For a given value of the parameters $b$ and $W$ (mean and covariance of normally distributed $\beta_{n}$ ) a value of $\beta_{n}$ is drawn from its distribution. Using this draw $S_{n}\left(\beta_{n}\right)$ (equation 3 ) is calculated. This process is repeated for many draws, and the mean of the resulting $S_{n}\left(\beta_{n}\right)$ 's is taken as the approximate choice probability:

$$
S P_{n}(b, W)=\frac{1}{R} \sum_{r=1}^{R} S_{n}\left(\beta_{n}^{r \mid b, W}\right)
$$

where $\mathrm{R}$ is the number of draws of $\beta_{n^{\prime}} \beta_{n}^{r l b, W}$ is the $r$-th draw from $\varphi\left(\beta_{n} \mid b, W\right)$, and $S P_{n}(b, W)$ is the simulated probability of individual $n$ 's sequence of observed choices. The simulated log-likelihood function is constructed as: 
(6)

$$
S L L(b, W)=\sum_{n=1}^{N} \ln \left(S P_{n}(b, W)\right.
$$

and the estimated parameters are those who maximize SLL. As noted in Revelt and Train (1998), the log of the simulated probability with a fixed number of draws is not an unbiased estimate of the log of the true probability. However, the bias in SLL decreases as the number of draws increases, and 500 draws commonly generate adequate results. We use 1000 draws in our estimation.

\subsection{The right $\mathrm{CV}$ for getting invited to the job interview}

Table 3.2 presents the results of the mixed logit model for graduates' probability of getting invited to a job interview. With the exception of the coefficients for attribute levels "master's degree" and "study abroad entirely", all coefficients are statistically significant. The insignificance of the coefficients for "master's degree" and "study abroad entirely" is a remarkable finding. We will show below that this mean result stems from very opposing views with regard to employers' preferences for these attributes across countries.

Table 3.2

Mixed logit model of selecting graduates for a job interview

\begin{tabular}{|c|c|c|}
\hline \multicolumn{3}{|c|}{ Attributes with normally distributed coefficients: } \\
\hline \multicolumn{3}{|l|}{ Degree: } \\
\hline Bachelor's & Ref. & \\
\hline \multicolumn{3}{|l|}{ Master's } \\
\hline Mean coefficient & 0.045 & $(0.05)$ \\
\hline SD of coefficient & $0.977^{* * *}$ & $(0.07)$ \\
\hline \multicolumn{3}{|l|}{ Doctorate } \\
\hline Mean coefficient & $-0.357^{* * *}$ & $(0.06)$ \\
\hline SD of coefficient & $1.195^{* * *}$ & $(0.08)$ \\
\hline \multicolumn{3}{|c|}{ Match of field of study and job tasks } \\
\hline Unrelated & Ref. & \\
\hline \multicolumn{3}{|l|}{ Incomplete } \\
\hline Mean coefficient & $0.709^{* * *}$ & $(0.06)$ \\
\hline SD of coefficient & $0.762^{* * *}$ & $(0.10)$ \\
\hline \multicolumn{3}{|l|}{ Complete } \\
\hline Mean coefficient & $1.137^{* * *}$ & $(0.07)$ \\
\hline SD of coefficient & $1.228^{* * *}$ & $(0.07)$ \\
\hline \multicolumn{3}{|c|}{ Relevant work experience } \\
\hline No & Ref. & \\
\hline \multicolumn{3}{|l|}{1 year } \\
\hline Mean coefficient & $0.556^{* * *}$ & $(0.05)$ \\
\hline SD of coefficient & $0.775^{* * *}$ & $(0.07)$ \\
\hline \multicolumn{3}{|l|}{2 years } \\
\hline Mean coefficient & $0.711^{* * *}$ & $(0.06)$ \\
\hline
\end{tabular}


Table 3.2

Mixed logit model of selecting graduates for a job interview

\begin{tabular}{lll}
\hline SD of coefficient & $1.179^{* * *}$ & $(0.08)$ \\
Study experience abroad & Ref. & \\
No & & $(0.04)$ \\
Partly & $0.123^{* *}$ & $(0.10)$ \\
Mean coefficient & $0.542^{* * *}$ & $(0.05)$ \\
SD of coefficient & & $(0.07)$ \\
Entirely & -0.004 & $(0.05)$ \\
Mean coefficient & $0.795^{* * *}$ & $(0.07)$ \\
SD of coefficient & Ref. & \\
Below average & & $(0.06)$ \\
Average & $0.355^{* * *}$ & $(0.08)$ \\
Mean coefficient & $0.575^{* * *}$ & \\
SD of coefficient & & $(0.04)$ \\
Above average & $0.549^{* * *}$ & $(0.07)$ \\
Mean coefficient & $0.784^{* * *}$ & \\
SD of coefficient & & $(0.06)$ \\
Top 10\% & $0.579^{* * *}$ & $(0.08)$ \\
Mean coefficient & $0.790^{* * *}$ & \\
SD of coefficient & & \\
Prestige/reputation of university \\
Average \\
High
\end{tabular}

Fixed coefficient attributes

Salary

$25 \%$ below average

$0.935^{* * *} \quad(0.08)$

$10 \%$ below average

$0.980^{* * *}$

Average

$1.044^{* * *}$

$10 \%$ above average

0.600 ***

$25 \%$ above average

Ref.

None

0.083

(0.16)

Standard errors adjusted for 903 clusters (individuals) in parentheses. ${ }^{*} p<0.05,{ }^{* *} p<0.01,{ }^{* * *} p<0.001$. Estimation based on 1000 random draws per iteration. Log likelihood-9627.26, $N=36120$. The Wald-test of the joint significance of the attributes with 17 degrees of freedom is 1071.73 and has a $p$-value $>0.000$. The model has no alternative-specific constants, as is common practice with data from so-called unlabelled choice experiments, where randomly generated alternatives (graduates) have no utility beyond the characteristics attributed to them in the experiment.

The match between the field of study and the job tasks is one of the most important CV attributes with the mean coefficient of a complete match being 1.137 and that of the field 
of study and the job tasks being related being 0.709. Having a degree in a field of study which matches the job tasks of the vacancy well gives graduates a decisive advantage over competing applicants who do not have this match. Considering the size of the mean coefficients of the levels of the other attributes, a disadvantage with respect to the match between the field of study and the job tasks will be difficult to compensate for with an advantage with respect to another attribute. The importance of the match between the field of study and the job tasks in the recruitment process stems from employers' expectation that graduates with a complete match have higher levels of occupation-specific human capital and will therefore require a shorter adjustment period and less firm-provided training.

A second attribute which can be understood as a measure of graduates' stock of occupation-specific human capital and low training costs is relevant work experience. Relevant work experience has a substantial impact on graduates' probability to get invited to a job interview for a junior position. The mean coefficient of 2 years of work experience, as opposed to none, is similar to that of having a field of study which is related, as opposed to unrelated, to the job on offer (0.711 vs. 0.709). This implies that relevant work experience can to some extent compensate for a lacking match between the field of study and the job tasks; a graduate with 2 years of relevant work experience and an field of study unrelated to the job tasks has a similar probability of being invited to a job interview as a graduate with an incomplete match between the field of study and the job tasks and no relevant work experience, all other attributes being equal. Likewise, a graduate with an incomplete match between the field of study and the job tasks and one year of relevant work experience has a similar probability of being invited to a job interview as a graduate with a complete match and no relevant work experience.

There are obvious decreasing marginal returns to relevant work experience, and the first year increases graduates' chances to get invited to a job interview most. The mean coefficient of the second year of relevant work experience is slightly larger and statistically significantly different from the first. An important difference between the match of field of study and job tasks and relevant work experience is that relevant work experience is not only likely to be a signal of graduates' stock of occupation-specific knowledge and skills, but also general productive factors such as punctuality and attitudes towards hierarchical settings. Employers' expected savings through a shorter adjustment period and lower training costs when recruiting graduates with relevant work experience do therefore not only stem from graduates' higher occupation-specific human capital but also from their greater familiarity with work-life in general.

Remarkably, the standard deviation of 0.775 implies that $23.7 \%$ of employers have a negative coefficient for the 1 year of relevant work experience dummy [ $\varphi(-0.556 / 0.775)]$. The in-depth interviews suggest that this is not merely an artefact of the assumption of a normally distributed coefficient but that this represents real employer preferences. Whereas most employers prefer graduates who have demonstrated their functioning in work-life and have gathered experience which enables them to "hit the ground running", as one employer expressed it, there are also those employers who prefer "fresh" graduates. These employers 
argue that individuals who just graduated from university could be integrated into the firm's culture more easily?

Employers' indifference between graduates with a bachelor's and a master's degree in the pooled sample stems from opposing views on the value of these two degrees in different countries. A separate analysis (not shown here ${ }^{8}$ ) reveals that in the UK, graduates with a bachelor's degree are actually preferred over graduates with a master's degree, whereas in the Czech Republic, France, Germany and Poland employers tend to prefer graduates with master's degrees over graduates with bachelor's degrees when it comes to filling vacancies for junior positions. In Italy and Spain, employers' average preference for master's degrees does not significantly differ from that of employers in the UK, and in the Netherlands and Sweden, employers on average seem to be indifferent about the two degrees.

Graduates' degree is generally seen as an indicator of graduates' skill level and general ability. Yet, degree also correlates with other characteristics relevant for job performance, such as ambition or a hands-on attitude. As a result, the degree is a much broader signal than just one relating to candidates' skill level. In this regard, a good graduate-job match is likely to inter alia depend on the extent to which the skill level required by the job matches the skill level of the graduate, but also the extent to which the career prospects associated with the job match career expectations of the graduate. Consequently, because graduates' degree correlates with other factors such as ambition, it is not self-evident that the employer's best option is recruiting the graduate with the highest degree without taking into account job skill requirements. This becomes apparent when looking at employers' preference for a doctorate whose mean coefficient indicates that the average employer in our sample values a doctorate less than a master's or a bachelor's degree, all other things being equal. This result may be driven by the specific context of our experiment where employers were asked to recruit a graduate for a typical junior position in their organization. The in-depth interviews brought forth several arguments why employers are hesitant to hire a doctorate for a junior position, ranging from doctorates being too ambitious to doctorates being too theoretical in their approach for the average junior position. As recruitment is costly, employers try to avoid hiring graduates who will leave the organization as soon as a better opportunity opens up. Moreover, for some employers the doctorate sends a mixed signal: while employers tend to take for granted that doctorates who apply for junior positions have an elevated level of knowledge, they expect them to have a lower level of other productive factors - such as motivation or self-confidence - than their counterparts who apply for positions which better match their qualification level. This is another reason why some employers are hesitant to consider doctorates for their junior positions. However, the significant standard deviation of the mean coefficient for the doctorate attribute level implies that $38.3 \%$ of employers prefer doctorates over graduates with bachelor's degrees

7 "If you need to train someone in quality control, for example, each company has its own way of working. We prefer to take a young, inexperienced candidate, especially so we can integrate him into a team. It is easier than with a person who has experience." (7, R\&D, Pharmaceutical Industry, France); "The odds are in favour of persons with more experience. On the other hand since this is a junior position we approach it in a way that sometimes it is better to take a person with no experience, to teach him everything, than to accept a person with manners that do not fully correspond to our organization." (3, Finance, Bank, Poland). Quotes always indicate the respondent number as well as the interviewee's occupational field, economic sector and country.

8 We analysed the heterogeneity of preferences using a conditional logit model with attribute dummies interacted with country dummies. The detailed results are available from the authors upon request. 
(the coefficient of the dummy indicating a doctorate level is positive for $38.3 \%$ of employers, [1- $\varphi(0.357 / 1.195)])$, and that there is a relevant labour market segment for doctorates.

Having above average as opposed to below average grades matters similarly for graduates' chances of getting invited to a job interview, as does having 1 year of relevant work experience. Graduates can compensate for their low grades with relevant work experience, yet graduates with high grades have a higher chance of getting a job.

Marginal returns to grades are decreasing. Employers seem to put the most value on avoiding below average performers. On average, belonging to the upper $10 \%$ of the grades distribution has no additional effect on graduates' probability to be invited to a job interview, over and above the effect of having above average grades. ${ }^{9}$ However, this is not the case for some junior positions with high skill requirements and possibly better career prospects. Some employers interviewed in-depth indicated that they exclusively recruit graduates who are among the best $5 \%$ with regard to grades.

Graduates who have spent some time abroad during their studies are, on average, preferred by employers over graduates who did not gather any study experience abroad. Besides being an indicator of foreign language skills, results from the in-depth interviews strongly suggest that this attribute level is often used by employers as a signal of graduates' independence and resourcefulness. Rather than being decisive for employers' final decision to invite a graduate to a job interview or not, having some study experience abroad is seen as a nice extra and may tip the balance in the improbable case that two graduates are otherwise identical.

Judging from the pooled sample of employers, having studied entirely abroad does not improve graduates' chances of getting invited to a job interview when compared to graduates who studied exclusively in the home country. There is, however, substantial variation across employers from different countries..$^{10}$ Employers from the UK on average prefer graduates who studied exclusively at home over graduates who followed entire programmes abroad. The average employer in the Czech Republic, France, Germany, the Netherlands, Spain and Sweden seems to be indifferent between graduates who did not go abroad during their studies and graduates who earned a degree abroad, all else being equal. The signalling value of having studied entirely abroad, without specification where precisely the degree was obtained, is only positive in Italy and Poland.

While relevant, the importance of the university's prestige ${ }^{11}$ in the recruitment process is much smaller than that of the match between the field of study and the job tasks or that of relevant work experience. Its impact is, however, comparable to having partly studied abroad or to having above average grades. The prestige of the university is a signal for both the positive self-selection (and thus higher than average ability) of graduates as well as the

9 The difference between the mean coefficients of both attribute levels is not statistically significant.

10 Here also, we analysed the heterogeneity of preferences using a conditional logit model with attribute dummies interacted with country dummies. The detailed results are available from the authors upon request.

11 It is important to note that the translation to the languages of the 9 countries in which the study was carried out was based on keeping the meaning comparable across countries but adjusting the concept to the national context where necessary. For example, in the UK where university rankings are widely known, used and available, high prestige was translated to high ranking. Referring to ranking would, however, not make much sense in countries like the Netherlands or Germany. In these countries, the concept of reputation was used. This was done as the concept we had in mind for prestige was rather broad, pertaining to the subjective evaluation of a university, not necessarily an objective one. This, however, has to be taken into account when interpreting the results. 
quality and rigour of education. Many employers interviewed in-depth therefore indicated that they use the prestige of the university to validate grades.

The hypothetical candidate profiles also included the starting salary the graduate would have to be paid when hired. Figure 3.3 illustrates employers' preference for starting salary. While higher than average starting salaries (almost) linearly decrease employers' preference for candidates, lower than average salaries do not affect employers' selection decision in favour of applicants. An explanation is that employers' preferences reflect institutional arrangements. In Europe, entry salaries for graduates are strongly regulated with minimal room for negotiation. Moreover, negotiation mostly takes place with respect to getting a higher than average salary if justified by a higher level of qualification. Employers may experience the below average starting salary attribute levels as meaningless as it is not feasible to pay one employee less than the institutionalised salary.

If we accept that the parameter estimates for above average attribute levels are a good representation of employers' average preferences for labour costs, we can use these estimates to calculate employers' willingness to pay (WTP) for particular CV attributes. Entering starting salary as a fixed coefficient attribute ensures that it can be used to calculate employers' WTP by simply taking the ratio of attribute and salary coefficients (Revelt and Train, 1998). We take the difference between the coefficients of the average salary level and the $10 \%$ above average salary level as the equivalent of $10 \%$ of the average wage (1.044 $0.600=0.444)$. Employers' willingness to pay for particular CV attribute levels is presented in Table 3.3.

Figure 3.3

Graphical illustration of salary attribute coefficients displayed in Table 3.2

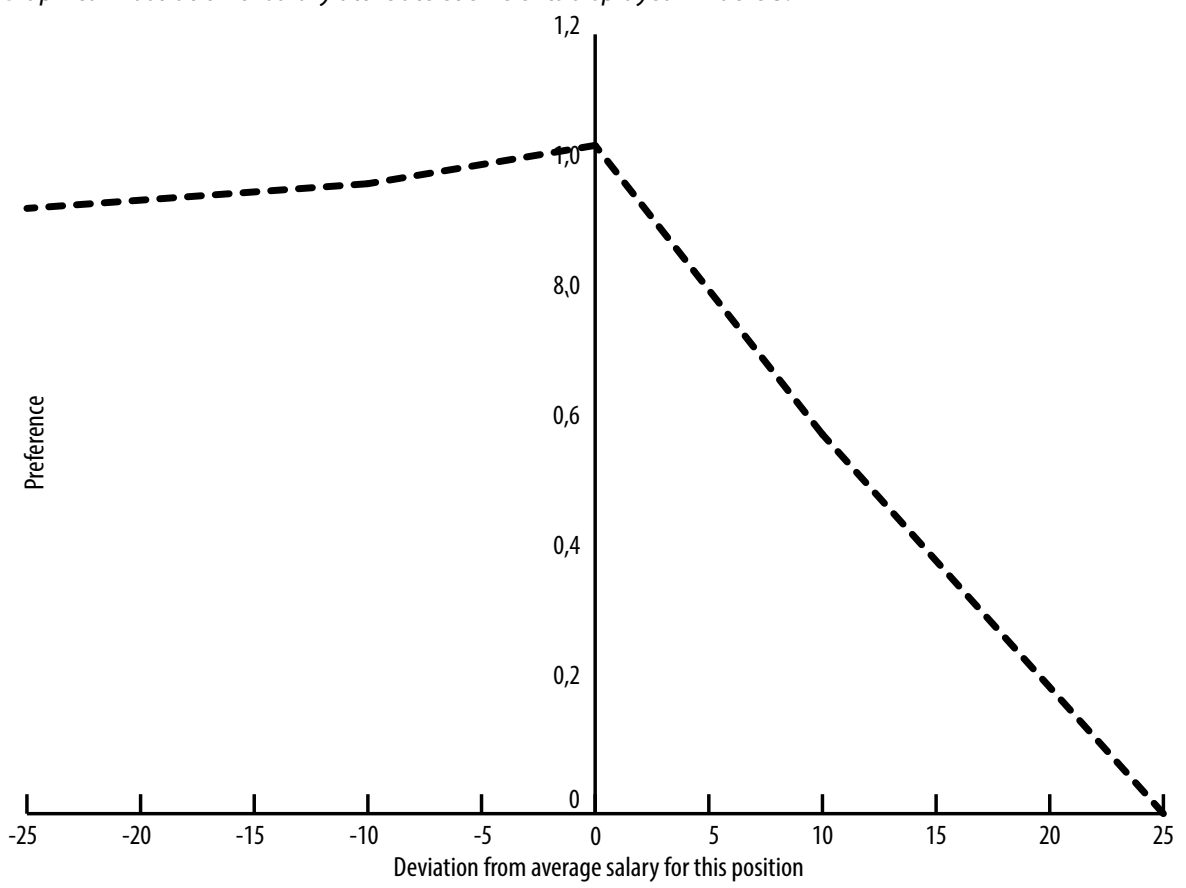


Table 3.3 shows that on average employers are willing to pay a $12.5 \%$ higher wage for the first year of work experience. The standard deviation of $17.5 \%$ implies that the variation in this willingness to pay is quite substantial. The return to a second year of relevant work experience, over and above that of the first year, is 3.5\% on average. This is very much in line with estimated Mincerian returns to experience of around $4 \%$ for European countries (Bils and Klenow, 2000). Even after accounting for a steep learning curve in the first year of work, employers' very high willingness to pay for the first year of relevant work experience strongly suggests that work experience is a very important signal of general work readiness. Employers are willing to pay a premium for reducing their risk of hiring someone who is not ready for work-life yet.

Therefore, CV attributes indicating occupation-specific human capital, a shorter adjustment period in the job and a lower need for less firm-provided training have the highest impact on graduates' probability of getting invited to a job interview. In addition, graduates' general ability and capacity to learn as indicated by above average grades signalling low training costs - have a substantial impact on employers' choices. These results support the view that general human capital can to some extent compensate for specific human capital but not entirely. Other CV attributes, such as study experience abroad or the reputation of the university, are much fuzzier signals of graduates' human capital than the match between the field of study and the job tasks, relevant work experience and grades. They also determine employers' choices but to a much lesser degree.

Table 3.3

Employers' willingness to pay for CV attributes

\begin{tabular}{lrr}
\hline & Mean WTP & SD \\
\hline Degree & Ref. & $22.0 \%$ \\
Bachelor's & $1.0 \%$ & $26.9 \%$ \\
Master's & $-8.0 \%$ & $17.2 \%$ \\
Doctorate & & $27.6 \%$ \\
Match of field of study and job tasks & Ref. \\
Unrelated & $16.0 \%$ & $17.5 \%$ \\
Incomplete & $25.6 \%$ & $26.6 \%$ \\
Complete & & $17.9 \%$ \\
Relevant work experience & &
\end{tabular}


Table 3.3

Employers' willingness to pay for CV attributes

\begin{tabular}{lcc}
\hline \hline Grades & & \\
Below average & Ref. & $12.9 \%$ \\
Average & $8.0 \%$ & $17.7 \%$ \\
Above average & $12.4 \%$ & $17.8 \%$ \\
Top 10\% & $13.0 \%$ & \\
& & $10.3 \%$ \\
Prestige/reputation of university & & Ref. \\
Average & $2.9 \%$ & High
\end{tabular}

Willingness to pay is assumed to be distributed normally in the population with mean MeanWTP and standard deviation SD. For calculation, attribute level mean coefficients (and their standard deviations) are multiplied by 10 and divided by the difference between the coefficients of the average salary level and the $10 \%$ above average salary level (0.444).

Interestingly, employers' preferences do not cluster along the lines of categories often used to describe them. In an extended analysis not shown here, we tested whether employers' preferences for CV attributes differed by firm size, occupational field, nationality and the degree to which the firm is operating on the local, regional, national or international market. ${ }^{12}$ With the exception of graduates' degree and study experience abroad, which were briefly discussed above, no systematic differences were found. This suggests that employers' needs are too diverse to be captured by these variables.

The statistically insignificant coefficient of the none-option dummy implies that employers are indifferent to the choice between inviting no one or a graduate with a relatively weak CV to the job interview. This may be an indication of the relatively low risk involved in inviting the wrong graduate to a job interview. ${ }^{13}$

\subsection{Which skills are getting graduates the job?}

Table 3.4 presents the results of the second stated choice experiment of the survey in which we asked respondents to select the graduates they would hire. As shown in Figure 3.2, graduates now differed with regard to their mastery of different types of skills and could be considered equally suited in all other respects. Therefore, in contrast to the first stage of the

12 We focus here on employer categories most referred to in the literature. Other background variables we collected, such as the economic sector, the respondent's kind of involvement in the recruiting process, the role of the respondent in the firm, the number of graduate recruitments the respondent was involved in in the past 5 years, or the proportion of graduates in the firm do also not explain the heterogeneity of preferences.

13 The none-option dummy was included in the model assuming a fixed rather than a randomly varying parameter. The coefficient expresses whether employers' utility is higher when not inviting anybody compared to inviting the reference graduate. In our case, this is the graduate with a field of study unrelated to the job task, no work experience, below average grades, a bachelor's degree from a university of average prestige or reputation, no study abroad, and with a starting salary of $25 \%$ above average. In the data, the none-option is operationalized as a graduate profile with all attribute level dummies being o and a none-option dummy variable indicating that this is the profile representing the none-option. The none-option dummy is zero for the three hypothetical graduate profiles in the choice set. 
experiment, the estimated parameters represent employers' preferences for actual skills, not for some other dimension of human capital.

As expected, employers always prefer higher skill levels over lower skill levels, no matter what skill type they are considering. There is, however, an obvious asymmetry between the penalty for low ${ }^{14}$ skill levels and the reward for high skill levels: the positive coefficients of the dummies indicating that graduates have a high skill level are always less than half the size, in absolute terms, of the negative coefficients of the dummies indicating that graduates have a low skill level.

With respect to the probability of being hired, the reward for having a high skill level as opposed to an average one is largest for professional expertise and smallest for commercial/entrepreneurial skills. The reward for having a high skill level is second-largest for interpersonal skills, followed by innovative/creative skills and strategic/organizational skills. The reward for a high level of general academic skills lies somewhere in between that of strategic-organizational skills and commercial/entrepreneurial skills. These differences are, however, not always statistically significant. ${ }^{15}$

Table 3.4

Mixed logit model of selecting graduates for hiring

\begin{tabular}{|c|c|c|c|}
\hline \multicolumn{4}{|c|}{ Attributes with normally distributed coefficients: } \\
\hline \multicolumn{4}{|c|}{ Professional expertise } \\
\hline \multicolumn{4}{|c|}{ High } \\
\hline \multicolumn{2}{|c|}{ Mean coefficient } & $0.507^{* * *}$ & $(0.08)$ \\
\hline \multicolumn{2}{|c|}{ SD of coefficient } & $0.969^{* * *}$ & $(0.12)$ \\
\hline \multicolumn{2}{|c|}{ Average } & Ref. & \\
\hline \multicolumn{4}{|c|}{ Low } \\
\hline \multicolumn{2}{|c|}{ Mean coefficient } & $-1.219^{* * *}$ & $(0.09)$ \\
\hline \multicolumn{2}{|r|}{ SD of coefficient } & $1.300^{* * *}$ & $(0.12)$ \\
\hline \multicolumn{4}{|c|}{ General academic skills } \\
\hline \multicolumn{4}{|c|}{ High } \\
\hline \multicolumn{2}{|c|}{ Mean coefficient } & $0.305^{* * *}$ & $(0.05)$ \\
\hline \multicolumn{2}{|c|}{ SD of coefficient } & $0.657^{* * *}$ & $(0.07)$ \\
\hline \multicolumn{2}{|c|}{ Average } & Ref. & \\
\hline \multicolumn{4}{|c|}{ Low } \\
\hline \multicolumn{2}{|c|}{ Mean coefficient } & $-0.900^{* * *}$ & $(0.08)$ \\
\hline \multicolumn{2}{|c|}{ SD of coefficient } & $1.140^{* * *}$ & $(0.10)$ \\
\hline \multicolumn{4}{|c|}{ Innovative/creative skills } \\
\hline \multicolumn{4}{|c|}{ High } \\
\hline \multicolumn{2}{|c|}{ Mean coefficient } & $0.392^{* * *}$ & $(0.05)$ \\
\hline 14 & \multicolumn{3}{|c|}{$\begin{array}{l}\text { Note that in accordance with the attribute levels used in the choice experiment, a graduate has a low skill level if } \\
\text { he or she belongs to the bottom } 25 \% \text { of his or her reference group, and a high level of skill if he or she belongs to } \\
\text { the top } 25 \% \text { of his or her reference group. }\end{array}$} \\
\hline 15 & \multicolumn{3}{|c|}{$\begin{array}{l}\text { The coefficient of the dummy indicating a high level of professional expertise is not statistically significantly } \\
\text { different from that of interpersonal skills, yet is statistically significantly different from the other coefficients (at } \\
\text { the } 10 \% \text { level for innovative/creative skills). The coefficient of a high level of interpersonal skills is statistically } \\
\text { significantly different from that of general academic skills and commercial/entrepreneurial skills (10\% level and } \\
5 \% \text { level, respectively) and the reward to a high level of innovative/creative skills as well as strategic/organizational } \\
\text { skills is statistically significantly different from that of commercial/entrepreneurial skills ( } 10 \% \text { level). }\end{array}$} \\
\hline
\end{tabular}


Table 3.4

Mixed logit model of selecting graduates for hiring

\begin{tabular}{|c|c|c|}
\hline SD of coefficient & $0.660^{* * * *}$ & $(0.10)$ \\
\hline Average & Ref. & \\
\hline \multicolumn{3}{|l|}{ Low } \\
\hline Mean coefficient & $-1.045^{* * *}$ & $(0.07)$ \\
\hline SD of coefficient & $1.176^{* * *}$ & $(0.21)$ \\
\hline \multicolumn{3}{|c|}{ Strategic/organizational skills } \\
\hline \multicolumn{3}{|l|}{ High } \\
\hline Mean coefficient & $0.376^{* * *}$ & $(0.06)$ \\
\hline SD of coefficient & $0.693^{* * *}$ & $(0.11)$ \\
\hline Average & Ref. & \\
\hline \multicolumn{3}{|l|}{ Low } \\
\hline Mean coefficient & $-0.878^{* * *}$ & $(0.07)$ \\
\hline SD of coefficient & $0.859^{* * *}$ & $(0.08)$ \\
\hline \multicolumn{3}{|l|}{ Interpersonal skills } \\
\hline \multicolumn{3}{|l|}{ High } \\
\hline Mean coefficient & $0.422^{* * *}$ & $(0.06)$ \\
\hline SD of coefficient & $0.844^{* * *}$ & $(0.08)$ \\
\hline Average & Ref. & \\
\hline \multicolumn{3}{|l|}{ Low } \\
\hline Mean coefficient & $-1.329^{* * *}$ & $(0.09)$ \\
\hline SD of coefficient & $1.350^{* * *}$ & $(0.10)$ \\
\hline \multicolumn{3}{|c|}{ Commercial/entrepreneurial skills } \\
\hline \multicolumn{3}{|l|}{ High } \\
\hline Mean coefficient & $0.248^{* * *}$ & $(0.06)$ \\
\hline SD of coefficient & $1.136^{* * *}$ & $(0.13)$ \\
\hline Average & Ref. & \\
\hline \multicolumn{3}{|l|}{ Low } \\
\hline Mean coefficient & $-1.114^{* * *}$ & $(0.07)$ \\
\hline SD of coefficient & $1.105^{* * *}$ & $(0.09)$ \\
\hline \multicolumn{3}{|c|}{ Fixed coefficient attributes } \\
\hline \multicolumn{3}{|l|}{ Salary } \\
\hline $25 \%$ below average & 0.014 & $(0.07)$ \\
\hline $10 \%$ below average & -0.019 & $(0.06)$ \\
\hline Average & Ref. & \\
\hline $10 \%$ above average & $-0.340^{* * *}$ & $(0.07)$ \\
\hline $25 \%$ above average & $-0.874^{* * * *}$ & $(0.1)$ \\
\hline None & $-2.515^{* * *}$ & $(0.12)$ \\
\hline
\end{tabular}

Standard errors adjusted for 903 clusters (individuals) in parentheses. ${ }^{*} p<0.05,{ }^{* *} p<0.01,{ }^{* * *} p<0.001$. Estimation based on 1000 random draws per iteration. Log likelihood $-8674.02, N=36120$. The Wald-test of the joint significance of the attributes with 17 degrees of freedom is 1252.29 and has a $p$-value $>0.000$. The model has no alternative-specific constants, as is common practice with data from so-called unlabelled choice experiments, where randomly generated alternatives (graduates) have no utility beyond the characteristics attributed to them in the experiment. 
The penalty ${ }^{16}$ for having low skill levels as opposed to average skill levels is larger than the premium for having high skill levels. Two findings stand out. First, the negative coefficient of the dummy indicating that graduates have a low level of interpersonal skills is largest. While not statistically significantly different from that of professional skills, this result highlights the importance of interpersonal skills in today's workplaces. In line with the findings of Mason $(1998,1990)$ employers attach a high value to having at least an average level of interpersonal skills, as one team member with a low level of interpersonal skills can endanger the functioning - and thus productivity - of an entire team.

Second, while the reward for a high level of commercial/entrepreneurial skills is relatively small, the penalty for a low level is relatively large, comparable to that of having a low level of professional expertise. Employers avoid employees with no commercial intuition or sense of entrepreneurship.

The reward for having a high skill level is similar for innovative/creative and strategic/ organizational skills. However, the penalty for having a low skill level is higher for innovative/ creative skills. The penalty for having a low level, as opposed to an average one, is similar for strategic/organizational and general academic skills.

The coefficient of the none-option dummy is negative and highly significant, indicating that employers are on average better off hiring a graduate with average levels of all skills and earning the average salary than hiring no one. However, when running a model with the bottom skill level and a starting salary of $25 \%$ above average as the reference category (not shown here), the none-option dummy is positive and significant, suggesting that it is better to hire no one rather than taking the risk of hiring a graduate without the necessary skills.

Employers' preference for starting salary in the hiring stage is similar to that of the interview stage. Lower than average starting salaries are not associated with a higher probability of being hired. A possible explanation for this result is that paying graduates less than the average is, for the average employer, either not possible (because of institutional agreements) or not desirable (because of disruption in the group), or both. In contrast, employers' preferences for graduates decreases linearly for above average salaries, as shown in Figure 3.4.

For calculating employers' willingness to pay for skills, we make use of the absolute value of the coefficient of the dummy indicating that the graduate's starting salary is $10 \%$ above the average salary. Table 3.5 indicates that employers are willing to pay on average a $14.9 \%$ higher salary for a graduate from the upper $25 \%$ of the distribution of professional expertise, compared to a graduate with average professional expertise. The standard deviation of $28.5 \%$ indicates that this willingness to pay varies substantially. For a junior position with an average salary of 30,000 Euro per year the estimates in Table 3.5 imply an average premium of around 4,500 Euro per year for a graduate belonging to the top $25 \%$ as opposed to the average group with regard to professional expertise.

16 We deliberately ran the model with average skills as the reference category to emphasise that there is a penalty for having low skill levels, rather than a reward for having average skill levels. The vast majority of employers interviewed in-depth state that they consider an average skill level as the minimum skill level necessary to come into consideration for the job (note that in our definition, the average level contains $50 \%$ of individuals around the mean). This implies that graduates with skill deficiencies are seriously disrupting the production process, incurring costs to the organization. 
Figure 3.4

Graphical illustration of salary attribute coefficients displayed in Table 3.4

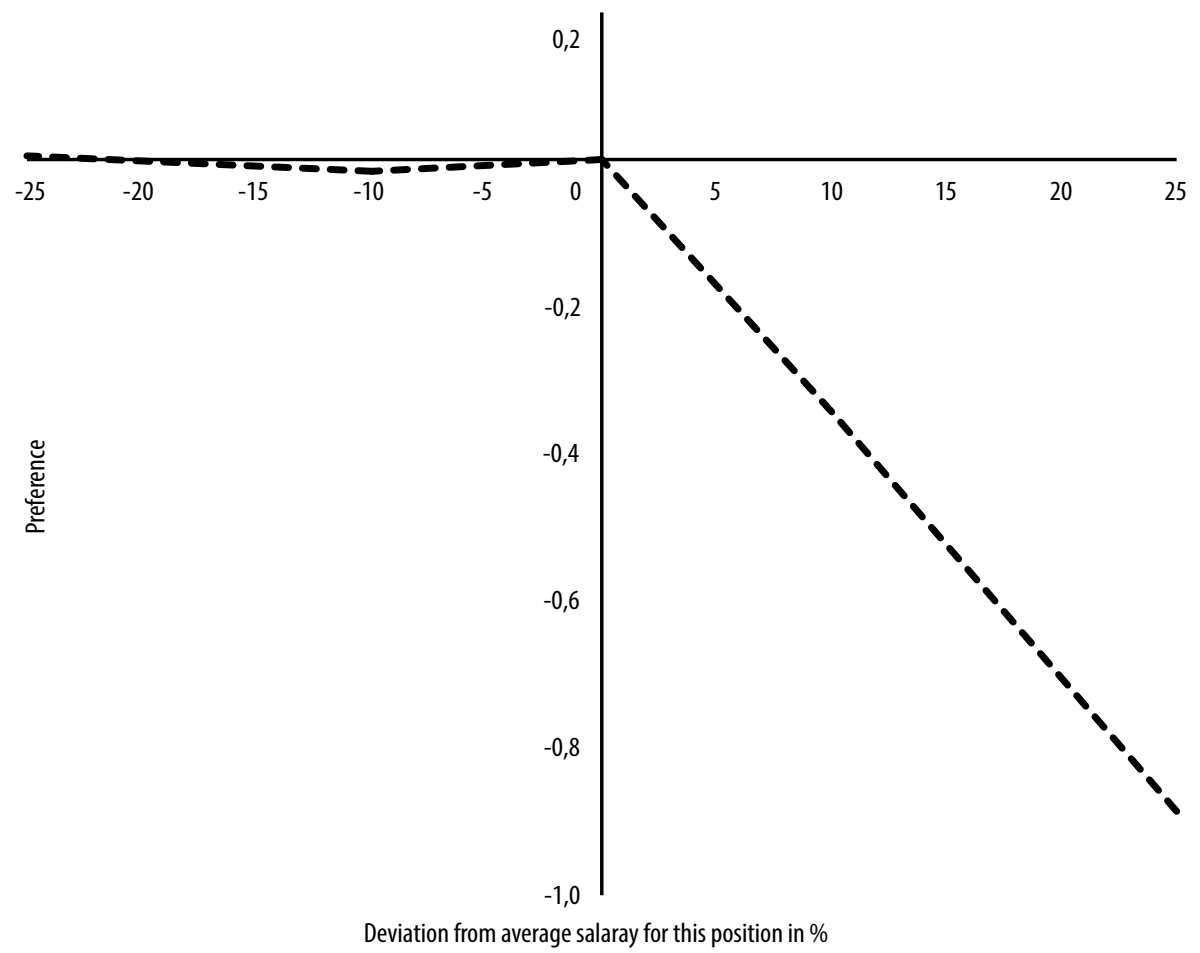

Employers' willingness to pay for a graduate with low professional expertise is negative, indicating that employers would require compensation for hiring such a graduate. This compensation amounts to about a third of the average salary of a junior position. Taking the example of a junior position with an average salary of 30,000 Euro per year again, the average employer would require compensation of 10,770 Euro per year for hiring a graduate with a low level of professional expertise. This amount can be understood in terms of productivity loss or training costs which have to be spent in order to improve the graduate's skills to average level.

Employers attach the highest overall importance to professional expertise and interpersonal skills (the difference between high and low skill levels). Employers expect graduates with high levels of professional expertise to already have been exposed to the occupational challenges occurring most often and to be able to perform the new job tasks quickly. Given the smaller coefficients for general academic skills, the average employer does not seem to perceive professional expertise and general academic skills as perfect substitutes, possibly because the latter implies higher costs for training and a longer adjustment period. 
Table 3.5

Employers' willingness to pay for skills

\begin{tabular}{|c|c|c|}
\hline & Mean WTP & SD \\
\hline \multicolumn{3}{|c|}{ Professional expertise } \\
\hline High & $14.9 \%$ & $28.5 \%$ \\
\hline Average & Ref. & \\
\hline Low & $-35.9 \%$ & $38.2 \%$ \\
\hline \multicolumn{3}{|c|}{ General academic skills } \\
\hline High & $9.0 \%$ & $19.3 \%$ \\
\hline Average & Ref. & \\
\hline Low & $-26.5 \%$ & $33.5 \%$ \\
\hline \multicolumn{3}{|c|}{ Innovative/creative skills } \\
\hline High & $11.5 \%$ & $19.4 \%$ \\
\hline Average & Ref. & \\
\hline Low & $-30.7 \%$ & $34.6 \%$ \\
\hline \multicolumn{3}{|c|}{ Strategic/organizational skills } \\
\hline High & $11.1 \%$ & $20.4 \%$ \\
\hline Average & Ref. & \\
\hline Low & $-25.8 \%$ & $25.3 \%$ \\
\hline \multicolumn{3}{|c|}{ Interpersonal skills } \\
\hline High & $12.4 \%$ & $24.8 \%$ \\
\hline Average & Ref. & \\
\hline Low & $-39.1 \%$ & $39.7 \%$ \\
\hline \multicolumn{3}{|c|}{ Commercial/entrepreneurial skills } \\
\hline High & $7.3 \%$ & $33.4 \%$ \\
\hline Average & Ref. & \\
\hline Low & $-32.8 \%$ & $32.5 \%$ \\
\hline
\end{tabular}

Willingness to pay is assumed to be distributed normally in the population with mean MeanWTP and standard deviation SD. For calculation, attribute level mean coefficients (and their standard deviations) are multiplied by 10 and divided by the coefficient of the $10 \%$ above average salary coefficient multiplied by -1 (0.340).

In some instances the influence of innovative/creative skills, strategic/organizational skills and commercial/entrepreneurial skills in the hiring decision is not statistically separable from that of interpersonal skills and professional expertise. ${ }^{17}$ They nevertheless tend to form a group of relatively less important skills for labour market entry. The findings from the in-depth interviews support this view. Employers acknowledge these three skills as being important, but for further career development rather than for immediate employability. Depending on the kind of job, these types of skills determine employees' selection for promotion and the ease and speed with which they leave the junior position. Finally, in additional analyses not shown here ${ }^{18}$ we find no systematic differences in the relative

17 The difference of the coefficients of the dummies indicating a high level of interpersonal skills, innovative/ creative skills and strategic/organizational skills is not statistically significant at the $10 \%$ level. The difference of the coefficients of the dummies indicating a low level of professional expertise and commercial/entrepreneurial skills is not statistically significant.

18 Available from the authors upon request. 
importance of types of skills between employers of different countries, occupational fields, firm size and international market exposure.

\subsection{Conclusions}

In this study we elicit employers' preferences for a variety of CV attributes and types of skills when recruiting recent university graduates. Using two discrete choice experiments, we are able to show that employers' selection of candidates for job interviews is most strongly influenced by $C V$ attributes which signal a high stock of occupation-specific human capital indicating short adjustment periods in the job and low training costs. Accordingly, professional expertise is a type of skill strongly influencing the hiring decision. However, we also find that having good interpersonal skills is as important for graduates' employability as having professional expertise. The large impact of interpersonal skills on graduates' chances to get hired confirms earlier studies emphasizing the increasing importance of communication in today's work-life in general, and especially for team productivity (Autor et al., 2003; Biesma et al., 2007; Felstead et al., 2007; Dede, 2010; Allen, 2011; Humburg and Van der Velden, 2013).

Other types of skills and attributes also play a role in the recruitment process but are less important and can therefore not easily compensate for a lack of more specific human capital and interpersonal skills.

Our findings can also be interpreted as evidence for a logistic or concave relationship between skills and productivity. ${ }^{19}$ The productivity loss associated with hiring a graduate with low skills is much larger than the benefits of recruiting a high skilled graduate instead of one with average skills. This suggests that having low skilled workers in the workplace cannot be compensated for by team members with high skills. What is more, our findings suggest that the costs associated with below average performance are so substantial that salary is not an adequate adjustment mechanism. Employers are in general willing to pay average salary for average performance but are unwilling to hire underperforming graduates just because they are cheaper.

The large standard deviations of the estimated mean coefficients imply that there is not the graduate profile which all employers prefer. Rather, employers' demand for skills varies substantially. Some employers may not want to recruit the graduates with the highest skill levels because the job does not require them and they fear that graduates will get bored too quickly. Other employers, and the in-depth interviews confirm this, may not have a strong preference for graduates with high professional expertise because they have the internal training facilities to teach them the occupation-specific knowledge they need. The same employers may therefore put more emphasis on other, more transversal types of skills such as general academic skills because they are an important ingredient for further professional growth. Remarkably, background variables, such as employers' country, occupational field, firm size or international market exposure, explain little of the variance in preferences; the relative importance employers attach to CV attributes and types of skills does not cluster

19 For scatter plots indicating a concave relationship between productivity (the mixed logit coefficients) and skill levels see Figure 3.1 in the Appendix. 
according to characteristics often used to describe and categorize them. More detailed information on the particular junior positions employers had in mind when doing the experiments would be necessary to explain the differences in employers' preferences. This has important implications for individuals intending to maximize their employability. When envisaging employment with a particular employer, graduates need more detailed information on this employer's preferences when making decisions regarding their skill profile. Merely depending on characteristics such as firm size or the sector is insufficient for making optimal choices. Individuals who aim to maximize their average chances on the labour market without having a particular employer in mind do best by investing in their professional expertise and interpersonal skills.

The implications of our results for higher education institutions are similar. Aggregate skill supply should match aggregate skill demand reasonably well, and some graduate skill profiles need to be developed in higher quantity than others. Our findings show that some types of skills are more important for labour market entry while others are more important for individuals' future careers. From the employer's perspective types of skills such as commercial/entrepreneurial skills, innovative/creative skills and strategic/organizational skills are more important and better developed after having acquired a few years of work experience. This suggests that initial higher education should focus on the transmission of occupation-specific knowledge, problem-solving skills, general academic skills and interpersonal skills. Unless it is a central characteristic of a study programme aligned to the needs of particular employers, providing individuals with high levels of commercial/ entrepreneurial skills, innovative/creative skills and strategic/organizational skills may not be optimal for graduates' employability. 


\section{Appendix}

\section{Figure 3.5}

Concave relationship between productivity and skill level

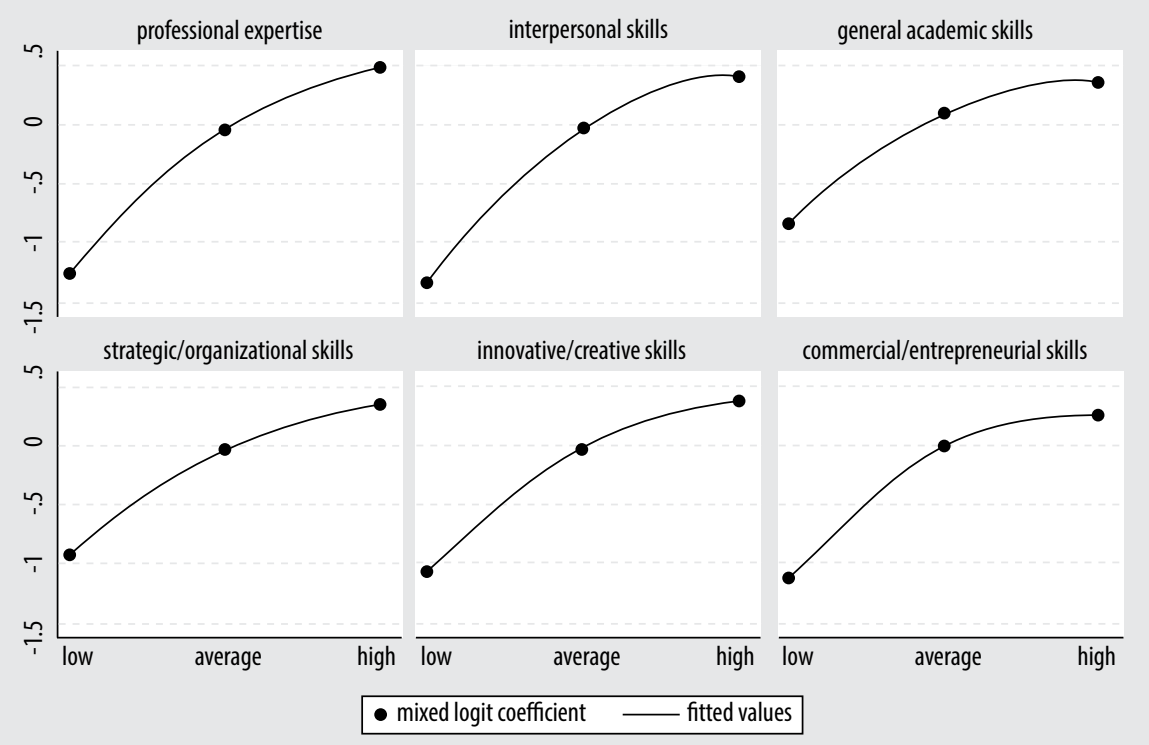

This figure contains scatter plots indicating the concave relationship between productivity (the mixed logit coefficients) and skill levels by type of skill. The fitted values are based on the prediction for the mixed logit coefficient from a regression of the mixed logit coefficient on skill level and skill level squared.

Table 3.6

Proportional frequencies of attributes in choice set and selected graduate profile

\begin{tabular}{ccr}
\hline \hline Attribute & $\begin{array}{r}\text { Proportional Frequency } \\
\text { in Choice Set }\end{array}$ & $\begin{array}{r}\text { Proportional Frequency in } \\
\text { Selected Graduate Profile }\end{array}$ \\
\hline
\end{tabular}

First Stage (CV attributes)

Degree:

Bachelor's

Master's

Doctorate

Match of field of study and job task

Unrelated

Incomplete

Complete

Relevant work experience

No

1 year

2 years

Study experience abroad 
Table 3.6

Proportional frequencies of attributes in choice set and selected graduate profile

\begin{tabular}{lll}
\hline \hline No & 0.33 & 0.33 \\
Partly & 0.33 & 0.35 \\
Entirely & 0.33 & 0.33 \\
Grades & & \\
Below average & 0.25 & 0.19 \\
Above average & 0.25 & 0.25 \\
Average & 0.25 & 0.29 \\
Top 10\% & 0.25 & 0.27 \\
Prestige/reputation of university & & \\
Average & 0.5 & 0.53 \\
High & 0.5 & 0.47 \\
Salary & & \\
$25 \%$ below average & 0.2 & 0.23 \\
$10 \%$ below average & 0.2 & 0.23 \\
Average & 0.2 & 0.23 \\
$10 \%$ above average & 0.2 & 0.18 \\
$25 \%$ above average & 0.2 & 0.13
\end{tabular}

\section{Second Stage (Hiring)}

\section{Professional expertise}

Top 25\%

Average

Bottom 25\%

General academic skills

Top 25\%

0.33

Average

Bottom 25\%

Innovative/creative skills

Top 25\%

Average

0.33

0.35

Bottom 25\%

Strategic/organizational skills

Top 25\%

Average

0.33

0.34

Bottom 25\%

0.33

Interpersonal skills

Top 25\%

Average

Bottom 25\%

0.33

Commercial/entrepreneurial skills 
Table 3.6

Proportional frequencies of attributes in choice set and selected graduate profile

Salary

$25 \%$ below average

0.2

0.22

$10 \%$ below average

0.2

0.21

Average

0.2

0.22

$10 \%$ above average

0.2

0.2

$25 \%$ above average

0.2

0.15 



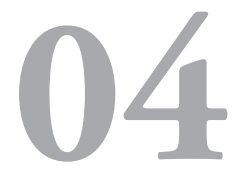

PERSONALITY AND FIELD

OF STUDY CHOICE 


\subsection{Introduction}

Individuals' personality traits are related to a variety of educational and labour market outcomes. ${ }^{20}$ For example, personality traits have been shown to affect individuals' academic performance in school, as well as their probability of finishing secondary school, attending university, and obtaining a university degree (Heckman, Stixrud and Urzua, 2006; Cunha and Heckman, 2007; O'Connor and Paunonen, 2007; Borghans, Duckworth, Heckman and ter Weel, 2008; Barón and Cobb-Clark, 2010). After leaving education, personality traits influence individuals' probability of being employed (Heckman et al. 2006) as well as their earnings (Nyhus and Pons, 2005; Mueller and Plug, 2006, Heineck and Anger, 2010). The present paper explores the relationship between the Big Five personality traits and another important educational outcome: field of study choice. Field of study choice has far-reaching implications for individuals enrolling in university. As fields of study are strongly linked to occupations, choosing a particular field of study narrows down the job options available to individuals after graduation. Field of study choice is therefore strongly linked to the subject matter graduates will specialize in, the kind of work environment they will be working in, and the returns to their skills they can expect once they enter the workforce.

Expected life time earnings have long been identified as one of the major determinants of field of study choice (Berger, 1988; Flyer, 1997; Arcidiacono, 2004; Arcidiacono, Hotz and Kang, 2012; Wisfall and Zafar, 2013). Individuals have been shown to be aware of careers which maximize their expected life time earnings given their abilities, and they tend to choose their field of study accordingly. However, Arcidiacono (2004) and Wiswall and Zafar (2013) have recently argued that expected life time earnings may be less important than what Arcidiacono (2004) calls preference for "subject matters" and what Wiswall and Zafar (2013) refer to as the "enjoyability of coursework". Of particular importance to my study, Arcidiacono (2004) shows that cognitive skills are related to both these determinants of field of study choice: math ability and verbal ability influence field of study choice by generating different returns in different occupational fields, and by being related to the preference and taste for doing math or tasks related to using verbal ability.

This paper presents evidence that personality traits influence field of study choice in much the same way cognitive skills do. I argue that individuals with particular personality traits a) enjoy some fields of study and related occupations more than others and b) are more productive in some fields of study and related occupations than others. The main contribution of this study is thus the inclusion of individual differences in utility functions as captured by the Big Five personality traits - extraversion, agreeableness, conscientiousness, emotional stability and openness to experience - into the prediction of individuals' field of study.

As alluded to above, previous research has shown that individuals choose subject matters and jobs which they like and which they are good at. Both enjoying tasks and being good at them is likely to increase productivity in these tasks. Evidence that this may be

20 I am grateful to Eric Bonsang, Andries de Grip, Ingrid Rohde, Tom Stolp, Tanja Traag, Rolf van der Velden and conference participants at the 2nd Lisbon Research Workshop on Economics, Statistics and Econometrics of Education 2013, SOLE 2013 in Boston and EALE 2013 in Turin for their discussions and comments on earlier versions of this paper. 
related to the Big Five personality traits has been found in both the economic literature and the literature on vocational psychology. Holland (1997) has documented that individuals choose their work environments on the basis of their vocational interests, and de Fruyt and Mervielde (1997) have found that vocational interests and the Big Five personality traits are related. Filer (1986) and Cobb-Clark and Tan (2011) show that the Big Five personality traits (or related measures in the case of Filer) are associated with individuals' occupational choice; Nyhus and Pons (2005), Mueller and Plug (2006) as well as Heineck and Anger (2010) find that the Big Five personality traits are factors of production which can be rewarded and sometimes penalized by employers. More specifically, emotional stability and agreeableness have been found to be particularly important in jobs involving large amounts of teamwork and dyadic customer interaction (Mount, Barrick and Steward, 1998). Judge and Cable (1997) find that more agreeable job seekers are more attracted to supportive and team-oriented organizational cultures and less attracted to aggressive, outcome-oriented, and decisive organizational cultures. Barrick and Mount (1991) show that extraversion is associated with higher job performance in management and sales occupations. Cattan (2010) ${ }^{21}$ shows that sociability, a trait related to extraversion, is rewarded in some occupations and penalized in others. Controlling for selection, she finds that a standard deviation increase in sociability leads to a $6 \%$ increase in the wages of managers, a $4 \%$ increase in the wages of sales workers, and a $2 \%$ increase in the wages of clerical workers, but leads to a $2 \%$ decrease in the wages of professionals. Krueger and Schkade (2008) show that extroverted persons sort into jobs which provide them with the opportunity for social contact. Borghans, ter Weel and Weinberg (2008) find that sociability in youth is related to interpersonal tasks in the occupation individuals are working in as adults. They also find that occupations differ with regard to the personality traits they demand, and that individuals are most productive in jobs which fit their personality.

Evidence for a relationship between personality traits and occupational sorting from previous studies is strongest for extroversion. Looking at the definition of the Big Five personality traits in Table 4.1 it is, however, easy to imagine how the other Big Five personality traits may be related to field of study and occupational career choice as well.

\section{Table 4.1}

Personality traits and their definitions

\begin{tabular}{ll}
\hline \hline Personality trait & Definition \\
\hline $\begin{array}{l}\text { Openness to experience } \\
\text { Conscientiousness }\end{array}$ & $\begin{array}{l}\text { The tendency to be open to new aesthetic, cultural, or intellectual experiences. } \\
\text { The tendency to be organized, responsible, and hardworking. } \\
\text { Extraversion }\end{array}$ \\
$\begin{array}{l}\text { An orientation of one's interests and energies toward the outer world of people and things rather } \\
\text { than the inner world of subjective experience; characterized by positive affect and sociability. }\end{array}$ \\
Agreeableness & The tendency to act in a cooperative, unselfish manner. \\
Emotional stability (Neuroticism) & $\begin{array}{l}\text { Emotional stability is predictability and consistency in emotional reactions, with absence of rapid } \\
\text { mood changes. }\end{array}$ \\
& Neuroticism is a chronic level of emotional instability and proneness to psychological distress. \\
\hline \hline
\end{tabular}

Definitions from American Psychological Association Dictionary (2007) cited in Almlund et al. (2011).

21 Cattan's work is currently not publicly available but is reported in Almlund et al. (2011). 
For example, agreeableness - defined as the tendency to act in a cooperative, unselfish manner - may be expected to be related to sorting into healthcare occupations and into fields of study concerned with the (well) functioning of society. Emotionally stable persons are more effective in dealing with stress than neurotic persons (Costa and McCrae, 1985) which may lower their disutility of choosing fields of study with higher workloads. Openness to experience and conscientiousness are important predictors of academic success (O'Connor and Paunonen, 2007) and may therefore be expected to be mainly relevant for educational achievement rather than field of study choice. However, they may increase the probability of entering those study programs for which access is granted on the basis of grades.

In this paper, I find that the Big Five personality traits indeed affect field of study choice. The results represent an important contribution to the literature as I am able to estimate the effect personality measured around the age of 14 will have on field of study choice four years later. This allows me to circumvent the reverse causality problem faced by analyses using contemporaneous personality measures (personality measured at the same time as field of study choice). By measuring personality well before field of study choice, I can exclude the possibility that individuals' personality has been influenced by enrolling in a particular field of study; for example, through individuals' adaptation to their peers or through behavioural stereotypes associated with particular fields of study and related occupations.

The remainder of this paper is structured as follows: The next section will explain the data as well as the econometric model and will describe the mean personality differences across educational levels and fields of study. In section 3 I will briefly show how personality traits affect educational attainment before presenting the main results on how personality traits are associated with field of study choice. I draw conclusions in section 4.

\subsection{Data and methodology}

This paper uses data of a large longitudinal Dutch youth survey of 19,391 individuals who entered secondary education and were around the age of 13 in $1999 .{ }^{22}$ Students were drawn from a random selection of 126 Dutch schools (Van Berkel, 1999). The cohort has been shown to be a representative 10 percent sample of students in the first grade of secondary education in the Netherlands (Kuyper and Van der Werf, 2003).

In January 2000, four months after entering secondary education, all students were administered a subset of the traditional Dutch Cito test used to sort students across secondary education tracks. This test assessed math ability, verbal ability and information processing ability. Each ability was assessed using a battery of 20 multiple choice items.

In February 2001 of the second year of the cohort study, students were administered the Five-Factor Personality Inventory (FFPl; Hendriks, Hofstee, and De Raad, 1999) which assesses the Big Five personality dimensions: extraversion, agreeableness, conscientiousness, emotional stability, and openness to experience. The questionnaire contained 100 items on a five-point scale ranging from 1 (not at all accurate) to 5 (fully accurate). Each personality

22 Please note that these individuals have either not yet, or else just recently, entered the labour market. Data on their labour market outcomes is therefore not yet available. 
dimension was assessed using 10 positively and 10 negatively formulated items. The data set contains the factor scores computed by the FFPI scoring programme (Hofstee and Hendriks, 1998). The constructed Big Five factors are uncorrelated. The internal consistency reliability (stratified-alpha) of extraversion is $a=0.841$, of agreeableness $a=0.82$, of conscientiousness $a=0.84$, of emotional stability $a=0.83$, and of openness to experience $a=0.72$. For analysis, all measures of personality traits and cognitive ability were standardized to have a mean of zero and a standard deviation of one.

Personality traits measured at age 14 can be considered a good proxy for personality traits at the time of choosing a field of study, four to five years later. Despite individuals' maturation, differential continuity of personality in childhood, adolescence and young adulthood has been found to be strong: the vast majority of individuals keep their relative position within the personality trait distribution over time (Roberts, Caspi and Moffit, 2001; de Fruyt et al., 2006).

Table 4.2

Comparison of sample to national distribution

\begin{tabular}{|c|c|c|c|c|c|c|}
\hline & \multicolumn{3}{|c|}{ Women } & \multicolumn{3}{|c|}{ Men } \\
\hline & \multicolumn{2}{|c|}{ Sample } & \multirow{2}{*}{$\begin{array}{r}\text { Nationally } \\
\%\end{array}$} & \multicolumn{2}{|c|}{ Sample } & \multirow{2}{*}{$\begin{array}{r}\text { Nationally } \\
\%\end{array}$} \\
\hline & $\mathrm{N}$ & $\%$ & & $\mathrm{~N}$ & $\%$ & \\
\hline \multicolumn{7}{|l|}{ Enrolment in the year after secondary education: } \\
\hline Post-secondary vocational education (mbo) & 3610 & 54.2 & 60.0 & 3793 & 57.9 & 64.6 \\
\hline Higher professional education (hbo) & 2002 & 30.0 & 25.5 & 1650 & 25.16 & 21.3 \\
\hline \multirow[t]{2}{*}{ University education (wo) } & 1051 & \multirow[t]{2}{*}{15.8} & \multirow[t]{2}{*}{14.5} & 1114 & 17.0 & 14.1 \\
\hline & 6663 & & & 6557 & & \\
\hline \multicolumn{7}{|l|}{ Field of study (university only) } \\
\hline Humanities & 201 & 19.4 & 17.8 & 119 & 10.9 & 10.3 \\
\hline Social Sciences & 351 & 34.0 & 32.6 & 147 & 13.5 & 13.8 \\
\hline Law & 81 & 7.8 & 14.9 & 47 & 4.3 & 10.4 \\
\hline Business, Economics & 142 & 13.7 & 10.0 & 324 & 29.7 & 25.5 \\
\hline Science, Technology, Engineering, Mathematics & 78 & 7.5 & 9.2 & 336 & 30.8 & 31.6 \\
\hline \multirow[t]{2}{*}{ Medical Studies } & 181 & \multirow[t]{2}{*}{17.5} & \multirow[t]{2}{*}{15.5} & 119 & 10.9 & 8.4 \\
\hline & 1034 & & & 1092 & & \\
\hline
\end{tabular}

Note: mbo: middelbar beroepsonderwijs, hbo: hoger beroepsonderwijs, wo: wetenschappelijk onderwijs. Nationwide enrolment in the year after secondary education was calculated on the basis of data of the Dutch statistical office on students' transition from secondary to post-secondary or higher education in 2005. About $9 \%$ of women and men in our sample and $11 \%$ nationally did not continue education after secondary education. This category is omitted in the table and the analysis of educational attainment. 2187 observations for women and 2253 observations for men are lost due to missing personality and cognitive skill measures. Nationwide field of study choice is based on data of the Dutch statistical office and the Association of Universities in the Netherlands (VSNU) for the year 2005.17 women and 22 men in agricultural and environmental studies were omitted from the analysis of field of study choice due to the small size of this category. 
After having registered background information as well as test and personality scores, individuals' pathways were followed until 2009 or until they left education. In my sample, the vast majority of those individuals entering university education did so in 2005 and 2006 at age 18 to $19 .{ }^{23}$ I use detailed information on the field of study individuals have chosen in their first year in university and group them into six commonly used broader field of study categories 1) Humanities, 2) Social Sciences (excluding Business, Economics and Law), 3) Business and Economics, 4) Law, 5) Science, Technology, Engineering and Mathematics (STEM), and 6) Medical Studies. ${ }^{24}$ Higher education institutions with a professional orientation, sometimes also referred to as universities of applied sciences or higher professional education (Dutch: hbo), are not incorporated in this study. This type of education is distinct from university education (Dutch: wo) and including it in the analysis would diminish international comparability of the results.

Table 4.3

Personality traits and cognitive skills by educational level and gender

\begin{tabular}{|c|c|c|c|c|c|c|}
\hline & \multicolumn{3}{|c|}{$\begin{array}{c}\text { Women } \\
\text { Mean (s.d.) }\end{array}$} & \multicolumn{3}{|c|}{$\begin{array}{c}\text { Men } \\
\text { Mean (s.d.) }\end{array}$} \\
\hline & $\begin{array}{c}\text { Post- } \\
\text { secondary } \\
\text { vocational } \\
\text { education }\end{array}$ & $\begin{array}{c}\text { Higher } \\
\text { professional } \\
\text { education }\end{array}$ & $\begin{array}{l}\text { University } \\
\text { education }\end{array}$ & $\begin{array}{c}\text { Post- } \\
\text { secondary } \\
\text { vocational } \\
\text { education }\end{array}$ & $\begin{array}{c}\text { Higher } \\
\text { professional } \\
\text { education }\end{array}$ & $\begin{array}{l}\text { University } \\
\text { education }\end{array}$ \\
\hline \multirow[t]{2}{*}{ Extraversion } & 1.31 & 1.41 & 1.35 & 0.97 & 1.12 & 1.04 \\
\hline & $(0.85)$ & $(0.84)$ & $(0.85)$ & $(0.85)$ & $(0.83)$ & $(0.85)$ \\
\hline \multirow[t]{2}{*}{ Agreeableness } & 1.97 & 2.25 & 2.26 & 1.22 & 1.53 & 1.69 \\
\hline & $(1.07)$ & $(0.96)$ & $(0.92)$ & $(1.06)$ & $(1.02)$ & $(0.99)$ \\
\hline \multirow[t]{2}{*}{ Conscientiousness } & 0.29 & 0.37 & 0.33 & 0.38 & 0.48 & 0.56 \\
\hline & $(1.08)$ & $(1.02)$ & $(1.02)$ & $(1.01)$ & $(1.04)$ & $(1.04)$ \\
\hline \multirow[t]{2}{*}{ Emotional Stability } & 0.82 & 0.97 & 1.02 & 1.14 & 1.35 & 1.35 \\
\hline & $(0.93)$ & $(0.91)$ & $(0.84)$ & $(0.88)$ & $(0.84)$ & $(0.84)$ \\
\hline \multirow[t]{2}{*}{ Openness to Experience } & 0.37 & 0.53 & 0.69 & 0.46 & 0.59 & 0.69 \\
\hline & $(0.87)$ & $(0.86)$ & $(0.86)$ & $(0.83)$ & $(0.83)$ & $(0.86)$ \\
\hline \multirow[t]{2}{*}{ Math ability } & 9.96 & 14.18 & 16.02 & 11.23 & 15.12 & 17.00 \\
\hline & (3.79) & (3.28) & (2.74) & $(4.07)$ & $(3.02)$ & $(2.42)$ \\
\hline \multirow[t]{2}{*}{ Verbal ability } & 11.72 & 14.87 & 16.32 & 10.61 & 13.82 & 15.63 \\
\hline & $(3.29)$ & $(2.63)$ & $(2.32)$ & $(3.43)$ & (2.91) & $(2.61)$ \\
\hline \multirow[t]{2}{*}{ Information processing ability } & 10.17 & 13.84 & 15.50 & 10.48 & 14.12 & 16.13 \\
\hline & $(3.49)$ & (3.12) & $(2.94)$ & (3.83) & (3.26) & $(2.92)$ \\
\hline
\end{tabular}

As female and male students have different personality trait endowments but also make different field of study choices I run regressions separately for men and women. Table $\mathbf{4 . 2}$

23 The Dutch secondary education allows for some flexibility. Changing from lower tracks to the academic track, which is a prerequisite for university, is possible but often linked to repeating grades. This explains the low percentage of students entering university after 2006.

24 For a description of how study programmes are grouped into the six categories see Appendix table 4.7. Study programmes belonging to the category of agricultural and environmental studies are omitted from the analysis as they only contain 17 women and 22 men. 
shows that the sample is broadly nationally representative with regard to the percentage of individuals who enrol in university as well as the distribution across fields of study.

Tables 4.3 and 4.4 present the means and standard deviations of personality traits and cognitive skills both by level of educational attainment and by field of study. Personality traits and cognitive skills with large mean differences between educational levels are likely to be related to individuals' educational attainment. For instance, differences of openness to experience are substantial between educational attainment levels for both men and women, suggesting that this trait plays a major role with regard to individuals' probability of going to university. With regard to fields of study, differences of openness to experience are less pronounced, with a high mean level in Law being an exception. Rather, differences between fields of study seem to be most substantial with regard to extraversion, indicating that extraversion is important for sorting into particular fields of study. In the analysis in section 3, I will use standardized measures of personality traits and cognitive skills. Moreover, I will present the regression results in terms of average marginal effects. While mean comparisons already give some indication about sorting into different educational levels and fields of study, average marginal effects draw a clearer picture about the percentage change in the probability of going to university (choosing a particular field of study) associated with a one standard deviation change of the respective personality trait or cognitive skill.

I will estimate the effect of personality traits and cognitive skills on individuals' probability of going to university using an ordered probit model where the ranked dependent variable is vocational education, higher professional education, and university. In particular, I am interested in the change of individuals' probability of going to university $\left(P_{i c}\right)$ as a result of a one standard deviation change in the scores on a particular Big Five personality trait or cognitive skill $\left(x_{k}\right)$ given by:

$$
\frac{\partial P_{i c}}{\partial x_{i k}}=\beta_{k} \phi\left(\alpha_{2}-x_{i}^{\prime} \beta\right)
$$

where $\mathrm{a}_{2}$ is the estimated second cut-off point of the ordered probit regression and $x_{i}$ the is vector of independent variables including the measures of personality traits and cognitive skills; indicators for highest parental education, and a dummy which is one if the individual has a migration background.

I model the field of study choice as a choice between six discrete alternatives and use a multinomial logit framework to estimate how the Big Five personality traits as well as cognitive skills relate to this choice. The probability that individual $i$ chooses field of study $j$ is

$$
\operatorname{Pr}\left(Y_{i}=j \mid x_{i}\right)=P_{i, j}=\frac{\exp \left(x_{i}^{\prime} \beta_{j}\right)}{1+\sum_{k=1}^{J} \exp \left(x_{i}^{\prime} \beta_{k}\right)}, j=0,1, \ldots, 5
$$




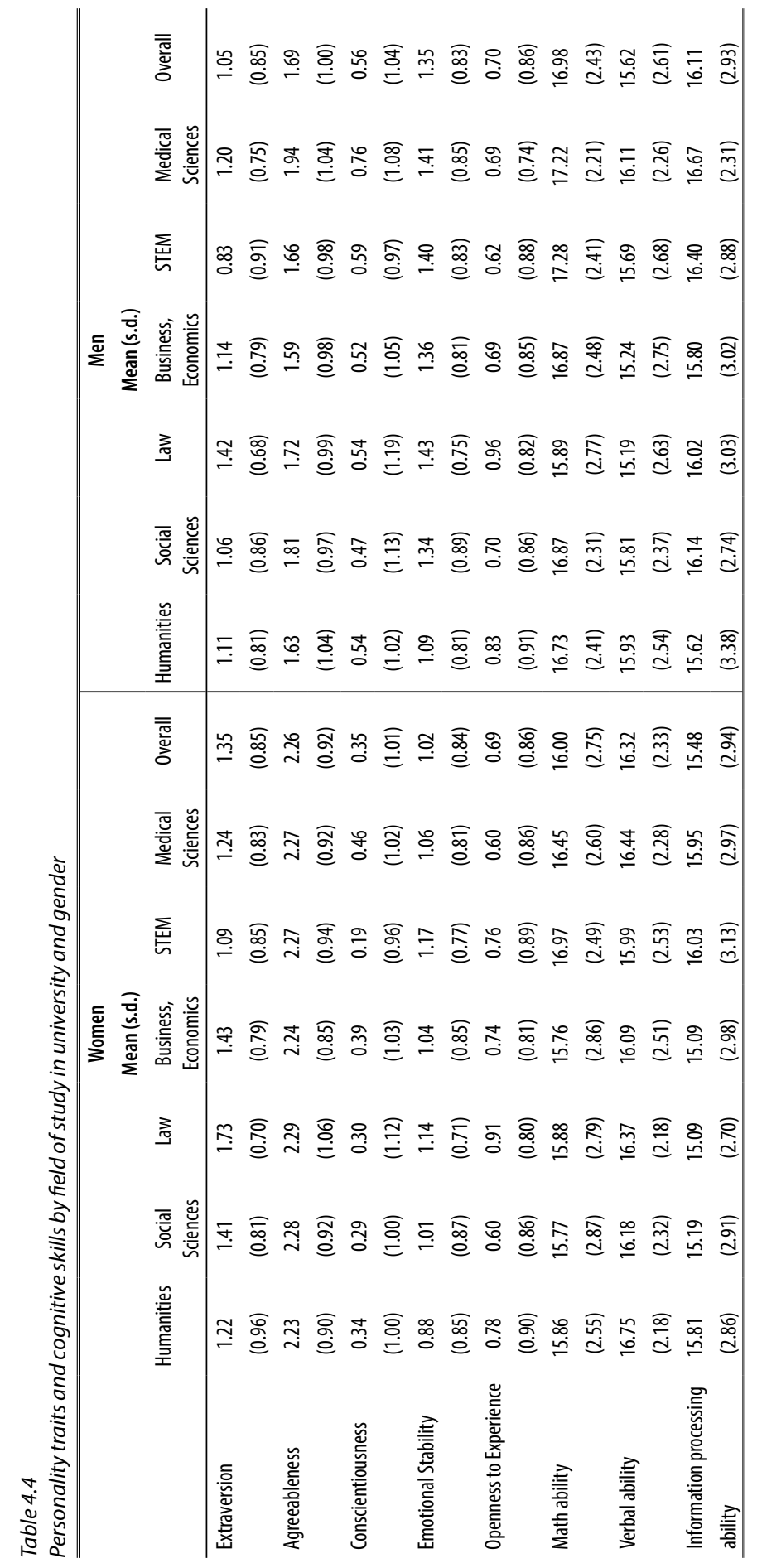


where $\beta_{o}$ has been normalized to equal o. $X_{i}$ is the same vector of independent variables as used in the ordered probit model of educational attainment, with additional indicators of father's occupation as control for differences in information sets. The marginal effect of independent variable $x_{h}$ on an individual's probability of choosing field of study $j$ depends on the coefficients of all fields of study $\left(\beta_{h k}\right)$ and is given by:

$$
\frac{\partial P_{i, j}}{\partial x_{i h}}=P_{i, j}\left[\beta_{h j}-\sum_{k=0}^{J} P_{i, k} \beta_{h k}\right]
$$

\subsection{Results}

Before proceeding to the main results on field of study choice, it is worthwhile to briefly examine how personality traits affect the probability of entering university. Table 4.5 displays the average marginal effects of personality traits and cognitive skills on the probability of going to university. Average marginal effects were obtained from an ordered probit regression of educational attainment where the ranked dependent variable is vocational education, higher professional education, and university education. The ordered probit regression implies that all three measures of cognitive skills as well as agreeableness, conscientiousness, and openness to experience increase both women's and men's probability of entering a university. For women, emotional stability is also positively related to educational attainment. Cognitive skills seem to be the primary driver of educational attainment. For example, a one standard deviation increase in math ability is associated with an increase in the probability of entering a university of 7.8 percentage points for women and 8.4 percentage points for men. These effects are very large given that only around 16 to $17 \%$ of women and men in our sample go to university. Of the personality traits that influence individuals' probability of going to university, conscientiousness has the largest effect. A one standard deviation increase in conscientiousness is associated with an increase in probability of entering university of 1.8 percentage points for women and 2.7 percentage points for men. While much smaller than the impact of cognitive skills, this effect is substantial and amounts to a relative increase of the probability of entering university by $11 \%$ for women and $16 \%$ for men. Openness to experience affects the probability of going to university equally for women and men (1.3 percentage points). Men and women with a one standard deviation higher score on openness to experience are about $8 \%$ more likely to go to university. Agreeableness has the smallest effect on individuals' educational attainment, especially for women. A one standard deviation increase in agreeableness increases the probability of going to university by 0.6 percentage points $(4 \%)$ for women and 1.1 percentage points $(6 \%)$ for men.

The positive impact of conscientiousness and openness to experience on educational attainment is consistent with the findings of O'Connor and Paunonen (2007) who report a positive relationship between these two personality traits and academic success. More conscientious individuals are thought to be more motivated to succeed academically and 
have the tendency to be organized, hard-working, and achievement oriented. Openness to experience has been found to be related to measures of intelligence (Chamorro-Premuzic and Furnham, 2005) and the positive relationship between openness to experience and academic success has often been interpreted in this light. With regard to the relation between agreeableness and academic success, $\mathrm{O}^{\prime}$ Connor and Paunonen (2007) conclude that evidence is mixed: while some studies find a negative relationship between agreeableness and academic success, some find a positive. All studies, however, find only small effects. The results from table 4.5 add to the evidence that the relationship is positive.

Table 4.5

Average marginal effects of personality traits and cognitive skills on individuals' probability of going to university (ordered probit model)

\begin{tabular}{lll}
\hline & Women & Men \\
\hline Extraversion & 0.001 & 0.000 \\
Agreeableness & $(0.003)$ & $(0.003)$ \\
& $0.006^{* *}$ & $0.011^{* * *}$ \\
Conscientiousness & $(0.003)$ & $(0.003)$ \\
& $0.018^{* * *}$ & $0.027^{* * *}$ \\
Emotional stability & $(0.003)$ & $(0.003)$ \\
& $0.005^{*}$ & 0.004 \\
Openness to experience & $(0.003)$ & $(0.003)$ \\
Math ability & $0.013^{* * *}$ & $0.013^{* * *}$ \\
Verbal ability & $(0.003)$ & $(0.003)$ \\
& $0.078^{* * *}$ & $0.084^{* * *}$ \\
Information processing ability & $(0.004)$ & $(0.004)$ \\
& $0.060^{* * *}$ & $0.063^{* * *}$ \\
\hline \hline
\end{tabular}

Note: Average marginal effects from an ordered probit model where the ranked dependent variable is vocational education, higher professional education and university education. ${ }^{* *} p<0.01,{ }^{* *} p<0.05$ and ${ }^{*}$ $p<0.1$. Controls for highest parental education and migration background were included, as well as missing dummies. The pseudo $R 2$ of both underlying ordered probit models (women and men) is 0.32 . For women $N=6663$, for men $N=6557$.

Table 4.6 presents the average marginal effects of personality traits and cognitive skills on the probability of choosing a particular field of study by gender. The results are conditional on entering university, thus net of the effect of personality traits on entering university. The results indicate that extraversion has one of the strongest associations with field of study choice. For both women and men, higher extraversion is associated with a higher probability of choosing Law and a lower probability of choosing a STEM field of study in university.

A one standard deviation increase of extraversion decreases the probability of choosing STEM fields by 7.8 percentage points for men and 2.5 percentage points for women. While the absolute effect is larger for men, the relative effect is larger for women. Given that STEM field enrolment rates in our sample are $30.8 \%$ for men and only $7.5 \%$ for women, men with a one 
standard deviation higher score on extraversion are $25 \%$ less likely to enrol in a STEM field, whereas women with a similarly higher score on extraversion are $33 \%$ less likely to enrol in a STEM field. With regard to choosing Law in university, a one standard deviation increase in extraversion increases the probability of choosing this field of study by $46 \%$ (3.6 percentage points) for women and $42 \%$ (1.8 percentage points) for men. The multinomial logit model further implies that extraversion is associated with choosing Business, Economics and Medical Studies for men; for women, it associates with Social Sciences and Humanities. Men who score one standard deviation higher on extraversion are 10\% (2.9 percentage points) more likely to choose Business and Economics and 20\% (2.2 percentage points) more likely to choose Medical Studies. In contrast, women who score one standard deviation higher on extraversion are $7 \%$ ( 2.5 percentage points, marginally significant) more likely to choose Social Sciences and 14\% (2.7 percentage points) less likely to choose Humanities. Increasing levels of extraversion seem to shift young men's field of study choice from STEM to Law, Business, Economics and Medical Sciences. For women, increasing levels of extraversion seems to shift field of study choice from STEM and Humanities to Social Sciences and Law. All other things being equal, Social Sciences, Business, Economics, Law and Medical Studies seem to fit extroverts better in terms of the opportunity for social interaction, for persuading others, and for being the focus of attention. In the words of Sherwin Rosen: "Musicians cannot be tone-deaf; football players tend to be large; while lawyers, and many economists, have a propensity to talk" (Rosen, 2002:9).

Agreeable individuals are persons who are considered warm and who enjoy helping others. One might therefore expect that agreeable individuals have a comparative advantage in, and would have a preference for, fields of study involving healthcare, such as Medical Studies, or fields of study concerned with the functioning of societies, such as the Social Sciences (excluding Business, Economics and Law). In line with this reasoning, Judge and Cable (1997) find that more agreeable job seekers are more attracted to supportive and team-oriented organizational cultures and less attracted to aggressive, outcome-oriented, and decisive organizational cultures. The results of the multinomial logit model are consistent with these findings, yet only for men. Men who score one standard deviation higher on agreeableness are $22 \%$ (2.4 percentage points) more likely to choose Medical Studies, $16 \%$ (2.1 percentage points, marginally significant) more likely to choose Social Sciences and 9\% (2.7 percentage points, marginally significant) less likely to study Business or Economics. The latter effect is perfectly in line with the findings of Cobb-Clark and Tan (2011) who show that for men, a one standard deviation increase in agreeableness is associated with a 2.8 percentage point decrease in the probability of being a manager, and a 2.9 percentage point decrease in the probability of being a business professional. This finding strongly suggests that the occupational sorting on the basis of personality traits found by Cobb-Clark and Tan (2011) already starts in late adolescence when choosing a field of study. 


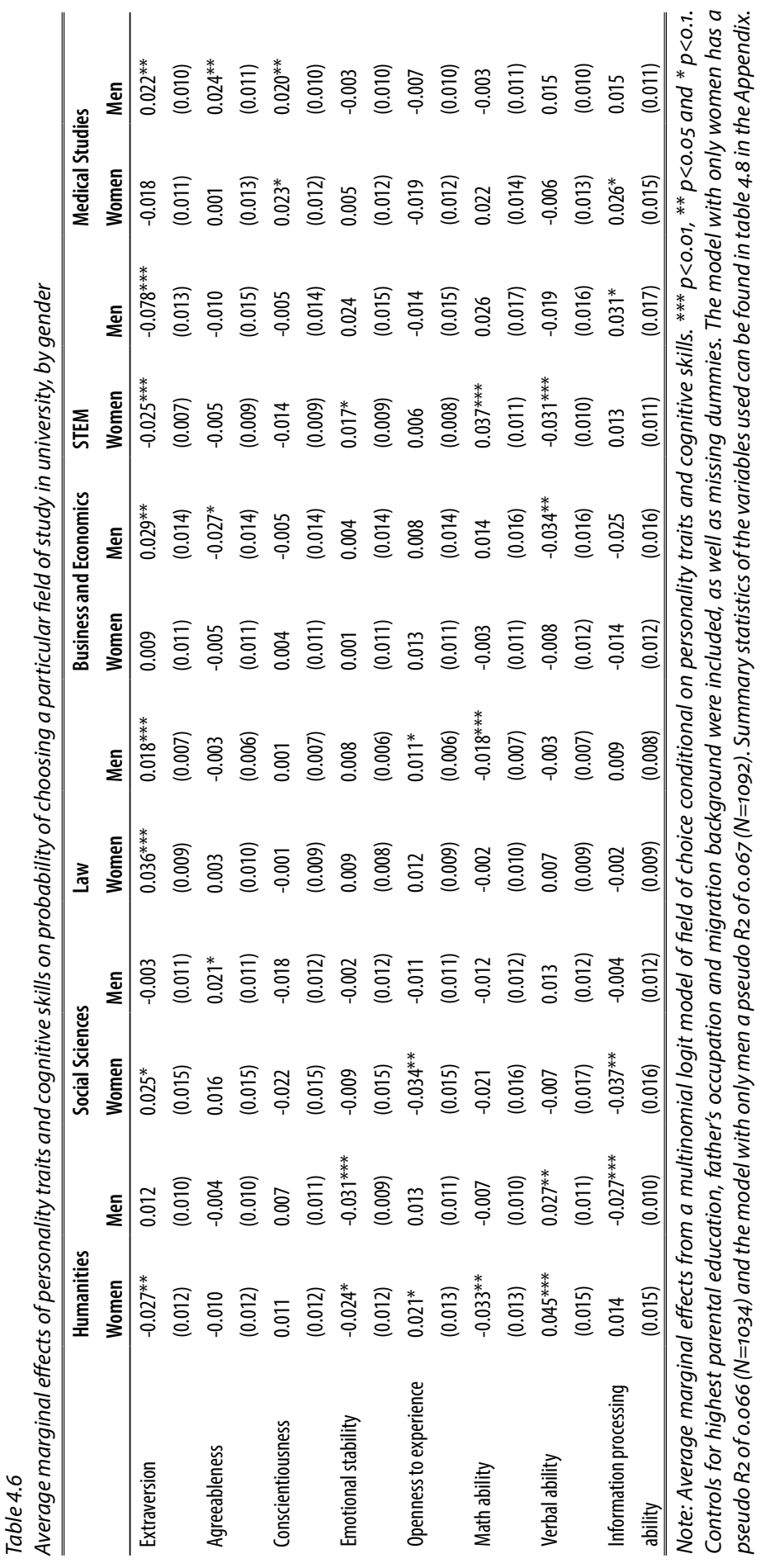


The results from the ordered probit regression of educational attainment presented in Table 4.5 highlighted the substantial influence of conscientiousness and openness to experience on individuals' probability of entering university. They are, however, also associated with field of study choice, yet less prominently and with some differences between women and men. Women who score one standard deviation higher on openness to experience are $11 \%$ (2.1 percentage points, marginally significant) more likely to choose Humanities and $10 \%$ (3.4 percentage points) less likely to enrol in Social Sciences in university. Men who score one standard deviation higher on openness to experience are $26 \%$ (1.1 percentage point, marginally significant) more likely to choose Law in university. Conscientiousness affects field of study choice similarly for women and men. Women with a one standard deviation higher score on conscientiousness have a $14 \%$ higher probability of choosing Medical Studies and men with a one standard deviation higher score on conscientiousness have an $18 \%$ (2.0 percentage points) higher probability of sorting into Medical Studies. The effects of openness to experience are somewhat puzzling, given that it is not obvious that the Social Sciences are less intellectually challenging or should offer fewer opportunity for aesthetic and cultural experiences than the Humanities or Law. However, there are two potential explanations for the finding that conscientiousness is positively related to the probability of studying Medical Sciences. Firstly, access to Medical studies is restricted in the Netherlands. Access is granted via a weighted lottery in which high school grades are taken into account. Conscientiousness is related to academic achievement (O'Connor and Paunonen, 2007) and this could account for the effect I have identified. Secondly, although conscientiousness increases productivity in all occupations, the expected rewards of productivity are high for doctors. $^{25}$

Emotional stability - to be calm, self-confident and cool rather than insecure, anxious, depressed and emotional - is positively related to the probability of enrolling in STEM fields for women and negatively linked to the probability of choosing Humanities for both genders. A one standard deviation increase in emotional stability is associated with a $12 \%$ (2.4 percentage point) decrease in the probability of choosing Humanities for women, and a $35 \%$ (3.1 percentage points) decrease for men. The same change in emotional stability increases women's probability of enrolling into STEM fields by $23 \%$ ( 1.7 percentage points). The positive effect of emotional stability on choosing a STEM field of study in university is consistent with the findings of Cobb-Clark and Tan (2011) who present evidence that emotional stability is positively related to sorting into Science and Engineering professions. They find this relationship, however, for both women and men.

A potential explanation of the effect of emotional stability on field of study choice is that emotional stability is positively related to being a conventional vocational interest type (De Fruyt and Mervielde, 1997). Consequently, more emotionally stable individuals may sort into STEM fields because they enjoy structured environments and rules and therefore dislike the seemingly unstructured environment of Humanities and the Social Sciences. Following Holland's (1997) description of more artistic work environments and personality types, it may

2510 years after graduation, the average monthly gross earnings of Medical students are 6000 Euro, followed by Business and Economics students (5600 Euro) and Law students (5100 Euro). In contrast, Psychology and Neuroscience students (Humanities and Social Sciences category) earn an average of 3500 Euro gross per month 10 years after leaving university. Source: ROA (2011). Maastricht University graduate survey (UM Scanner). 
also be that the more disorderly and emotionally charged nature of individuals studying humanities is an important stimulus for their more artistic activities, and might, in the end, represent a comparative advantage in tasks related to this field of study. A third explanation is that less emotionally stable individuals exhibit higher career indecision (Tokar, Fischer and Subich, 1998). As the Humanities have weaker links to particular occupations and careers than STEM fields, the associations I have found may be the result of individuals' postponing their career decision by choosing Humanities.

The results for math ability and verbal ability are in line with the findings of Turner and Bowen (1999), although they differ in some respects. Higher math ability increases the probability of choosing STEM fields and decreases the probability of choosing Humanities, yet only for women. The results deviate from those of Turner and Bowen (1999) in that they find similar effects for both genders. Some of the differences between their results and mine can be attributed to the fact that I am able to control for information processing ability in addition to math and verbal ability. Excluding information processing ability from the regression (not shown here) results in the positive effect of math ability on the probability of choosing a STEM field of study to become stronger and statistically significant for men. The negative effect of math ability on the probability of choosing Humanities remains, however, insignificant. This suggests that the effect of math ability found by Turner and Bowen (1999) stems at least partly from the positive correlation between math ability and information processing ability ( 0.41 in my sample).

The impact of math ability on field of study choice is substantial. For women, a one standard deviation increase in math ability increases the probability of enrolling in a STEM field of study by $49 \%$ (3.7 percentage points) and decreases the probability of enrolling in Humanities by $17 \%$ (3.3 percentage points). For men, a similar increase in math ability decreases the probability of choosing Law in university by $41 \%$ ( 1.8 percentage points).

The effects of verbal ability are, again with some deviations, comparable to those of Turner and Bowen (1999). Verbal ability increases the probability of choosing Humanities in university similarly for both genders. For women, a one standard deviation increase in verbal ability increases the probability of choosing Humanities by about $23 \%$ (4.5 percentage points), while for men the same increase in verbal ability is associated with a $25 \%$ ( 2.7 percentage points) increase in the probability of choosing Humanities in university. For women, math and verbal ability seem to work in opposite directions. For men, this is not the case. While verbal ability, similar to math ability, influences the decision to choose a STEM field of study for women, it instead affects the decision to study Business or Economics for men. Women with a one standard deviation higher verbal ability are about 41\% (3.1 percentage points) less likely to choose a STEM field of study in university. Men with similar verbal ability are some $12 \%$ (3.4 percentage points) less likely to choose Business or Economics.

I have found that higher information processing ability shifts women's field of study choice from Social Sciences to Medical Sciences and men's field of study choice from Humanities to STEM fields. Women with a one standard deviation higher information processing ability are some $11 \%$ (3.7 percentage points) less likely to study Social Sciences and 15\% (2.6 percentage points, marginally significant) more likely to choose Medical Studies. Men with similarly higher information processing ability are $25 \%$ ( 2.7 percentage points) less likely to study Humanities and some 10\% (3.1 percentage points, marginally significant) more likely 
to choose a STEM field of study. A potential explanation for these findings is that Medical Sciences and STEM fields are known to involve a tight curriculum which necessitates higher than average information processing ability. Women who seek challenges seem to choose Medical Studies while men who seek challenges choose STEM fields of study. ${ }^{26}$

\subsection{Conclusion}

This paper shows that the Big Five personality traits have a significant influence on individuals' field of study choice. This shows that personality traits are already affecting occupational sorting of the highly skilled when they are entering university.

In many respects, personality affects field of study choice similarly for women and men. For both genders, higher verbal ability increases, and higher emotional stability decreases, the probability of choosing Humanities in university. As well, higher levels of extraversion are associated with a higher probability of choosing Law and a lower probability of choosing STEM fields for both women and men. In addition, higher levels of conscientiousness increase both women's and men's probability of choosing Medical Studies. There are, however, substantial differences in how women and men sort into fields of study based on their personality and cognitive skills. This is most apparent for fields of study such as Business and Economics, STEM fields, and Medical Studies; for these, sorting of women and men seems to follow different rules. As elaborated by Turner and Bowen (1999), Zafar (2009), and Antecol and Cobb-Clark (2013), the reasons for this may be gender differences in the weights allocated to post-university opportunities or gender differences in labour market (dis-) incentives. For instance, the non-existent effect of disagreeableness on choosing Business or Economics in university for women is in line with Judge, Livingston and Hurst's (2012) finding that, due to conventional gender roles, the wage returns for disagreeableness are higher for men than they are for women.

While cognitive skills are the primary driver of the probability of entering university, the effects of personality traits and cognitive skills are similar (the differences not statistically significant) with regard to field of study choice. In the case of sorting into STEM fields for men, extraversion is even more important than information processing ability.

With regard to policies aimed at increasing the supply of graduates in fields of study such as Engineering that are considered crucial for economic development, my findings seem to suggests that influencing young individuals' personalities towards introversion and emotional stability would increase the enrolment rates in STEM fields. This, however, presupposes a causal interpretation of the results which is not warranted: in the estimation framework used in this study, personality traits capture various productive factors and preferences and it is not obvious that when personality traits are changed, these will

26 In the 2005 REFLEX survey, Dutch university graduates in the Humanities and Social Sciences (excluding Business, Economics and Law) reported studying for 30 and 27 hours per week respectively. In contrast, self-reported hours spent studying per week were 37 for STEM graduates and 38 for graduates in Medical Studies. Similarly, when rating whether their studies were regarded as demanding on a five point scale, graduates in the Humanities and Social Sciences rated their studies 2.7 and 2.6 respectively, while STEM graduates reported 3.8 and graduates in Medical Studies 3.7. Appendix tables 4.9 and 4.10 report hours spent studying and demandingness for all six fields of study. 
change, too. Rather, my findings confirm the importance of taking individuals' preferences for subject matters and work environments into account when designing policies aimed at managing flows into particular fields of study. Given the importance of these preferences for field of study choice, providing moderate monetary incentives for choosing STEM fields will not significantly increase enrolment rates in these fields. 


\section{Appendix}

Table 4.7

Detailed field of study categories and six categories used in multinomial logit framework by gender

\begin{tabular}{|c|c|c|c|c|c|}
\hline $\begin{array}{l}\text { Broad field of study category } \\
\text { used in study }\end{array}$ & Dutch V0CL99 data fields of study & $\begin{array}{r}\mathrm{N} \\
\text { (women) }\end{array}$ & $\%$ & $\begin{array}{r}\mathrm{N} \\
\text { (men) }\end{array}$ & $\%$ \\
\hline \multicolumn{6}{|l|}{ Humanities } \\
\hline & Theology & 3 & 0.29 & 1 & 0.09 \\
\hline & $\begin{array}{l}\text { Languages (Dutch, French, Spanish, German, } \\
\text { English) }\end{array}$ & 80 & 7.74 & 61 & 5.59 \\
\hline & History & 19 & 1.84 & 20 & 1.83 \\
\hline & History of Art/Archaeology & 5 & 0.48 & 2 & 0.18 \\
\hline & Philosophy & 4 & 0.39 & 6 & 0.55 \\
\hline & Humanities-other & 90 & 8.70 & 29 & 2.66 \\
\hline & & 201 & 19.44 & 119 & 10.90 \\
\hline
\end{tabular}

Social Sciences

$$
\begin{aligned}
& \text { Administrative Studies } \\
& \text { Physical Education } \\
& \text { Geography } \\
& \text { Anthropology/Sociology } \\
& \text { Health Sciences } \\
& \text { Sociology } \\
& \text { Political Sciences } \\
& \text { Psychology } \\
& \text { Educational Sciences } \\
& \text { Social Sciences-other }
\end{aligned}
$$

Business and Economics

Business/Economics
Econometrics
Technical Business studies
Business/Economics-other

Law

Law

Mathematics, Natural Sciences, Engineering, other technical studies

Mathematics
Physics
Chemistry
Biology
Pharmaceutical studies
Mathematics/Natural Sciences-other
Technical Mathematics
Technical Physics
Technical Chemistry

\begin{tabular}{rrrr}
13 & 1.26 & 22 & 2.01 \\
11 & 1.06 & 7 & 0.64 \\
5 & 0.48 & 5 & 0.46 \\
14 & 1.35 & 2 & 0.18 \\
36 & 3.48 & 8 & 0.73 \\
7 & 0.68 & 8 & 0.73 \\
4 & 0.39 & 12 & 1.10 \\
113 & 10.93 & 30 & 2.75 \\
62 & 6.00 & 3 & 0.27 \\
86 & 8.32 & 50 & 4.58 \\
\hline 351 & 33.95 & 147 & 13.46
\end{tabular}

\begin{tabular}{rrrr}
93 & 8.99 & 183 & 16.76 \\
2 & 0.19 & 9 & 0.82 \\
1 & 0.10 & 24 & 2.20 \\
46 & 4.45 & 108 & 9.89 \\
\hline 142 & 13.73 & 324 & 29.67
\end{tabular}

\begin{tabular}{llll}
81 & 7.83 & 47 & 4.30 \\
\hline 81 & 7.83 & 47 & 4.30
\end{tabular}

$\begin{array}{rrrr}0 & 0 & 4 & 0.37 \\ 2 & 0.19 & 0 & 0 \\ 2 & 0.19 & 9 & 0.82 \\ 13 & 1.26 & 19 & 1.74 \\ 5 & 0.48 & 2 & 0.18 \\ 18 & 1.74 & 61 & 5.59 \\ 3 & 0.29 & 1 & 0.09 \\ 3 & 0.29 & 26 & 2.38 \\ 0 & 0 & 10 & 0.92\end{array}$


Table 4.7

Detailed field of study categories and six categories used in multinomial logit framework by gender

\begin{tabular}{lrrrr} 
Civil Engineering & 3 & 0.29 & 24 & 2.20 \\
Construction & 8 & 0.77 & 35 & 3.21 \\
Electrotechnology & 0 & 0 & 17 & 1.56 \\
Toolmaking & 4 & 0 & 43 & 3.94 \\
Aerospace & 0 & 0 & 24 & 2.20 \\
Technical studies - others & 17 & 1.64 & 61 & 5.59 \\
\cline { 2 - 5 } & 78 & 7.54 & 336 & 30.77
\end{tabular}

Medical Studies

\begin{tabular}{lrrrr} 
Medical studies Medicine & 104 & 10.06 & 73 & 6.68 \\
Medical studies other & 53 & 5.13 & 33 & 3.02 \\
Dentistry & 4 & 0.39 & 3 & 0.27 \\
Veterinary & 20 & 1.93 & 10 & 0.92 \\
& 181 & 17.50 & 119 & 10.90 \\
\cline { 2 - 5 } & 1034 & & 1092 &
\end{tabular}


Table 4.8

Summary statistics of variables used in multinomial logit model of field of study choice

\begin{tabular}{|c|c|c|c|c|}
\hline & \multicolumn{2}{|c|}{ Women } & \multicolumn{2}{|c|}{ Men } \\
\hline & mean & s.d. & mean & s.d. \\
\hline \multicolumn{5}{|l|}{ Personality traits } \\
\hline Extraversion & 1.35 & 0.85 & 1.05 & 0.85 \\
\hline Agreeableness & 2.26 & 0.92 & 1.69 & 1 \\
\hline Conscientiousness & 0.35 & 1.01 & 0.56 & 1.04 \\
\hline Emotional Stability & 1.02 & 0.84 & 1.35 & 0.83 \\
\hline Openness to Experience & 0.69 & 0.86 & 0.70 & 0.86 \\
\hline \multicolumn{5}{|l|}{ Cognitive skills } \\
\hline Math ability & 16.00 & 2.75 & 16.98 & 2.43 \\
\hline Verbal ability & 16.32 & 2.33 & 15.62 & 2.61 \\
\hline Information processing ability & 15.48 & 2.94 & 16.11 & 2.93 \\
\hline \multicolumn{5}{|l|}{ Highest parental education } \\
\hline Low & 0.04 & & 0.03 & \\
\hline $1^{\text {st }}$ step secondary education & 0.05 & & 0.05 & \\
\hline $2^{\text {nd }}$ step secondary education & 0.27 & & 0.27 & \\
\hline Bachelor's degree (ref) & 0.32 & & 0.31 & \\
\hline Master's degree or doctorate & 0.26 & & 0.29 & \\
\hline Parental education missing & 0.06 & & 0.05 & \\
\hline Migration background & 0.19 & & 0.15 & \\
\hline \multicolumn{5}{|l|}{ Father's occupation } \\
\hline Agriculture & 0.03 & & 0.02 & \\
\hline Business, Economics & 0.19 & & 0.19 & \\
\hline Medical Studies & 0.09 & & 0.09 & \\
\hline Government & 0.11 & & 0.10 & \\
\hline STEM & 0.15 & & 0.15 & \\
\hline other & 0.20 & & 0.23 & \\
\hline Father's occupation missing & 0.23 & & 0.22 & \\
\hline
\end{tabular}


CHAPTER 4

Table 4.9

Mean self-reported hours spent studying per week

\begin{tabular}{ll}
\hline \hline Humanities & 30
\end{tabular}

$\begin{array}{lr}\text { Social Sciences } & 27\end{array}$

Law 25

$\begin{array}{lr}\text { Business, Economics } & 30\end{array}$

$\begin{array}{lr}\text { STEM } & 37\end{array}$

\begin{tabular}{lr} 
Medical Studies & 38 \\
\hline
\end{tabular}

Source: REFLEX survey

Table 4.10

Mean self-reported demandingness of study (5 point scale)

\begin{tabular}{ll}
\hline Humanities & 2.7
\end{tabular}

Social Sciences $\quad 2.6$

$\begin{array}{ll}\text { Law } & 2.7\end{array}$

$\begin{array}{lr}\text { Business, Economics } & 3.1\end{array}$

$\begin{array}{lr}\text { STEM } & 3.8\end{array}$

\begin{tabular}{ll} 
Medical Studies & 3.6 \\
\hline
\end{tabular}

Source: REFLEX survey 


\section{WHICH SKILLS PROTECT GRADUATES}

AGAINST A SLACK LABOUR MARKET 


\subsection{Introduction}

Several studies analyse the cyclical crowding out of low-skilled workers by high-skilled workers (Gautier, Van den Berg, Van Ours, and Ridder, 2002; Devereux, 2002; Gesthuizen and Wolbers, 2010; Keane and Prasad, 1993; Pollmann-Schult, 2005; Teulings and Koopmanschap, 1989; Van Ours and Ridder, 1995). ${ }^{27}$ In general, their findings suggest that having a higher level of education protects workers against unemployment in slack labour markets: when overall labour demand decreases, higher-educated workers will enter the jobs previously occupied by lower-educated workers and these in turn will face a higher probability of becoming unemployed. While previous studies focus on workers with different levels of education, we expect the same mechanisms to lead to competition for jobs among workers with the same level of education but different skill endowments. Workers with the lowest skill endowments within their level of education are least likely to secure a job which requires their level of education when excess labour supply increases. To our knowledge, this study is the first to focus on individuals with the same level of education with respect to whether the protective effect of a higher level of skills against overeducation and unemployment increases with the degree of excess supply in the labour market. For our analysis, we use data from a graduate ${ }^{28}$ survey conducted in 17 European countries; these data contain skill measures and offer variation in labour market conditions across countries and fields of study. We examine whether the extent to which graduates' labour market risks are affected their field-specific and academic skills depends on the labour supply and demand ratio. By focusing on individuals at the upper end of the educational distribution around the time of their entering the labour market, we are able to distinguish two risks associated with excess labour supply: the risk of overeducation and the risk of unemployment. We examine field-specific and academic skills because these represent one of the most important skills dichotomies. ${ }^{29}$

This paper contributes to the literature in two ways. First, we shed more light on the relationship between field-specific and academic skills and the labour market outcomes of graduates. Second, we analyse how the protective effect of field-specific and academic skills varies with the labour supply and demand ratio. In line with the predictions of the crowding out hypothesis, we find that the level of protection afforded by field-specific skills against the risk of overeducation is higher when the degree of excess labour supply in the occupational domain of the graduate's field of study is higher. Conversely, academic skills offer more protection against the risk of overeducation when excess labour supply in the overall labour market is higher. Further, field-specific skills also protect graduates against the

27 This chapter is joint work with Andries de Grip and Rolf van der Velden. I am grateful to Jim Allen and Arnaud Dupuy for their comments on earlier versions of this chapter.

28 Throughout this paper, graduates refer to individuals who have been the subject of a graduation from a higher education institution, including both universities and universities of applied sciences.

29 Economic literature usually distinguishes between firm-specific and general skills. While the former augment productivity only in a specific firm, the latter are productive in multiple firms. In our analysis of labour market outcomes of graduates, the unit of analysis is the field of study rather than the firm. Following Heijke, Meng, and Ris (2003), we therefore deviate from the standard dichotomy by referring to field-specific instead of firmspecific skills. We define field-specific skills as skills which are productive in jobs related to a graduate's field of study and which are transferable to the occupational domain of other fields of study only with considerable value depreciation. Academic skills, on the other hand, are productive in all occupational domains and do not depreciate when transferred from one domain to another. 
risk of unemployment, whereas graduates' level of academic skills appears to be unrelated to the risk of unemployment.

The remainder of this paper is structured as follows: Section 2 presents the conceptual framework and section 3 the hypotheses. In Section 4 we discuss our data, and in Section 5 we present our estimation results. Section 6 then sets forth our conclusions.

\subsection{Conceptual framework}

The crowding out hypothesis is compatible with the job competition model (Thurow, 1975) and is based on the idea that when jobs become scarce, vacancies previously filled with low-skilled workers are filled with higher skilled workers, pushing the former into ever lower skilled jobs or even into unemployment. This process is also referred to as skill bumping (Borghans and De Grip, 2000) and is likely to intensify with the degree of excess labour supply. There are several studies supporting this hypothesis. Devereux (2002) finds that the mean level of education of those employed in a particular occupation increases during recessions in the US. Keane and Prasad (1993) show that workers with college degrees were protected from cyclical variation in employment in the US in the 1970s. Pollmann-Schult (2005) finds evidence for crowding out in Germany in the period 1984-2000. For the Dutch labour market, Teulings and Koopmanschap (1989) find evidence for crowding out of workers with lower levels of education by workers with higher levels of education during the recession of the 1980s. For the 1990s, Van Ours and Ridder (1995), and similarly Gautier et al. (2002) suggest that crowding out might have been limited to university-educated versus higher professional-educated workers. Gesthuizen and Wolbers (2010) argue that over the period 1980-2004 in the Netherlands, crowding out resulted from higher education expansion rather than economic shocks.

The above-mentioned studies analysing cyclical crowding out define skills as years of schooling or level of education. In our analysis, we use direct (self-assessed) skill measures at the individual level. We are therefore able to examine the risk of overeducation and the risk of unemployment of graduates from higher education with different skill endowments under different labour supply and demand ratios. We distinguish two types of skills, field-specific skills and academic skills. These skill types have been shown to affect labour market entrants' risk of overeducation as well as their risk of unemployment. Studies on labour market entrants at the intermediate education level emphasize the relevance of field-specific skills for labour market success (Bishop, 1995; Campbell and Laughlin, 1991; Goux and Maurin, 1994; Kang and Bishop, 1989; Mane, 1999; Payne, 1995; Ryan, 2001). Non-college bound high school students with field-specific skills have a smoother transition into work and higher earnings than their more generally educated counterparts. The situation may differ for higher-educated graduates. Heijke et al. (2003) show that both field-specific and academic skills affect the labour market outcomes of graduates. High field-specific skills increase graduates' chances of getting a job in occupations related to their own field of study, which is on average associated with higher wages. Academic skills, on the other hand, increase graduates' probability of receiving training during their first years in the labour market, which is also associated with higher wages. Both types of skills, these authors conclude, 
therefore positively impact wages: field-specific skills by securing a job related to the field of study, and academic skills by increasing the incidence of training. Verhaest and Van der Velden (2013), however, find that graduation from a study programme which is more focused on academic skills significantly increases the probability of being overeducated in the first job. But graduating from such general programmes also increases the probability to 'escape' from a situation of overeducation and finding a job which matches the level of education. These findings suggest that academic skills enable individuals to adapt to disequilibrium situations, such as working outside one's field of study or being overeducated.

In addition to distinguishing two types of skills, we differentiate between two labour market domains: the specific labour market for a field of study and the overall labour market (the 'general labour market'). Specific labour markets refer to multiple, mutually exclusive occupational domains related to particular fields of study. We argue that graduates' prospects in the occupational domain related to their field of study are based on their level of field-specific skills. This labour market segment includes occupations which require a very specific set of skills, such as medical doctors, pilots, or engineers. In the occupational domain of a particular field of study, field-specific skills are the dominant factor for labour market success, because these are instantly deployable and are associated with low costs for further field-specific training. Alternatively, graduates can work in the general labour market, for example when they are not able to find employment in the occupational domain related to their field of study. The general labour market segment contains occupations which require graduates to have broadly applicable skills, such as the ability to think analytically. In the general labour market, competition for jobs is not limited to graduates of particular fields of study. Rather, all graduates can compete for these jobs. We argue that graduates' prospects in the general labour market are based on their academic skills. This is because graduates' field specific skills are not transferable to this segment. Examples of general jobs are trainee programmes in large firms, management positions, and general administrative positions.

\subsection{Hypotheses}

We now present our hypotheses. When unemployment is average, there will still be some level of job-worker mismatch in terms of overeducation, and a graduate's risk of becoming one of these mismatched workers will certainly depend on the level of skill. We therefore expect graduates with high levels of field-specific or academic skills to have a lower risk of becoming overeducated than graduates with low levels of these skills (hypothesis 1).

The distinction between a labour market where more field-specific skills are required and a labour market where more academic skills are required has important implications for the formulation of our hypotheses with regard to the consequences of supply and demand shocks. Shocks taking place in the field-specific labour market will affect the relationship between field-specific skills and labour market outcomes, whereas shocks in the general labour market will affect the relationship between academic skills and labour market outcomes. When the number of graduates in a particular field of study increases relative to the number of graduate jobs at the tertiary level in the occupational domain related to this field, given an economic and/or demographic shock, more graduates with low levels of field- 
specific skills will be forced to take up jobs previously available for workers with intermediate qualifications for that field. The higher the excess labour supply in the field-specific labour market, the greater the difference will be in the risk of overeducation between graduates with high and graduates with low field-specific skills. We therefore expect the protective effect of field-specific skills against overeducation to be higher when the degree of excess supply of graduates in the field-specific occupational domain is higher (hypothesis 2).

In the general labour market, employers prefer workers with the highest academic skills available. Therefore, graduates with lower levels of academic skills will accept jobs otherwise available for workers with intermediate levels of education when jobs which require higher education are scarce. We therefore expect to observe a higher the protective effect of academic skills against overeducation when unemployment and competition for jobs in the general labour market is higher (hypothesis 3).

Let us now turn to the risk of unemployment. According to a strict interpretation of the crowding out hypothesis, individuals with higher levels of education always possess higher and more productive skills than workers with lower levels of education. It will therefore always be attractive for firms to hire graduates for intermediate-level jobs - at the expense of workers with an intermediate level of education. Consequently, field-specific and academic skills would be relevant only to the distribution of graduates across job levels, but not to unemployment. However, this strict interpretation of the crowding out hypothesis ignores that there may be other adjustment mechanisms. Wieling and Borghans (2001), for example, find that for graduates, accepting a job for which no tertiary-level degree is required is only one of the adjustment mechanisms in the labour market. They also find that for some specific fields of study, an increasing excess supply of graduates is associated with an increase in graduate unemployment. This is contrary to what we would expect if the higher educated were always higher skilled and better suited for jobs than the lower educated. Nickell and Bell (1995) suggest that high-skilled workers are only able to crowd out lower skilled workers if they can perform many of the tasks undertaken by the lower skilled. This argument is key to formulating expectations about limitations to the crowding out process in the two labour market segments we distinguish.

In contrast to academic skills, the field-specific skills of the higher educated do not necessarily substitute for the field-specific skills of the medium educated: being a good plumber requires different skills than developing and constructing domestic drainage systems. If the better jobs at the intermediate level are assigned to well trained workers with intermediate levels of education, then some graduates - more precisely those whose level and nature of field-specific skills cannot compete with the level and nature of the field-specific skills of workers with intermediate levels of education - will not be able to find a job, or will be able to find a job acceptable to them in terms of pay and job quality. ${ }^{30}$ Consequently, graduates with low field-specific skills will be more likely to be unemployed than graduates with high field-specific skills, as the latter will be able to find work at an adequately high level. These limitations to graduates' opportunity to crowd out the lower educated are less pronounced in the general labour market. In occupations which require

$30 \quad$ These graduates might also opt for unemployment because they fear that accepting a low skilled job signals low ability to potential future employers or because they find it more efficient to search for a better job while unemployed (Evans, 1999). 
academic skills, workers with intermediate levels of education can much more easily be substituted by graduates. In this labour market segment, it is much more attractive for firms to hire graduates instead of workers with intermediate levels of education, as graduates have'more of the same' skills. In the general labour market, jobs at the intermediate level are thus available for graduates, so that even the least skilled graduates have a high probability of finding acceptable jobs in terms of pay and job quality (see Fig. 5.1).

Figure 5.1 illustrates how this conceptualisation of the labour market for graduates might look.

Figure 5.1

Four labour market segments and available jobs for graduates.

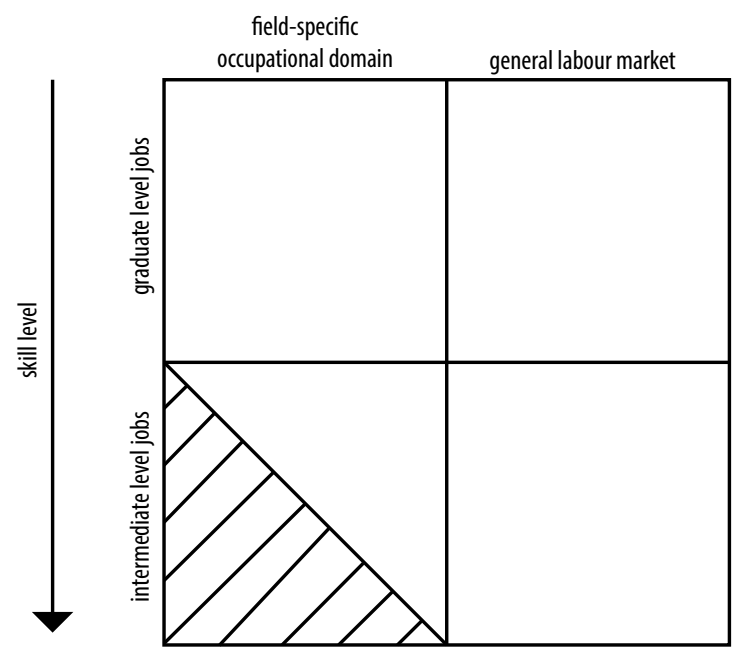

Graduates entering the labour market can potentially take jobs in two labour market segments, which are subdivided into two levels. Graduates can accept a graduate-level job related to the occupational domain of their field of study or outside this domain (the general labour market). The same applies for intermediate-level jobs. Here, graduates can also take up a job related to the occupational domain of their field of study or in the general labour market. The downward arrow on the left side indicates the decreasing level of skill required of these workers. The argument here is that for some intermediate-level jobs in the field-specific occupational domain, the skills higher-educated workers bring are not suited (indicated by the diagonally striped area). Consequently, these jobs are not available for graduates despite their higher level of education, leaving some graduates with low fieldspecific skills unemployed. We therefore expect that high field-specific skills also protect graduates against unemployment (hypothesis 4). We therefore further expect the protective effect of field-specific skills against unemployment to be higher when excess supply of graduates in the respective occupational domain is higher (hypothesis 5). The limitations to graduates' opportunities to crowd out lower-educated workers are expected to be far less pronounced in the general labour market. We therefore expect the protective effect 
of academic skills against unemployment to be significantly weaker than the protective effect of field-specific skills (hypothesis 6). However, here too we might expect that the protective effect of academic skills against unemployment to be higher when excess supply of graduates in the general labour market is higher (hypothesis 7).

\subsection{Data}

Our analysis is based on original and representative data from the REFLEX and HEGESCO surveys among graduates from 17 European countries. ${ }^{31}$ The questionnaire was sent to higher education graduates 5 years after graduation. Our sample contains 11,552 individuals for the estimation of the probability of being unemployed, and 11,129 individuals for the estimation of the probability of being overeducated.

In the questionnaire, respondents were asked to rate their level of 19 different skills on a scale from 1 (very low) to 7 (very high). Two of these skills, 'mastery of own field or discipline' and 'analytical thinking' used in this study to proxy field-specific and academic skills, respectively. 'Mastery of own field or discipline' refers to graduates' level of theoretical and practical knowledge in their own field and to the ability to apply this knowledge in practice. Analytical thinking, on the other hand, refers to the ability to generalize from a concrete problem to abstract ideas, and to manipulate these ideas to arrive at a solution, not only to the original problem, but to a whole class of similar problems. These skills match our definition of field-specific and academic skills quite well.

Our definition of the dependent variables is straightforward. We consider an individual unemployed if that individual had been actively trying to obtain paid work in the four weeks preceding the survey but was not in paid work at the time of the survey. With regard to overeducation, we asked respondents to indicate the type of education most appropriate to their job. ${ }^{32}$ We consider graduates overeducated if the appropriate type of education for their job is below tertiary level.

We use the unemployment rate among graduates at the time of the survey as a proxy for labour market conditions. In order to test our hypotheses, we include two different unemployment rates in our models: (1) the unemployment rate among graduates in the respondent's country, and (2) the unemployment rate among graduates in the respondent's field of study within that country. The former is a good proxy for excess supply in the general labour market, as every unemployed graduate can compete for jobs in the general labour market. The latter is a proxy for excess supply in the occupational domain related to a particular field of study. Due to the specificity of skills required, only graduates of the respective field of

31 The REFLEX survey (The Flexible Professional in the Knowledge Society) was conducted in 2005 among 15 European countries and Japan. The HEGESCO survey (Higher Education as a Generator of Strategic Competences) is the extension of REFLEX to four new EU member states and Turkey conducted in 2009. In our analysis, we focus only on European countries to ensure comparability. We excluded Sweden and Portugal because their survey design substantially deviated from the rest of the survey. For the remaining countries, we include only individuals who were less than 36 years old at the time of the survey to avoid unobserved pre-university labour market experience influencing the results. Moreover, we exclude all individuals who were not living or working in their home country at the time of the survey or who enrolled in further education after the initial education they reported on. The number of observations per country varies between 382 and 995 .

32 For a discussion on measurement issues in assessing overeducation, see Van der Velden and Van Smoorenburg (1997), Dolton and Vignoles (2000) and Hartog (2000). 
study can enter competition for jobs in the occupational domain related to a particular field of study. Both unemployment rates are calculated on the basis of the combined REFLEX and HEGESCO data as posterior means..$^{33}$ Their values per country and field of study are displayed in Table 5.1. In the probit regressions, we include the unemployment rate in the occupational domain of a particular field of study (the field-specific unemployment rate within a country) as the deviation from the overall unemployment rate (the country-level unemployment rate), and we include the overall unemployment rate as the deviation from the unemployment rate of the whole sample. This ensures that both unemployment rates are uncorrelated and brings advantages concerning the interpretation of the regression results, as pointed out in the next section. Note that using international variation for the identification of effects of skills and their interaction with labour market conditions has advantages over national studies, but also obvious limitations. The main advantage is that measures generated from international data offer variation usually unavailable within a single country and provide insight into long-term, general equilibrium effects. A clear limitation of cross-country, crossfield evidence is the possible omission of country-level and field-level variables, such as institutional differences in ability sorting or employers' beliefs. This makes identification of effects less clean than in studies exploiting changes within countries and fields over time.

Table 5.1

Overall unemployment rates and unemployment rates in the occupational domain of particular fields of study per country

\begin{tabular}{lrrrrrrrrrr}
\hline \hline & Mean & ED & HU & SJI & BL & SMC & EMC & AV & HW & SE \\
\hline Austria & 4.3 & 2.4 & 6.1 & 4.4 & 4.5 & 3.6 & 3.2 & 5.8 & 4.8 & 3.7 \\
Belgium & 2.2 & 1.9 & 3.3 & 2.2 & 1.1 & 3 & 2 & 2.1 & 1.2 & 1.9 \\
Czech Republic & 2.6 & 3.1 & 3.9 & 1.6 & 1.9 & 2.6 & 2.1 & 2.5 & 2.6 & 2.1 \\
Estonia & 1.9 & 1 & 2.3 & 1.7 & 1.2 & 1.2 & 1.1 & 2.3 & 2.4 & 2.5 \\
Finland & 4.4 & 4.4 & 4.9 & 3.3 & 4 & 4.1 & 3.1 & 3.5 & 5.8 & 6.5 \\
France & 7.6 & 6.6 & 10.5 & 8.7 & 8.2 & 9.7 & 5.7 & 7.2 & 5.9 & 7.5 \\
Germany & 4.8 & 4.7 & 5.9 & 4.7 & 4.1 & 7.3 & 4.6 & 4.1 & 3.8 & 4 \\
Hungary & 5 & 6.7 & 4.2 & 5.3 & 4.9 & 4.6 & 4.5 & 4.9 & 4.1 & 5.9 \\
Italy & 7.6 & 9 & 10.2 & 9.1 & 7.4 & 8.4 & 3.6 & 8.1 & 6.6 & 7.4 \\
Lithuania & 3.2 & 3.8 & 4.4 & 2.7 & 2.7 & 2.8 & 2.7 & - & 2.9 & 3 \\
Netherlands & 4.2 & 2.6 & 6 & 4 & 3.6 & 6.1 & 3.5 & 4.7 & 2.8 & 4.1 \\
Norway & 2.7 & 2.4 & 3.3 & 3 & 2.1 & 2.5 & 2.2 & 2.6 & 2.1 & 3.1 \\
Poland & 2.2 & 3.3 & 2 & 1.5 & 2.1 & 2.3 & 1.7 & 2 & 1.8 & 1.8 \\
Spain & 8.9 & 9.8 & 12.5 & 9.9 & 7.8 & 10.3 & 5.1 & 11.3 & 7.5 & 8 \\
Slovenia & 3.8 & 3.9 & 4.1 & 3.3 & 3.6 & 3.5 & 2.4 & 5.1 & 1.6 & 5.4 \\
Switzerland & 4.4 & 3.6 & 5.2 & 5.3 & 4.2 & 6.4 & 3.2 & 4.3 & 3.1 & - \\
United Kingdom & 3.6 & 2.7 & 5.6 & 3.5 & 3.3 & 2.6 & 3.8 & 4 & 2.5 & 3.8 \\
\hline \hline
\end{tabular}

Note: Values are posterior means derived from REFLEX/HEGESCO data. ED=Education, HU=Humanities and Arts, SJI=Social Sciences, Journalism and Information, BL=Business, LaW, SMC=Science, Mathematics

33 When using posterior means instead of simple means, the mean country unemployment and the mean fieldspecific unemployment are corrected for reliability by shifting toward the Grand Mean, depending on the number of observations within each country and field of study. 
and Computing, EMC=Engineering, Manufacturing and Construction, AV=Agriculture and Veterinary, $H W=$ Health and Welfare, SE=Services. "-" stands for no observations.

As control variables, we use only variables which influence the probability of being overeducated or unemployed, because of signalling or network effects, but which are not necessarily outcomes of skills. We include gender, age, age squared, a dummy for whether the father has a higher education, a dummy for whether the respondent had a master's degree or equivalent, ${ }^{34}$ a dummy for whether the respondent had study-related work experience during higher education, and a dummy for whether the respondent had non-study-related work experience during the higher education period..$^{35}$

\subsection{Estimation results and discussion}

In this section, we present our estimation results using pooled probit models. For both dependent variables, i.e., the probability of being overeducated as well as the probability of being unemployed, we estimate three models.

In model 1, the labour market mismatch, MM, of graduate $i$ is estimated as follows:

$$
\begin{aligned}
& M M_{i}^{*}=\beta_{10}+\beta_{11} \text { spec }_{i}+\beta_{12} \text { acad }_{i}+\beta_{13} u f_{c f}+\beta_{14} u c_{c}+\beta_{15} X_{i}+\varepsilon_{1 i} \\
& \text { (1) } M M_{i}=1\left[M M_{i}^{*}>0\right] \\
& \varepsilon_{i} \sim N(0,1),
\end{aligned}
$$

where $M M_{i}$ is either 1 if unemployed or 1 if overeducated, depending on the mismatch examined. $M M_{i}^{*}$ is the latent variable underlying the probability of being unemployed or overeducated. Spec $_{i}$ is the respondent's level of field-specific skills, acad $_{i}$ is the respondent's level of academic skills (analytical thinking), $u f_{c f}$ is the unemployment rate in the occupational domain of the field of study, $u c_{c}$ is the overall (country-level) unemployment rate, and $X_{i}$ is our vector of controls.

Model 2 (equation 2) is our preferred model which tests our hypotheses. Here, we additionally include the interaction term of field-specific skills with the unemployment rate in the occupational domain of the field of study, specxuf $f^{\prime}$ as well as acadxuc $c$, the interaction term of academic skills with the overall unemployment rate. Negative coefficient $\beta_{21}$ in combination with negative coefficient $\beta_{25}$ would indicate that the protective effect of fieldspecific skills against unemployment (or overeducation) increases with the degree of excess supply of graduates in the occupational domain of the field of study. Negative coefficient $\beta_{22}$ in combination with negative coefficient $\beta_{26}$ would indicate that the protective effect

34 Note that the respondents in the survey completed their study before the Bologna process. Strictly speaking, we are talking about second-level higher education degrees at ISCED level $5 \mathrm{~A}$ allowing direct access to doctoral studies. For convenience however, we refer to this as a master's degree or equivalent. The reference category is a degree at ISCED level $5 \mathrm{~A}$ not offering direct access to doctoral studies (usually this is similar to a bachelor's degree).

35 Descriptive statistics for all variables used in the multivariate analysis can be found in table 5.6 in the Appendix. 
of academic skills against unemployment (or overeducation) increases with the degree of excess supply of graduates in the general labour market.

$$
\begin{aligned}
& M M_{i}^{*}=\beta_{20}+\beta_{21} \text { spec }_{i}+\beta_{22} \text { acad }_{i}+\beta_{23} u f_{c f}+\beta_{24} u c_{c}+\beta_{25} \text { specxuf }_{i}+\beta_{26} \text { acadxuc }_{i}+ \\
& \beta_{27} X_{i}+\varepsilon_{2 i}
\end{aligned}
$$

Model 3 (equation 3) includes two additional interaction terms between skills and unemployment rates; they test whether field-specific skills also interact with the overall unemployment rate, specxuci, and whether the effect of academic skills depends on fieldspecific labour market conditions, acadxufi. ${ }^{36}$

$$
\begin{aligned}
& M_{i}^{*}=\beta_{30}+\beta_{31} \text { spec }_{i}+\beta_{32} \text { acad }_{i}+\beta_{33} u f_{c f}+\beta_{34} u c_{c}+\beta_{35} \text { specxuf }_{i}+\beta_{36} \text { acadxuc }_{i}+ \\
& \beta_{37} \text { specxuc }_{i}+\beta_{38} \text { acadxuf }_{i}+\beta_{39} X_{i}+\varepsilon_{3 i}
\end{aligned}
$$

For the interpretation of the coefficients of the main effects of skills in model 2, it is important to keep in mind that the unemployment rate in the occupational domain of a particular field of study is expressed as the deviation from the overall unemployment rate, and that the overall unemployment rate is expressed as the deviation from the unemployment rate of the whole sample. This means that the averages of these two variables are each zero. Consequently, the main coefficients of skills in model 2 represent the effect of skills when the respective unemployment rate is average.

\section{Overeducation}

Table 5.2 presents the estimation results of the models, with the probability of being overeducated for one's job five years after graduation as the dependent variable. Model 1 shows that, on average, both types of skills are negatively related to the probability of being overeducated. ${ }^{37}$ For the average person in our sample, a one-standard-deviation increase in field-specific skills reduces the risk of being overeducated by 1 percentage point to $6.1 \%$. A one-standard-deviation increase in academic skills reduces the risk of being overeducated by 1.4 percentage points to $5.7 \%$.

Both unemployment rates are positively related to the probability of being overeducated for one's job. Moreover, as expected, both the coefficient of the interaction of academic skills ('analytical thinking') and the overall unemployment rate, as well as the coefficient of the interaction of field-specific skills ('mastery of own field') and the unemployment rate in the occupational domain of the field of study, are negative and significant at the $5 \%$ level in model 2. This indicates that when the degree of excess supply of graduates in the general labour market is higher, the protective effect of academic skills against the risk of overeducation is also higher. Similarly, the protective effect of field-specific skills against the

36 We also ran all six models including field of study dummies; this did not substantially change the results.

37 We also tested whether graduates working in jobs that match their level of education have higher skills because they receive more training than those who are overeducated (Van Smoorenburg and Van der Velden, 200o). We therefore reran our estimation once with hours of training in the past weeks and once with a dummy indicating participation in training in the past 12 months to account for the effect of training on skills. Including these variables did not substantially change the coefficients of our variables of interest, indicating that our skill variables are not picking up training effects. 
risk of overeducation is higher when the excess supply of graduates in the occupational domain of the field of study is higher.

Table 5.2

Probability of being overeducated five years after graduation

\begin{tabular}{llll}
\hline \hline & Model 1 & Model 2 & Model 3 \\
\hline Mastery of own field & $-0.076^{* * *}$ & $-0.077^{* * *}$ & $-0.077^{* *}$ \\
(standardized) & $(0.019)$ & $(0.019)$ & $(0.019)$ \\
Analytical thinking & $-0.101^{* * *}$ & $-0.099^{* * *}$ & $-0.100^{* * *}$ \\
(standardized) & $(0.019)$ & $(0.019)$ & $(0.019)$ \\
Overall unemployment rate & $0.101^{* * *}$ & $0.098^{* * *}$ & $0.098^{* * *}$ \\
& $(0.008)$ & $(0.008)$ & $(0.008)$ \\
Unemployment rate in occ. dom. of field of study & $0.073^{* * *}$ & $0.070^{* * *}$ & $0.070^{* * *}$ \\
& $(0.014)$ & $(0.014)$ & $(0.015)$ \\
Overall unemployment rate X Analytical thinking & & $-0.019^{* *}$ & $-0.021^{* *}$ \\
& & $(0.008)$ & $(0.009)$ \\
Unemployment rate in occ. dom. of field of study X & & $-0.030^{* *}$ & $-0.030^{* *}$ \\
Mastery of own field & & $(0.014)$ & $(0.015)$ \\
Unemployment rate in occ. dom. of field of study X & & & -0.006 \\
Analytical thinking & & & $(0.015)$ \\
Overall unemployment rate X Mastery of own field & & & 0.006 \\
& & & $(0.009)$ \\
Controls included & & 0.069 & \\
\hline \hline Pseudo R-squared & & 11129 & yes
\end{tabular}

Note: Coefficients reported are estimates from a pooled probit, robust standard errors in parentheses (significance levels ${ }^{* *} 0.01,{ }^{* *} 0.05, * 0.1$ ). Controls included are gender, age, age squared, father having higher education, respondent having a second-level degree, study-related work experience during higher education, and non-study-related work experience during higher education. Data: REFLEX/HEGESCO.

Table 5.3 (for field-specific skills) and Table 5.4 (for academic skills) show the predicted probabilities of being overeducated for different skill levels and unemployment rates, holding all other variables fixed at their means. The difference of the probability of being overeducated between graduates with high and low levels of field-specific skills is smaller when excess supply of graduates in the occupational domain of the field of study is lower. Similarly, the difference of the probability of being overeducated between graduates with high and low levels of academic skills is smaller when overall excess supply of graduates is lower. Our estimation results therefore support our hypotheses 2 and 3.

Model 3 shows that the interaction term of field-specific skills and the overall unemployment rate, as well as the interaction term of academic skills and unemployment in the occupational domain of the field of study, are not statistically significant. This suggests that fluctuations of the unemployment rate in one labour market segment does not affect job competition in the other labour market segment. In other words, the level of 
protection against the risk of overeducation afforded by field-specific skills does not depend on overall excess supply of graduates. Moreover, the level of protection against the risk of overeducation afforded by academic skills does not vary with the degree of excess supply of graduates in the occupational domain of the field of study.

Table 5.3

Probability of being overeducated for different levels of field-specific skills and unemployment in occupational domain of field of study (other variables fixed at mean)

\begin{tabular}{lrrr}
\hline \hline & $\begin{array}{c}\text { Low field-specific skills (1 } \\
\text { std. dev. below average) }\end{array}$ & $\begin{array}{c}\text { High field-specific skills (1 } \\
\text { std. dev. above average) }\end{array}$ & Difference \\
\hline $\begin{array}{l}\text { Low unemployment in occ. domain of a field } \\
\text { of study (2\% below average) }\end{array}$ & 6.5 & 4.8 & -1.7 \\
$\begin{array}{l}\text { Average unemployment in occ. domain of a } \\
\text { field of study }\end{array}$ & 8.5 & 6.4 & -2.1 \\
$\begin{array}{l}\text { High unemployment in occ. domain of a field } \\
\text { of study (2\% above average) }\end{array}$ & 11.1 & 8.4 & -2.7 \\
\hline \hline
\end{tabular}

This table shows the predicted probability of being overeducated five years after graduation evaluated at different levels of field-specific skills and unemployment rates in the occupational domain of a field of study. Own calculations.

Table 5.4

Probability of being overeducated for various levels of academic skills and overall unemployment (other variables fixed at mean)

\begin{tabular}{lrrr}
\hline \hline & $\begin{array}{r}\text { Low academic skills (1 } \\
\text { std. dev. below average) }\end{array}$ & $\begin{array}{r}\text { High academic skills (1 } \\
\text { std. dev. above average) }\end{array}$ & Difference \\
\hline Low overall unemployment (2\% below average) & 6.3 & 4.2 & -2.1 \\
Average overall unemployment & 9.2 & 6.3 & -2.9 \\
High overall unemployment (2\% above average) & 13.1 & 9.3 & -3.8 \\
\hline \hline
\end{tabular}

This table shows the predicted probability of being overeducated five years after graduation evaluated at different levels of academic skills and overall unemployment rates. Own calculations.

\section{Unemployment}

Table 5.5 presents the estimation results for the probability of being unemployed five years after graduation. The estimation results in model 1 show that graduates who have high fieldspecific skills have a lower probability of being unemployed than those who have a lower level of field-specific skills. For the average person in our sample, a one-standard-deviation increase in field-specific skills lowers the chance of being unemployed by 0.8 percentage points to $2.2 \% .{ }^{38}$ This finding confirms hypothesis 4 with regard to the protective effect of field-specific skills against unemployment. The coefficients of the interaction terms in neither model 2 nor model 3 are statistically significant. We thus find no support for hypothesis 5 that the protective effect of field-specific skills against the risk of unemployment varies with excess supply of graduates in the occupational domain of the field of study.

Further, the effect of academic skills on the probability of being unemployment five years after graduation is insignificant, which supports hypothesis 6 . Moreover, we do not find that the effect of academic skills is related to any of the two unemployment rates. We

$\overline{38}$ For a table with marginal effects see table 5.8 in the Appendix. 
thus find no evidence in support of hypothesis 7 . These results suggest that firms are always better off hiring graduates instead of workers with intermediate levels of education for jobs which require academic skills.

Table 5.5

Probability of being unemployed five years after graduation

\begin{tabular}{llll}
\hline \hline & Model 1 & Model 2 & Model 3 \\
\hline Mastery of own field & $-0.124^{* * *}$ & $-0.128^{* * *}$ & $-0.128^{* * *}$ \\
(standardized) & $(0.025)$ & $(0.025)$ & $(0.025)$ \\
Analytical thinking & 0.029 & 0.026 & 0.025 \\
(standardized) & $(0.024)$ & $(0.024)$ & $(0.025)$ \\
Overall unemployment rate & $0.088^{* * *}$ & $0.089^{* * *}$ & $0.089^{* * *}$ \\
& $(0.011)$ & $(0.011)$ & $(0.011)$ \\
Unemployment rate in occ. dom. of field of study & $0.167^{* * *}$ & $0.168^{* * *}$ & $0.169^{* * *}$ \\
& $(0.019)$ & $(0.019)$ & $(0.019)$ \\
Overall unemployment rate X Analytical thinking & & 0.014 & 0.011 \\
& & $(0.010)$ & $(0.012)$ \\
Unemployment rate in occ. dom. of field of study X & & 0.016 & 0.012 \\
Mastery of own field & & $(0.018)$ & $(0.019)$ \\
Unemployment rate in occ. dom. of field of study X & & & 0.008 \\
Analytical thinking & & & $(0.020)$ \\
Overall unemployment rate X Mastery of own field & & & 0.005 \\
& & & $(0.011)$ \\
Controls included & & & \\
Pseudo R-squared & & & yes \\
\hline Note: Cos & 11552 & 11552 & 0.068 \\
& & & 11552 \\
\hline
\end{tabular}

Note: Coefficients reported are estimates from a pooled probit, robust standard errors in parentheses (significance levels ${ }^{* * *} 0.01,{ }^{* *} 0.05, * 0.1$ ). Controls included are gender, age, age squared, father having higher education, respondent having a second-level degree, study-related work experience during higher education, and non-study-related work experience during higher education. Data: REFLEX/HEGESCO.

\subsection{Conclusion}

This paper focuses on two dimensions of the crowding out hypothesis by investigating the relationship between graduates' skills and the risk of being employed in a job for which no tertiary degree is required, or being unemployed.

We find that competition for graduate jobs is related to skills, and this relationship is more intensive when the degree of excess supply of graduates is higher.

We establish a conceptual framework in which two labour market domains are distinguished: a labour market domain where field-specific skills determine the allocation of graduates to jobs (the occupational domain of a particular field of study), and a labour market domain where academic skills determine the allocation of graduates to jobs (the 
general labour market). In line with the crowding out hypothesis, we find that the protective effect of field-specific skills against the risk of overeducation depends on the degree of excess supply of graduates in the occupational domain of the corresponding field of study, and that the protective effect of academic skills against overeducation depends on the degree of excess supply of graduates in the general labour market.

In line with a conceptual framework which deviates from strict interpretation of the crowding hypothesis, and which incorporates the idea that the substitutability of the fieldspecific skills of graduates and the field-specific skills of workers with intermediate levels of education is subject to substantial limitations, we find that graduates with low field-specific skills have a higher probability of being unemployed than graduates with high field-specific skills. We do not find this effect for academic skills. This supports the idea that field-specific skills of graduates and lower-educated workers really differ in nature, whereas the academic skills of graduates and lower-educated workers can be characterized as 'more of the same'.

The results of this study are encouraging and give new insight into the workings of the labour market for graduates. We realize, however, that using cross-sectional data to test our conceptual framework can be only a first step. Further research exploiting cyclical variation within fields and within countries over time is needed to better establish causality. 


\section{Appendix}

Table 5.6

Descriptives of variables used in multivariate analysis (overeducation model)

\begin{tabular}{|c|c|c|c|c|c|c|c|c|}
\hline & \multirow[t]{3}{*}{ obs } & \multirow{3}{*}{$\begin{array}{r}\% \\
\text { overeducated } \\
\end{array}$} & \multirow{2}{*}{\multicolumn{2}{|c|}{$\begin{array}{c}\text { Mastery of own } \\
\text { field or discipline* }\end{array}$}} & \multirow{2}{*}{\multicolumn{2}{|c|}{ Analytical thinking* }} & \multirow{2}{*}{\multicolumn{2}{|c|}{ age }} \\
\hline & & & & & & & & \\
\hline & & & mean & std.dev & mean & std.dev & mean & std.dev \\
\hline Austria & 520 & 10.9 & 5.8 & 0.9 & 5.8 & 1.2 & 31.6 & 0.09 \\
\hline Belgium & 457 & 3.0 & 5.2 & 0.9 & 5.4 & 1.1 & 28.2 & 0.06 \\
\hline Czech Republic & 943 & 2.9 & 5.6 & 1 & 5.5 & 1.1 & 28.6 & 0.05 \\
\hline Estonia & 392 & 1.8 & 5 & 0.9 & 5.3 & 1.1 & 30 & 0.1 \\
\hline Finland & 794 & 6.7 & 5 & 1 & 4.9 & 1.2 & 30.5 & 0.07 \\
\hline France & 552 & 5.2 & 5.1 & 1 & 5.2 & 1 & 28.2 & 0.07 \\
\hline Germany & 687 & 5.9 & 5.8 & 0.9 & 5.6 & 1.2 & 31.7 & 0.07 \\
\hline Hungary & 648 & 16.1 & 5 & 1.1 & 5 & 1.3 & 29 & 0.07 \\
\hline Italy & 843 & 14.7 & 5.2 & 1.1 & 5.5 & 1.2 & 31.5 & 0.06 \\
\hline Lithuania & 382 & 5.2 & 5.1 & 1.1 & 5.2 & 1.1 & 28.7 & 0.1 \\
\hline Netherlands & 842 & 6.4 & 5.3 & 0.9 & 5.4 & 1.1 & 29.1 & 0.06 \\
\hline Norway & 804 & 4.4 & 5.3 & 0.9 & 4.7 & 1.4 & 31.4 & 0.07 \\
\hline Poland & 697 & 4.0 & 4.9 & 1.2 & 5.2 & 1.3 & 29.6 & 0.05 \\
\hline Spain & 622 & 18.5 & 5.2 & 1.1 & 4.9 & 1.3 & 29.8 & 0.09 \\
\hline Slovenia & 995 & 10.7 & 5.2 & 1.2 & 5.2 & 1.2 & 30.8 & 0.06 \\
\hline Switzerland & 778 & 10.3 & 5.4 & 0.9 & 5.6 & 1.1 & 31 & 0.07 \\
\hline United Kingdom & 568 & 17.2 & 5.1 & 1.1 & 5.3 & 1.2 & 27.6 & 0.07 \\
\hline Total & 11524 & 8.6 & 5.3 & 1 & 5.3 & 1.2 & 30 & 0.02 \\
\hline
\end{tabular}

Note: * $z$-scores used in the regressions

Table 5.6

Descriptives of variables used in multivariate analysis (overeducation model), continued

\begin{tabular}{lrrrrr}
\hline \hline & \% female & $\begin{array}{r}\text { \% with higher } \\
\text { educated father }\end{array}$ & $\begin{array}{r}\text { \% with study } \\
\text { relevant work } \\
\text { experience during } \\
\text { higher education }\end{array}$ & $\begin{array}{r}\text { \% with non-study } \\
\text { relevant work } \\
\text { experience during } \\
\text { higher education }\end{array}$ & $\begin{array}{r}\text { \% second level } \\
\text { degree }\end{array}$ \\
\hline Austria & 49.1 & 21.8 & 71.1 & 63.3 & 89.5 \\
Belgium & 51.7 & 46.6 & 19.8 & 58 & 58.6 \\
Czech Republic & 49.3 & 34 & 45.9 & 66.6 & 88 \\
Estonia & 67.6 & 58.1 & 55 & 38.2 & 11.1 \\
Finland & 56.4 & 21.1 & 67.2 & 52.3 & 47.3 \\
France & 69.8 & 39 & 57.9 & 55.9 & 36.8 \\
Germany & 46.7 & 59.6 & 58.6 & 46.9 & 59.5 \\
Hungary & 62 & 24.8 & 29.3 & 37.7 & 35.5 \\
Italy & 53.2 & 16.6 & 17.9 & 37.4 & 92.2 \\
Lithuania & 63.6 & 42.1 & 37.3 & 43.1 & 34.3 \\
Netherlands & 60.6 & 38.1 & 37.4 & 71.9 & 27.5 \\
Norway & 57 & 46.9 & 55.5 & 54.4 & 37.5 \\
Poland & 56.8 & 27.8 & 24.5 & 36.7 & 67.6 \\
Spain & 64.5 & 21 & 19.6 & 32 & 58.8 \\
Slovenia & 69 & 24.1 & 58.2 & 67 & 4.2 \\
Switzerland & 37 & 46.9 & 50.2 & 45.1 & 61 \\
United Kingdom & 56.6 & 18.7 & 43.2 & 51.1 & 49.3 \\
\hline Total & 56.7 & 34.1 & 43.2 & & 5.9 \\
\hline \hline
\end{tabular}


Table 5.7

Marginal effects of preferred models of overeducation and unemployment

\begin{tabular}{|c|c|}
\hline & Marginal effect \\
\hline \multicolumn{2}{|l|}{ Unemployment } \\
\hline Mastery of own field & $-0.008^{* * *}$ \\
\hline (standardized) & $(0.002)$ \\
\hline \multirow[t]{2}{*}{ Analytical thinking } & 0.002 \\
\hline & $(0.002)$ \\
\hline \multicolumn{2}{|l|}{ Overeducation } \\
\hline Mastery of own field & $-0.010^{* * *}$ \\
\hline (standardized) & $(0.003)$ \\
\hline Analytical thinking & $-0.014^{* * *}$ \\
\hline (standardized) & $(0.002)$ \\
\hline \multirow[t]{2}{*}{ Overall unemployment rate X Analytical thinking } & $-0.005^{* * *}$ \\
\hline & $(0.001)$ \\
\hline \multirow[t]{2}{*}{ Field-specific unemployment rate X Mastery of own field } & $-0.005^{* * *}$ \\
\hline & $(0.002)$ \\
\hline \multicolumn{2}{|c|}{$\begin{array}{l}\text { Note: All marginal effects are calculated on the basis of the pooled probit procedure used for producing tables } \\
2 \text { and 3. The marginal effects of the interaction terms were calculated using the Ai and Norton (2003) inteff } \\
\text { stata programme. Controls included are a dummy for being female, age, age squared, a dummy equal to } \\
\text { one if father has higher education, a dummy equal to one if respondent has a second level degree, a dummy } \\
\text { equal to one if respondent had study related work experience during higher education, and a dummy equal } \\
\text { to one if respondent had non-study related work experience during higher education. }\end{array}$} \\
\hline
\end{tabular}


CONCLUSIONS 


\subsection{Summary}

This thesis examined the relationship between skills and the employability of university graduates. In particular, this thesis attempted to answer the following questions:

- What are the trends that shape the labour market of graduates and how do they affect employers' skill demand?

- Which skills are most important in the graduate recruitment process?

- How is students' personality related to their field of study choice?

- Which skills protect graduates against a slack labour market?

In this chapter, I summarize the answers to these four questions given in the respective chapters, and I will draw broader conclusions about the implications of the findings for individuals and universities.

\subsubsection{What are the trends that shape the labour market of graduates and how do they affect employers' skill demand?}

The thesis set out with a discussion of the labour market of today's graduates (Chapter 2). We brought forward the idea that various societal, economic and organizational trends are changing the work environment of graduates. A key concern which we tried to convey in this chapter is the changing demand for skills developed in higher education in terms of both character and level.

We identified six trends which are at the core of the changing role of graduates in economic life. These trends are the knowledge society, increasing uncertainty, the ICT revolution, high performance workplaces, globalization, and the change of the economic structure. By changing the nature and range of tasks graduates are expected to fulfil in today's economy, these trends generate new and intensify existing skill demands, which we summarized as professional expertise, flexibility, innovation and knowledge management, mobilization of human resources, international orientation, and entrepreneurship.

In post-industrial societies characterized by the prominence of the service sector as opposed to the manufacturing sector, theoretical knowledge becomes central to innovation and policy formulation (Bell, 1999). The emergence of the knowledge society increases the demand for knowledge workers (Reich, 1992) whose tasks are complex, non-repetitive and non-routine (Autor, Levy and Murnane, 2003). They can therefore not easily be replaced by rule-based information and communication technology (ICT). Chapter 2 argues that in order to deal with the demands of the knowledge society, graduates need to be equipped with the skills necessary to fulfil tasks which are at the heart of knowledge work. This entails: 1) a specific body of knowledge (the knowledge needed to solve occupation-specific problems, 2) the ability to apply expert thinking (a collection of specific solution methods which vary with the problem at hand, Levy, 2010), and 3) broad academic skills (e.g. analytical thinking, 
reflectiveness, and the ability to see the limitations of one's own discipline). We defined the combination of these three elements as professional expertise. ${ }^{39}$

In the past 40 years, we have witnessed the emergence of a labour utilization system which increasingly combines a core labour force with externally flexible workers. Although university graduates have a higher chance of belonging to the valued core labour force than medium or low educated workers (DiPrete et al., 2006), an increasing number of graduates may have to deal with labour market related changes and uncertainty in the $21^{\text {st }}$ century. Being flexible is one way of absorbing some of this uncertainty. In Chapter 2 we suggested that the following skills contribute to flexibility: 1) the ability to deal with changes and uncertainty, 2) the ability to learn new things, and 3) employability skills (e.g. the willingness to invest in further education and training and the ability to plan and take responsibility for one's own career).

The ICT revolution is probably one of the major drivers of the other trends identified in Chapter 2, such as globalization, the emergence of the knowledge society or the introduction of high performance workplaces (Bresnahan, Brynjolfsson, and Hitt, 2002). There is widespread consensus that the introduction of ICT into workplaces is skill biased - that it favours higher skilled workers. For repetitive, routine tasks - often performed by low and medium skilled workers - ICT can be seen as substituting labour as ICT is faster and cheaper than people in performing these tasks. With regard to knowledge work and professional expertise, however, ICT is mostly instrumental and complements labour (Levy, 2010). While knowledge work is not replaced by it, ICT nevertheless often changes the tasks associated with knowledge work and therefore impacts the skill demand of the highly skilled. Chapter 2 focused on ICT and its revolutionizing impact on the way data and knowledge is generated and diffused. It suggests that in order to manage, integrate and evaluate the vast amounts of data available today in a way that supports and facilitates innovation, graduates innovative/ creative skills, ICT skills and implementation skills.

It is widely believed that traditional bureaucratic management stifles innovation and is ill-equipped for globalization - the strengthening and acceleration of world-wide interconnectedness. High performance work places are designed to make optimal use of the potential of knowledge workers by fostering team work, reducing hierarchical levels, and the delegation of responsibility to individuals and teams (Betcherman, 1997). As a result, high performance work places sets high expectations on the mobilization of human resources. Chapter 2 demonstrates that if knowledge workers are required to optimally mobilize their own and others' human capital, they need to have at least the following skills: 1 ) interpersonal skills (the ability to work in a team and communicate and cooperate effectively with diverse colleagues and clients), 2) self-management skills (the ability to work within budget and time constraints, leadership), and 3) strategic-organizational skills (the ability to act strategically towards the achievement of organizational goals).

Globalization has changed the world of work of graduates in many ways. In Chapter 2 we highlighted the extent to which globalization increases the demand for graduates' international orientation. Globalization is characterized by fast flows of ideas, financial capital,

39 In Chapter 3 we use a slightly different definition of professional expertise, one which focuses on occupationspecific knowledge and skills, and which excludes broad academic skills. This was done in order to test the relative importance of these two components of professional expertise. 
goods, services and people across national borders. As a result, a substantial proportion of graduates' regular customer contact, brainstorming and consultation with colleagues, and decision-making nowadays takes place across national borders or involves groups of people with diverse national backgrounds. The international orientation of today's work life requires graduates to have: 1) a good proficiency of foreign languages and 2) intercultural skills (the ability to work with people from different cultural backgrounds and the ability to adapt to new cultural contexts).

Over the last decades, the proportion of workers employed in small and medium enterprises has been growing. In combination with the flattening of hierarchies within firms and higher market uncertainty, this has increased demand for graduates who are comfortable with assuming responsibility and with contributing to the success of the organization through entrepreneurship. For high-wage countries whose key comparative advantage lies in the generation of knowledge and innovation, entrepreneurship, at the firm but also at the institutional level, is one of the main determinants of global competitiveness. Chapter 2 proposes the following components of entrepreneurship: 1) the ability to identify commercial risks and opportunities, 2) a good sense of cost awareness and 3) the ability to turn an idea into a successful product.

\subsubsection{Which skills are most important in the graduate recruitment process?}

Chapter 2 laid out how economic and organizational trends affect the demand for various types of skills. In Chapter 3 we tested the relative importance of a selection of these types of skills for graduates employability by eliciting employers' preferences in two discrete choice experiments. We were able to show that employers attach most value to $C V$ attributes which signal a high stock of occupation-specific human capital indicating low training costs and short adjustment periods; attributes such as relevant work experience and a good match between the field of study and the job tasks. In line with the preferences for CV attributes, employers' actual hiring decision is mostly influenced by graduates' level of professional expertise and interpersonal skills. The latter finding emphasizes the role knowledge workers play in teams and networks, and indicates that occupation-specific knowledge and skills can only fully unfold their productivity in combination with interpersonal skills. Other types of skills, such as commercial/entrepreneurial skills or innovative/creative skills are also in demand but are found to be less important in the recruitment of recent graduates. They can therefore not easily compensate for a lack of more occupation-specific human capital and interpersonal skills. This finding indicates that while nearly all graduates need to possess professional expertise and interpersonal skills, other types of skills lend themselves to specialization and can be acquired by individuals according to their preferences and abilities.

\subsubsection{How is students' personality related to their field of study choice?}

Chapter 4 related measures of personality traits to young adults' field of study choice. Earlier studies have shown that expected life-time earnings as well as preferences for subject matters are important determinants of field of study choice (Berger, 1988; Flyer, 1997; Arcidiacono, 2004; Arcidiacono, Hotz and Kang, 2012; Wisfall and Zafar, 2013). As individuals with particular 
personality traits a) enjoy some majors and related occupations more than others and b) are more productive in some majors and related occupations than others, I hypothesized that personality affects field of study choice. Supporting this hypothesis, Chapter 4 showed that the Big Five personality traits measured at age 14 have a significant influence on individuals' field of study choice some 4 years later. For both women and men, higher emotional stability decreases the probability of choosing Humanities in university. Moreover, for both women and men higher levels of extraversion are associated with a higher probability of choosing Law and a lower probability of choosing Science, Technology, Engineering or Mathematics (STEM) in university. In addition, higher levels of conscientiousness increase both women's and men's probability of choosing Medical Studies. There are, however, substantial differences in how women and men sort into fields of study based on their personality. This is most apparent for fields of studies such as Business, Economics, STEM and Medical Studies for which sorting of women and men seems to follow different rules. As elaborated by Turner and Bowen (1999), the reasons for this may be gender differences in the weights allocated to post-college opportunities or gender differences in labour market (dis-)incentives. For instance, the non-existent effect of disagreeableness on choosing Business or Economics in university for women is in line with Judge, Livingston and Hurst's (2012) finding that, due to conventional gender roles, the wage returns to disagreeableness are higher for men than they are for women.

In addition to investigating the relationship between individuals' personality and their field of study choice, Chapter 4 shed light on the relative importance of personality and cognitive skills in this process. While cognitive skills are the primary driver of the probability of entering university, the effects of personality traits and cognitive skills are similar (i.e. the differences not statistically significant) with regard to field of study choice. In the case of sorting into STEM fields for men, being introverted is even more important than having high information processing ability.

\subsubsection{Which skills protect graduates against a slack labour market?}

Chapter 5 examined how two aspects of professional expertise, field-specific and general academic skills relate to graduates' employability. The crowding out hypothesis predicts that, in case of excess labour supply, graduates with the lowest skill levels 'bump down' and get allocated to jobs for which no higher education degree is required. In line with this hypothesis, we found that the level of protection afforded by field-specific skills against the risk of overeducation is higher when the degree of excess labour supply in the occupational domain of the graduate's field of study is higher. Conversely, academic skills afford more protection against the risk of overeducation when excess labour supply in the overall labour market is higher. In accordance with the idea that the substitutability of the field-specific skills of graduates and the field-specific skills of workers with intermediate levels of education is subject to substantial limitations, we found that graduates with low field-specific skills have a higher probability of being unemployed than graduates with high field-specific skills. However, we did not find this effect for academic skills, supporting the idea that fieldspecific skills of graduates and lower-educated workers really differ in nature, whereas the 
academic skills of graduates compared to those of lower-educated workers can be characterized as 'more of the same'.

\subsection{Contribution and implications}

In this section, I will highlight the main findings of this thesis. In addition, I will reflect on how strongly graduates' employability depends on decisions made by universities and students relating to the form and content of study programmes.

Low skills have dire effects on graduates' employability

One of the main findings of this thesis is its provision of new evidence for a logistic or concave relationship between skills and productivity. Graduates with low skills are very costly for employers and the productivity loss associated with hiring a graduate with low skills cannot be compensated by other team members with high skills (Chapter 3). Moreover, graduates' employability is strongly linked to their level of skills. These findings point to the existence of a minimum skill level which graduates need to possess with respect to each type of skill in order to be employable. Consequently, students have to consider their entire skill profile when making educational decisions. Students need to acquire at least the minimum level of each type of skill. They then can choose their specialization keeping in mind that some types of skill are more important for their employability than others.

The skill level employers consider to be the minimum in order for graduates to be employable varies with labour market conditions (Chapter 5). While graduates with higher skill levels always have a higher probability of finding a graduate job, this positive relationship intensifies when excess labour supply increases.

Professional expertise and interpersonal skills are most important for graduates' employability A finding which runs like a common thread through this thesis is the salience of professional expertise for graduates' employability. The importance of professional expertise for adequately performing graduate job tasks stems from the emergence of the knowledge society and the primacy of theoretical knowledge in today's economy (Chapter 2). In contrast to the application of more pragmatic and contextual knowledge, knowledge work entails unstructured decision making. Unstructured decisions concern important, novel, non-routine problems for which no established procedure exists for how to solve them. Professional expertise - the combination of a specific body of knowledge, the ability to apply expert thinking and broad academic skills - is what enables graduates to adequately execute their jobs tasks which are complex, non-repetitive and non-routine. The strong position of graduates relative to other lower educated groups in the labour market can partly be traced back to the fact that they cannot be replaced by rule-based information and communication technology (ICT).

The results presented in Chapter 3 show, however, that professional expertise alone is not sufficient for graduates to be productive. Interpersonal skills are as important for graduates' employability as professional expertise and this strongly underlines the interdependence of knowledge workers in today's workplaces. Graduate work is characterized by a high degree 
of information-sharing and communication, not only in management level jobs but also in non-management level jobs. In teams with wide-ranging responsibilities, graduates have to make shared decisions, and this demands graduates to be able to integrate well into teams, communicate effectively, and to seek advice, information and support when appropriate. Team members who do not have these skills present a serious threat to team productivity, which is reflected in the findings of Chapter 3.

\section{Entrepreneurial, strategic and innovative skills mainly determine graduates' later career advancement}

Entrepreneurial skills, strategic skills and creative skills affect recent graduates' employability less than professional expertise and interpersonal skills do. From the employer's perspective, these types of skills are not required for job tasks normally associated with entry-level positions. Rather, employers argue that these general types of skills are important for graduates' career development and their chances to get promoted to senior level positions. It may also be argued that these types of skills presuppose a deeper understanding about workplace and product related issues than university students can have. Consequently, these types of skills are more efficiently developed after graduates have gained a few years of work experience. This does not mean, however, that types of skills such as entrepreneurial skills, strategic skills or creative skills are irrelevant for graduates' initial employability. As pointed out earlier, belonging to the group with the lowest level of these skills severely works against graduates applying for junior positions (Chapter 3 ). Despite the dominance of professional expertise and interpersonal skills in the recruitment process, employers prefer graduates who have at least a basic notion of entrepreneurship, strategy, creativity and innovation. Furthermore, it is with regard to these latter skills that students can specialize according to their preferences and abilities, providing employers with a broad mix of skill profiles to choose from.

\section{Short-term equals long-term employability}

The discussion on short-term versus long-term employability is related to finding the right balance between graduates' specific knowledge and broad academic skills. The curricula of study programmes can of course allocate different weights to these components. The potential trade-off between short and long-term employability is based on the assumption that while specialized knowledge gives graduates an advantage in the transition from initial education to the labour market by being instantly deployable, broad academic skills enable workers to switch jobs or careers if their specialized knowledge becomes obsolete.

This study does not provide an unambiguous answer to the question whether occupation-specific knowledge or academic skills provide a better basis for long-term employability. On the one hand, the results of chapter 3 show that occupation-specific knowledge and skills are a stronger determinant of a good start of graduates' labour market career than broad academic skills. Quickly finding a job corresponding to the field of study may equip graduates with the occupation-specific experience and the training necessary to anticipate future market changes and to deal with them actively. Moreover, to the extent to which employers select graduates who are able to contribute to the organizations' long term success, the results of chapter 3 may reflect employers' belief that a good predictor of short- 
term employability (e.g. high levels of occupation-specific knowledge and skills) is a good predictor of long-term employability. On the other hand, chapter 5 finds that academic skills are more important for graduates' chances of finding a graduate job when excess graduate supply is higher. While this finding may stem from the larger pool of graduates employers' can choose from when graduate unemployment is higher, it may also point to employers' need to recruit graduates able to find creative ways of securing a firms' survival in times of economic distress. There is therefore suggestive evidence that both types of skills are related to graduates long-term employability.

\section{Employers' preferences are diverse}

The employer for graduate employment does not exist. Skill demand in jobs differs due to the characteristics of the job. Moreover, skill demand differs because employers' exposure to the trends we identified in Chapter 2 varies. However, these differences in job characteristics and exposure to trends are not captured by firm characteristics commonly used to describe employers. For example, while employers attach most value to professional expertise on average, some employers have a strong preference for graduates with broad academic skills and find graduates' level of professional expertise less important. These employers may prefer employees who have high analytical skills and who can quickly acquire the firmspecific professional expertise they need through internal training courses. In this context, one might expect the preference for broad academic skills to be related to firm size, as larger firms may have more sophisticated internal training programmes and more resources to invest in new employees' initial work-readiness. However, employers' preferences for graduates' broad academic skills - and skill profiles in general - do not cluster according to firm size or any other of the background variables we collected, such as occupational field, economic sector, or the kind market the firm is operating on.

This diversity of employers' preferences has important implications for universities and students. I will elaborate on this in more detail below.

\section{Abilities and labour market prospects are not the only factors influencing flows into technical fields of study}

With regard to policies aimed at increasing the supply of graduates in fields of study such as Engineering that are considered crucial for economic development, the findings of this thesis suggest that it is important to take individuals' preferences for subject matters and work environments into account. For example, while cognitive skills such as math ability (for women) and information processing ability (for men) matter, sorting into Science, Technology, Engineering or Mathematics (STEM fields) is also substantially influenced by individuals' preferences for social interaction. Individuals who have the right math skills for technical studies but are more extrovert have the tendency to choose fields of study such as Law, where they expect higher rewards for their interpersonal skills and more opportunity to find the kind of social interaction they enjoy. The current trend towards increasing customer and client interaction in all occupations, also technical ones, may in the medium or long term attract more extroverted individuals to STEM fields of study. Until then, however, moderate monetary incentives, such as tuition-fee waivers in the Dutch context, will not substantially affect sorting into these fields of study. 


\section{Implications for universities}

The findings of this thesis have important implications for universities. The significance of professional expertise and interpersonal skills for graduates' employability suggests that equipping students with these two types of skills should be considered a core task of initial higher education. Given the limited time available in higher education, this implies a tradeoff with regard to the development of other types of skills, such as entrepreneurial skills. While universities should make sure that graduates possess a certain minimum level of, for example, entrepreneurial and creative skills, further investment in these types of skills may be more efficient and effective after graduates have gathered a few years of work experience. This notwithstanding, universities should foster ways of teaching which enable students to develop several types of skills at the same time, such as problem-based learning, so that the trade-off between professional expertise and interpersonal skills on the one side, and entrepreneurial and creative skills on the other side, does not occur.

Another important finding of this thesis is that employers' preferences are very diverse. This has important implications for the skill profile and the breadth of professional expertise universities and students should strive for. Both graduates and universities have to know their market well in order to make good skill formation choices. As the employer does not exist, there is no standard solution to the trade-offs implied in acquiring a particular skill profile. For universities, it is important to know which student flows they manage. On the one hand, this refers to keeping track of the kind of employers for which they educate graduates and the particular skill profiles these employers demand. On the other hand, universities face the challenge to align the skill profiles they are aiming to produce to students' preferences and abilities. With regard study programmes in STEM fields, for example, this means equipping individuals who are on average more introvert with the level of interpersonal skills demanded by today's graduate labour market.

Finally, while the policy debate on higher education often focuses on excellence and its role in innovation and economic development, the costs incurred by firms due to underperforming employees are substantial. The detrimental effect of low skill levels on graduates' productivity suggests that fostering graduates' excellence must not be the only focus of higher education, and that guaranteeing that graduates possess the required minimum level of skills may even be more important. Moreover, for graduates' transition from education to work to be smooth, universities have to provide graduates with qualifications which send a strong signal of employability to employers.

\section{Implications for individual students}

For individual students, the challenge is to choose their studies carefully. In this respect, prospective students, students and graduates have to be aware of the importance of a specific body of knowledge, the ability to apply this knowledge to novel problems, and the ability to work effectively in a team for their chances of getting a job within the envisaged field and at the adequate level.

Variation in the breadth of graduates' professional expertise has important implications for the job options available to them when entering the labour market. While a large specific body of knowledge increases graduates' chances to find a job within their field of study, high 
levels of academic skills increase graduates' employability in the labour market segment in which productivity depends on general skills (Chapter 5 ).

The implications of employers' diversity for students in higher education are straight forward: employers demand a variety of graduate profiles which offers individuals some freedom with regard to educational and work-related choices. However, some graduate profiles are more employable than others and some trade-offs are worth making and some are not (Chapter 3). Employers base their hiring decisions on low adjustment and training costs. As a result, students should invest in the types of skills which give them a comparative advantage in the kind of jobs they envisage to work in, given their preferences and abilities.

Universities are intermediaries between students' preferences and abilities and employers' demands

In sum, my conclusions must not be misunderstood as a plea to negate any other purpose of university education but graduates' employability. This thesis is also not suggesting that young adults should be forced to acquire skill profiles which disregard their preferences and abilities. On the contrary. The literature on educational and occupational sorting, of which Chapter 4 forms part, emphasises the importance of a good fit between job tasks and individuals' preferences and abilities for productivity. Universities may be seen as intermediaries between students' preferences and abilities and employers' demands. Universities have a strong advantage over individuals with regard to access to information on employers' skill demand. From this advantage accrues an obligation to help students make good decisions about investments in their skill profile, even if this means limiting their choices. The main rationale behind this conclusion is straight forward: given the detrimental effects of unemployment and the inability of finding a graduate job on earnings, job satisfaction and other related life outcomes, universities serve young adults best when equipping them with the skills they need to have a labour market career which corresponds to their expectations. The challenge is to develop curricula and teaching methods which best integrate students preferences and abilities into a skill formation process at the end of which will be employable graduates. 


\section{VALORISATION ADDENDUM}

The question what makes university graduates employable is related to two phenomena which are high on the current international and European political agenda: graduate unemployment and educational mismatch, i.e. being employed in a job which does not formally require a university degree.

Certainly, the overall labour market situation of university graduates is less vulnerable than that of individuals with lower levels of education. This does not mean, however, that the employability of university graduates does not merit examination: if university graduates are unable to find a graduate job they will accept jobs for which they are formally overqualified, indirectly affecting the labour market chances of individuals with lower levels of education, through processes of 'crowding out' and 'bumping down'.

As pointed out in the introduction to this thesis, unemployment and educational mismatch are common problems among recent graduates: about one out of five European graduates is either unemployed or educationally mismatched. Both of these outcomes not only negatively affect the financial situation of graduates, but also other aspects of wellbeing, such as job satisfaction. This thesis finds that graduates' ability to avoid unemployment and educational mismatch is related to the skills they possess. There is strong evidence that graduates who are unemployed or employed in jobs which do not require a university degree simply do not possess the skill level or the type of skill required by graduate jobs. Employable graduates are thus graduates who possess the level, but also the types of skills employers need for their productive processes.

Graduate unemployment and educational mismatch do not only have negative consequences for individuals. They are also of broader societal relevance as a substantial portion of the costs of higher education is provided by the public. Consequently, apart from the individuals concerned, the public too has an interest in the returns to higher education to be in accordance with investments made. This is part of the reason why the concept of employability has become popular among policy makers in recent years. In particular, policy makers hope that increasing graduates' employability - i.e. aligning skill supply with skill demand - will lower youth unemployment by solving existing supply shortages and by stimulating economic growth through technological and organizational change and innovation (OECD, 1999; European Commission, 2010; Council of the European Union, 2012; OECD, 2013b).

The central theme of this thesis is the relationship between skills and university graduates' employability. While chapter 2 identifies the skills which graduates are expected to have in the 21st century and examines why this is the case, Chapter 3 tests the relative importance of these skills in the graduate recruitment process. Chapter 4 finds that individuals' personality traits are related to the types of skills individuals choose to acquire during their studies and proposes explanations for this relationship. Chapter 5 investigates the protective effect of different types of skills against unemployment and educational mismatch under various 
economic conditions. The results are relevant for a) prospective students in higher education - who have to make choices with regard to the types of skills they invest in, b) universities - which have to design curricula and trajectories which enable students to acquire the skills that make them employable, and c) policy makers - who have to define the framework of incentives which encourage universities and students to make employability an important criterion in their decision making processes.

The main findings of this thesis are:

- Low skills have dire effects on graduates' employability;

- Professional expertise and interpersonal skills are most important for graduates' employability;

- Entrepreneurial, strategic and innovative skills mainly determine graduates' later career advancement;

- Short-term equals long-term employability;

- Employers' preferences are diverse;

- Abilities and labour market prospects are not the only factors influencing flows into technical fields of study.

Most of the findings of this thesis support already existing findings, conclusions and arguments using different methods and different data. For example, this thesis finds further evidence for the importance of occupation-specific skills for graduates' employability, dismissing the persistent argument that in today's fast changing world graduates merely need to have transversal skills such as the ability to learn.

Chapter 6 section 2 formulates the following implications of this thesis' findings for universities and individual students:

\section{Implications for universities}

The significance of professional expertise and interpersonal skills for graduates' employability suggests that equipping students with these two types of skills should be considered a core task of initial higher education. Given the limited time available in higher education, this implies a trade-off with regard to the development of other types of skills, such as entrepreneurial skills.

While universities should make sure that graduates possess a certain minimum level of, for example, entrepreneurial and creative skills, further investment in these types of skills may be more efficient and effective after graduates have gathered a few years of work experience. This notwithstanding, universities should foster ways of teaching which enable students to develop several types of skills at the same time, such as problem-based learning, so that the trade-off between professional expertise and interpersonal skills on the one side, and entrepreneurial and creative skills on the other side, does not occur.

Another important finding of this thesis is that employers' preferences are very diverse. This has important implications for the skill profile and the breadth of professional expertise universities and students should strive for. Both graduates and universities have to know their market well in order to make good skill formation choices. As the employer does not exist, there is no standard solution to the trade-offs implied in acquiring a particular skill 
profile. For universities, it is important to know which student flows they manage. On the one hand, this refers to keeping track of the kind of employers for which they educate graduates and the particular skill profiles these employers demand. On the other hand, universities face the challenge to align the skill profiles they are aiming to produce to students' preferences and abilities. With regard study programmes in STEM fields, for example, this means equipping individuals who are on average more introvert with the level of interpersonal skills demanded by today's graduate labour market.

Finally, while the policy debate on higher education often focuses on excellence and its role in innovation and economic development, the costs incurred by firms due to underperforming employees are substantial. The detrimental effect of low skill levels on graduates' productivity suggests that fostering graduates' excellence must not be the only focus of higher education, and that guaranteeing that graduates possess the required minimum level of skills may even be more important. Moreover, for graduates' transition from education to work to be smooth, universities have to provide graduates with qualifications which send a strong signal of employability to employers.

\section{Implications for individual students}

For individual students, the challenge is to choose their studies carefully. In this respect, prospective students, students and graduates have to be aware of the importance of a specific body of knowledge, the ability to apply this knowledge to novel problems, and the ability to work effectively in a team for their chances of getting a job within the envisaged field and at the adequate level.

Variation in the breadth of graduates' professional expertise has important implications for the job options available to them when entering the labour market. While a large specific body of knowledge increases graduates' chances to find a job within their field of study, high levels of academic skills increase graduates' employability in the labour market segment in which productivity depends on general skills (Chapter 5).

The implications of employers' diversity for students in higher education are straight forward: employers demand a variety of graduate profiles which offers individuals some freedom with regard to educational and work-related choices. However, some graduate profiles are more employable than others and some trade-offs are worth making and some are not (Chapter 3). Employers base their hiring decisions on low adjustment and training costs. As a result, students should invest in the types of skills which give them a comparative advantage in the kind of jobs they envisage to work in, given their preferences and abilities.

The findings of this thesis and their implications have been presented to relevant stakeholders on several occasions, for example during a round table discussion on employability organised by the European Association of Institutions in Higher Education (EURASHE), during an internal seminar on employability and competences with staff responsible for teaching at the School of Business and Economics, Maastricht University, in the form of a policy paper for the OECD, and in an article for the Microsoft Futures Magazine. Moreover, chapter 3 is based on a study on graduates' employability for the European Commission which will use the results in the European policy making process. Similarly, the conclusions of this thesis will inform future contract research performed by the authors and by other ROA staff. 



\section{BIBLIOGRAPHY}

Acemoglu, D. (1998). Why Do New Technologies Complement Skills? Directed Technical Change and Wage Inequality. Quarterly Journal of Economics, 113, 1055-89.

Acs, Z.J. (1992). Small Business Economics: A Global Perspective. Challenge, 35 (6), 38-45.

Ai, C. and Norton, E.C. (2003). Interaction terms in logit and probit models, Economics Letters, 80, 123-29. Aigner, D.J. and Cain, G.G. (1977). Statistical Theories of Discrimination in Labor Markets. Industrial and Labor Relations Review, 1977, 30 (1), 175-87.

Allen, J. (2011). Mobilization of Human Resources. In: J. Allen and R. Van der Velden (eds.), The Flexible Professional in the Knowledge Society: New Challenges for Higher Education. Dordrecht, Heidelberg, London, New York: Springer, 139-76.

Allen, J. and Van der Velden, R. (2001). Educational Mismatches versus Skill Mismatches: Effects on Wages, Job Satisfaction, and On-the-Job Search. Oxford Economic Papers, 53 (3), 434-52.

Allen, J. and Van der Velden, R. (2011). The Flexible Professional in the Knowledge Society: Required Competences and the Role of Higher Education. In: J. Allen, and R. Van der Velden (eds.), The Flexible Professional in the Knowledge Society: New Challenges for Higher Education, Higher Education Dynamics, 35. Dordrecht, Heidelberg, London, New York: Springer, 15-53.

Allen, J., Coenen, J. and Humburg, M. (2011). The Transition and Early Career. In: J. Allen, S. Pavlin and R. Van der Velden (eds.), Competencies and Early Labour Market Careers of Higher Education Graduates in Europe. University of Ljubljana: Faculty of Social Sciences, 29-54.

Allen, J., Pavlin, S. and Van der Velden, R. (eds.) (2011). Competencies and Early Labour Market Careers of Higher Education Graduates in Europe. University of Ljubljana: Faculty of Social Sciences.

Allmendinger, J. (1989). Educational Systems and Labour Market Outcomes. European Sociological Review, 5, 231-50.

Altonji, J.G. and Pierret, C.R. (2001). Employer Learning and Statistical Discrimination. Quarterly Journal of Economics, 116 (1), 313-50.

Antecol, H. and Cobb-Clark, D. (2013). Do psychosocial traits explain gender segregation in young people's occupations? Labour Economics, 21, 59-73.

Appelbaum, E., Bailey, T., Berg, P. and Kalleberg, A.L. (2000). Manufacturing Advantage: Why High-Performance Work Systems Pay Off. Ithaca, N.Y.: ILR Press

Arcidiacono, P. (2004). Ability sorting and the returns to college major. Journal of Econometrics, 121 (1-2), 343-75.

Arcidiacono, P., Hotz V.J. and Kang, S. (2012). Modeling college major choices using elicited measures of expectations and counterfactuals. Journal of Econometrics, 166 (1), 3-16.

Arnal, E., Ok, W. and Torres, R. (2001). Knowledge, Work Organisation and Economic Growth, OECD Labour Market and Social Policy Occasional Papers, 50, Paris: OECD Publishing.

Arrow, K.J. (1998). What has Economics to Say about Racial Discrimination? Journal of Economic Perspectives, 12 (2), 91-100.

Astebro, T. and Thompson, P. (2011). Entrepreneurs, Jacks of all trades or Hobos? Research Policy, 40, 637-49. 
Audretsch, D.B. and Thurik, A.R. (2000). Capitalism and democracy in the 21st Century: from the managed to the entrepreneurial economy. Journal of Evolutionary Economics, 10, 17-34.

Autor. D., Levy, F. and Murnane, R. (2003). The Skill Content of Recent Technological Change: An Empirical Exploration. Quarterly Journal of Economics, 118 (4), 1279-1334.

Barón, J.D. and Cobb-Clark, D.A. (2010). Are Young People's Educational Outcomes Linked to their Sense of Control? IZA Discussion Papers 4907, Institute for the Study of Labor (IZA).

Barone, C. and Ortiz, Luis (2011). Overeducation among European University Graduates: a comparative analysis of its incidence and the importance of higher education differentiation. Higher Education, 61, 325-37.

Barrick, M.R. and Mount, M.K. (1991). The Big Five personality dimensions and job performance: a metaanalysis. Personnel Psychology, 44, 1-26.

Bartel, A.P. (2004). Human Resource Management and Organizational Performance: Evidence from Retail Banking. Industrial and Labor Relations Review, 57 (1), 181-202.

Becker, G. S. (1962). Investment in human capital: A theoretical analysis. Journal of Political Economy, 70, 9-49.

Bell, D. (1999). The Coming of Post-Industrial Society: A Venture in Social Forecasting. New York: Basic Books.

Berger, M.C. (1988). Predicted Future Earnings and Choice of College Major. Industrial and Labor Relations Review, 41 (3), 418-29.

Bernstein, P. (1997). American Work Values: Their Origin and Development. Albany: State University of New York Press.

Betcherman, G. (1997). Changing Workplace Strategies: Achieving Better Outcomes for Enterprises, Workers and Society. Ottawa: Government of Canada and OECD.

Biesma, R.G., Pavlova, M., Van Merode, G.G. and Groot, W. (2007). Using conjoint analysis to estimate employers preferences for key competencies of master level Dutch graduates entering the public health field. Economics of Education Review, 26 (3), 375-86.

Bills, D.B. (2004). The Sociology of Education and Work. Malden, Oxford and Victoria: Blackwell.

Bils, M. and Klenow, P. (2000). Does Schooling Cause Growth? American Economic Review, 90(5), 11601183.

Bishop, J. (1995). Expertise and Excellence, CAHRS Working Paper Series, No. 95-13, Cornell University, Ithaca, NY.

Black, S.E. and Lynch, L.M. (2004). What's driving the New Economy: the benefits of workplace innovation, Economic Journal, 117, 97-116.

Borghans, L. and de Grip, A. (eds.) (2000). The Overeducated Worker? The Economics of Skill Utilization. Cheltenham: Edward Elgar.

Borghans, L., Duckworth, A.L., Heckman, J.J. and ter Weel, B. (2008). The Economics and Psychology of Personality Traits. Journal of Human Resources, 43 (4), 972-1059.

Borghans, L., Romans, M. and Sauermann, J. (2010). What makes a good conference? Analysing the preferences of labour economists. Labour Economics, 17 (5), 868-74.

Borghans, L., ter Weel, B. and Weinberg, B.A. (2008). Interpersonal styles and labour market outcomes. Journal of Human Resources, 43 (4), 815-58.

Bowles, S. and Gintis, H. (1976). Schooling in Capitalist America: Educational Reform and the Contradictions of Economic Life. New York: Basic Books.

Brenner, R. (2006). The Economics of Global Turbulence. The Advanced Capitalist Economies from Long Boom to Long Downturn, 1945-2005. London, New York: Verso. 
Bresnahan, T.F., Brynjolfsson, E. and Hitt, L.M. (2002). Information Technology, Workplace Reorganization, and the Demand for Skilled Labor: Firm-Level Evidence. Quarterly Journal of Economics, 117 (1), 339-76.

Brock, W.A. and Evans, D.S. (1989). Small business economics, Small Business Economics, 1, 7-20.

Campbell, P.B. and Laughlin, S. (1991). Participation in Vocational Education: An Overview of Patterns and their Outcomes, National Center for Research in Vocational Education: Columbus, $\mathrm{OH}$.

Carlsson, B. (1989). The Evolution of Manufacturing Technology and its Impact on Industrial Structure: An International Study, Small Business Economics, 1, 21-37.

Carlsson, B. (1992). The Rise of Small Business: Causes and Consequences. In W.J. Adams (ed.), Singular Europe, Economy and Policy of the European Community after 1992. Ann Arbor, MI: University of Michigan Press, 145-69.

Carlsson, B. (1999). Small Business, Entrepreneurship, and Industrial Dynamics. In Z. Acs (ed.), Are Small Firms Important? Boston/Dordrecht: Kluwer Academic Publishers, 99-110.

Caroli, E. and Van Reenen, J. (2001). Skill-Biased Organizational Change: Evidence From A Panel Of British and French Establishments, Quarterly Journal of Economics, 116 (4), 1449-92.

Carree, M.A. and Thurik, A.R. (2003). The Impact of Entrepreneurship on Economic Growth. In Z.J. Acs and D.B. Audretsch (eds.), Handbook of Entrepreneurship Research, Kluwer Academic Publishers, 437-71.

Carroll, J.D. and Green, P.E. (1995). Psychometric methods in marketing research: Part I, conjoint analysis. Journal of Marketing Research, 385-91.

Castells, M. (1996). Enterprises and Jobs: Jobs in the Network Enterprise. Discussion paper for the ILO Enterprise Forum 96.

Castells, M. (2000). The Rise of the Network Society ( $2^{\text {nd }}$ edition). Cambridge, MA, Oxford: Blackwell.

Cattan, S. (2010). Heterogeneity and Selection in the Labor Market. PhD Thesis, Economics Department, University of Chicago.

Cattin, P. and Wittink, D.R. (1982). Commercial use of conjoint analysis: A Survey. Journal of Marketing, 46, 44-53.

Chamorro-Premuzic, T. and Furnham, A. (2005). Personality and intellectual competence. Mahwah, NJ: Lawrence Erlbaum Associates.

Chevalier, A. (2003). Measuring over-education. Economica, 70, 509-31.

Chevalier, A. and Lindley, J. (2009). Overeducation and the skills of UK graduates, Journal of the Royal Statistical Society: Series A (Statistics in Society), 172, 307-37.

Cobb-Clark, D. and Tan, M. (2011). Noncognitive Skills, Occupational Attainment, and Relative Wages. Labour Economics, 18 (1), 1-13.

Costa, P.T. and McCrae, R.R. (1985). The NEO personality inventory manual. Odessa, FL: Psychological Assessment Resources.

Council of the European Union (2012). Council conclusions of 26 November 2012 on education and training in Europe 2020 - the contribution of education and training to economic recovery, growth and jobs. Official Journal of the European Union, C393, 5-7.

Crafts, N. and Toniolo, G. (1996). Postwar Growth: An overview. In: N. Crafts and G. Toniolo (eds.), Economic Growth in Europe since 1945, Cambridge: Cambridge University Press, 1-37.

Crouch, C. (2005). Capitalist Diversity and Change: Recombinant Governance and Institutional Entrepreneurs. Oxford: Oxford University Press.

Cunha, F. and Heckman J. (2007). The Technology of Skill Formation. American Economic Review, 97 (2), 31-47. 
De Fruyt, F. and Bartels, M., Van Leeuwen, K.G., de Clercq, B., Decuyper, M., Mervielde, I. (2006). Five Types of Personality Continuity in Childhood and Adolescence. Journal of Personality and Social Psychology, 91(3), 538-52.

De Fruyt, F. and Mervielde, I. (1997). The Five-Factor Model of Personality and Holland's RIASEC Interest Types. Personality and Individual Differences, 23 (1), 87-103.

Dede, C. (2010). Comparing Frameworks for 21st Century Skills. In J. Bellanca and R. Brandt (eds.), 21st Century Skills. Bloomington, IN: Solution Tree Press, 51-76.

Devereux, P.J. (2002). Occupational Upgrading and the Business Cycle. Labour, 16, 423-52.

DiPrete, T.A., Goux, D., Maurin, E. and Quesnel-Vallee, A. (2006). Work and Pay in Flexible and Regulated Labor Markets: A Generalized Perspective on Institutional Evolution and Inequality Trends in Europe and the US. Research in Social Stratification and Mobility, 24, 311-32.

Dolton, P. and Vignoles, A. (2000). The incidence and effects of overeducation in the U.K. graduate labour market. Economics of Education Review, 19, 179-98.

Eckhardt, J.T. and Shane, S.A. (2003). Opportunities and Entrepreneurship. Journal of Management, 29 (3), 333-49.

Ericsson, K.A. and Crutcher, R.J. (1990). The Nature of Exceptional Performance. In: P.B. Baltes, D.L. Featherman and R.M. Lerner (eds.), Life-Span Development and Behavior. Hillsdale, NJ: Lawrence Erlbaum.

Eriksson, S., Johansson, P. and Langenskiöld, S. (2012). What is the Right Profile for Getting a Job? A Stated Choice Experiment of the Recruitment Process. IZA Discussion Papers 6691, Institute for the Study of Labor (IZA).

European Commission (2007). Key Competences for Lifelong Learning - A European Framework. Luxembourg: Office for Official Publications of the European Communities.

European Commission (2008). New Skills for New Jobs: Anticipating and Matching Labor Market and Skills Needs. Commission Staff Working Document. Brussels: European Commission.

European Commission (2010). An Agenda for new skills and jobs: A European contribution towards full employment. $\operatorname{COM}(2010) 682$ final.

Eurostat (2013). Unemployment rates by sex, age and highest level of education attained (\%). Downloaded from Eurostat website on 18.11.2013.

Evans, P. (1999). Occupational Downgrading and Upgrading in Britain. Economica, 66, 79-96.

Felstead, A., Gallie, D., Green, F. and Zhou, Y. (2007). Skills at Work, 1986 to 2006, Universities of Oxford and Cardiff, ESRC Centre on Skills, Knowledge and Organisational Performance.

Filer, R.K. (1986). The role of personality and tastes in determining occupational structure. Industrial and Labor Relations Review, 39 (3), 412-24.

Flyer, F.A. (1997). The Influence of Higher Moments of Earnings Distributions on Career Decisions. Journal of Labor Economics, 15(4), 689-713.

Froud, J., Shukdev, J., Leaver, A. and Williams, K. (2006). Financialization and strategy: narratives and numbers, London: Routledge.

Gautier, P.A., Van den Berg, G., Van Ours, G.C. and Ridder, G. (2002). Worker turnover at the firm level and crowding out of lower educated workers. European Economic Review, 46, 523-38.

Gesthuizen, M. and Wolbers, M.H.J. (2010). Employment transitions in the Netherlands, 1980-2004: Are low educated men subject to structural or cyclical crowding out? Research in Social Stratification and Mobility, 28, 437-51. 
Goux, D. and Maurin, E. (1994). Education, Expérience et Salaire: Tendances Recentes et Evolution de Long Terme. Economie et Prévision, 116, 155-78.

Green, F. and Zhu Y. (2010). Overqualification, job dissatisfaction, and increasing dispersion in the returns to graduate education. Oxford Economic Papers, 62 (4), 740-63.

Greenan, N. (2003). Organizational Change, Technology, Employment and Skills: An Empirical Study of French Manufacturing. Cambridge Journal of Economics, 27, 287-316.

Groot, W. and Maassen van den Brink, H. (2000). Overeducation in the Labour Market, a Meta-analysis. Economics of Education Review, 19, 149-58.

Hage, J. and Powers, C.H. (1992). Post-Industrial Lives: Roles and Relationships in the $21^{\text {st }}$ Century. Newbury Park: Sage.

Hartog, J. (1992). Capabilities, allocation and earnings. Dordrecht: Kluwer Academic.

Hartog, J. (2000). Overeducation and Earnings: Where are we, Where should we go? Economics of Education Review, 19, 131-47.

Hayes, J. (1981). The Complete Problem Solver. Philadelphia: The Franklin Institute Press.

Heckman, J.J., Stixrud, J. and Urzua, S. (2006). The Effects Of Cognitive and Noncognitive Abilities On Labor Market Outcomes and Social Behavior. Journal of Labor Economics, 24 (3), 411-82.

Heijke, H., Meng, C. and Ris, C. (2003). Fitting to the Job: the role of generic and vocational competencies in adjustment and performance. Labour Economics, 10, 215-29.

Heineck, G. and Anger, S. (2010). The return to cognitive abilities and personality traits in Germany. Labour Economics, 17, 535-46.

Hendriks, J.A.A., Hofstee W.K.B. and de Raad, B. (1999). The Five-Factor Personality Inventory (FFPI). Personality and Individual Differences, 27, 307-25.

Hensher, D. and Greene, W. (2003). The Mixed Logit model: The state of practice. Transportation, 30 (2), 133-76.

Hofstee, W.K.B. and Hendriks, A.A.J. (1998). The use of scores anchored at the scale midpoint in reporting individuals' traits. European Journal of Personality, 12, 219-28.

Holland, J.L. (1997). Making Vocational Choices: A Theory of Vocational Personalities and Work Environments, $3^{\text {rd }}$ Edition, Odessa, FL: Psychological Assessment Resources.

Hujer, R., Caliendo, M. and Radic, D. (2002). Skill Biased Technological and Organizational Change: Estimating a Mixed Simultaneous Equation Model Using the IAB Establishment Panel. IZA Discussion Paper 566, Bonn: IZA.

Humburg, M. and Van der Velden, R. (2013). What is expected of higher education graduates in the 21st century? Research Memorandum 2013/13, Research Centre for Education and the Labour Market (ROA). Forthcoming in: J. Buchanan, D. Finegold, K. Mayhew and C. Warhurst (eds.), Oxford Handbook of Skills and Training. Oxford: Oxford University Press.

Judge, T.A. and Cable, D.M. (1997). Applicant Personality, Organizational Culture, And Organization Attraction. Personnel Psychology, 50, 359-94.

Judge, T.A., Livingston, B.A. and Hurst, C. (2012). Do Nice Guys—and Gals—Really Finish Last? The Joint Effects of Sex and Agreeableness on Income. Journal of Personality and Social Psychology, 102 (2), 390-407.

Kang, S. and Bishop, J. (1989). Vocational and academic education in high school: Complements or substitutes? Economics of Education Review, 8, 133-48.

Karoly, L.A. (2004). The 21st Century at Work: Forces Shaping the Future Workforce and Workplace in the United States. Santa Monica, CA: RAND Corporation. 
Keane, M. and Prasad, E. (1993). Skill Levels and the Cyclical Variability of Employment, Hours, and Wages, Staff Papers - International Monetary Fund, 40, 711-43.

Knight, J.B. (1979). Job Competition, Occupational Production Functions, and Filtering. Oxford Economic Papers, 31 (2), 187-204.

Krueger, A.B. and Schkade, D. (2008). Sorting in the Labor Market: Do Gregarious Workers Flock to Interactive Jobs? Journal of Human Resources, 43 (4), 859-83.

Kuyper, H. and Van der Werf, M.P.C. (2003).VOCL'99: De resultaten in het eerste leerjaar. Groningen: GION. Lazear, E.P. (2004). Balanced skills and entrepreneurship. American Economic Review, 94 (2), 208-11.

Lazear, E.P. (2005). Entrepreneurship. Journal of Labor Economics, 23 (4), 649-80.

Leuven, E. and Oosterbeek, H. (2011). Overeducation and Mismatch in the Labor Market. IZA Discussion Papers 5523, Institute for the Study of Labor (IZA).

Levels, M., Van der Velden, R.K.W., and Allen, J. (2013). Educational mismatches and skills: New empirical tests of old hypotheses. Research Memorandum 2013/18, Research Centre for Education and the Labour Market (ROA)

Levy, F. (2010). How Technology Changes Demands for Human Skills, OECD Education Working Papers 45. Paris: OECD Publishing.

Louviere, J.J., Hensher, D.A. and Swait, J.D. (2000). Stated choice methods: analysis and applications. New York: Cambridge University Press.

Loveman, G. and Sengenberger, W. (1991). The re-emergence of small-scale production; an international comparison. Small Business Economics, 3, 1-37.

Mane, F. (1999). Trends in the payoff to academic and occupation-specific skills: the short and medium run returns to academic and vocational high school courses for non-college-bound students. Economics of Education Review, 18, 417-37.

Mason, G. (1998). Diversity and change: The challenges facing chemistry higher education. London: Royal Society of Chemistry/Council for Industry and Higher Education.

Mason, G. (1999). The labour market for engineering, science and IT graduates: Are there mismatches between supply and demand. Research Report No. 112, Department for Education and Employment London.

Mason, G., Williams, G. and Cranmer, S. (2009). Employability Skills Initiatives in Higher Education: what effect do they have on graduate labour market outcomes? Education Economics, 17 (1), 1-30.

McFadden, D. (1974). Conditional Logit Analysis of Qualitative Choice Behavior. In P. Zarembka (ed.), Frontiers in Economics, New York: Academic Press, 105-42.

McGuinness, M. (2003). University quality and labour market outcomes. Applied Economics, 35 (18), 1943-55.

Meredith, J. (1987). The Strategic Advantages of New Manufacturing Technologies for Small Firms. Strategic Management Journal, 8, 249-258.

Miles, I. and Martinez-Fernandez, C. (2011). Implications for Skills, Employment and Management. In: C. Martinez-Fernandez, I. Miles and T. Weyman (eds.), The Knowledge Economy at Work: Skills and Innovation in Knowledge Intensive Service Activities, Cheltenham: Edward Elgar, 239-65.

Mount, M.K., Barrick, M. R. and Stewart, G.L. (1998). Five-factor model of personality and Performance in jobs involving interpersonal interactions. Human Performance, 11, 145-65.

Mueller, G. and Plug, E.J.S. (2006). Estimating the Effect of Personality on Male and Female Earnings. Industrial and Labor Relations Review, 60 (1), 1-22. 
Muffels, R.J.A. (2008). Flexibility and Employment Security in Europe: Setting the Scene. In R.J.A Muffels (ed.), Flexibility and Employment Security in Europe: Labour Markets in Transition. Cheltenham, Northampton: Edward Elgar, 3-30.

Müller, W. and Gangl, M. (2003). The transition from school to work. A European perspective. In W. Müller and M. Gangl (eds.), Transitions from education to work in Europe. The integration of youth into EU labour markets. Oxford: Oxford University Press, 1-19.

Nelson, R. and Phelps, E. (1966). Investment in Humans, Technological Diffusion, and Economic Growth. American Economic Review, 56 (1/2), 69-75.

Nickell, S. and Bell, B. (1995). The collapse in demand for the unskilled and unemployment across the OECD. Oxford Review of Economic Policy, 11, 40-62.

Nyhus, E.K. and Pons, E. (2005). The effects of personality on earnings. Journal of Economic Psychology, 26, 363-84.

O'Connor, M.C. and Paunonen, S.V. (2007). Big Five personality predictors of post-secondary academic performance. Personality and Individual Differences, 43, 971-90.

OECD (1999). Economic Outlook. Paris: OECD Publishing.

OECD (2012). Literacy, Numeracy and Problem Solving in Technology-Rich Environments: Framework for the OECD Survey of Adult Skills. Paris: OECD Publishing.

OECD (2013a), OECD Skills Outlook 2013: First Results from the Survey of Adult Skills. OECD Publishing.

OECD (2013b), Education at a Glance 2013: OECD Indicators. OECD Publishing.

OECD/Eurostat (2005). Oslo Manual: Guidelines for Collecting and Interpreting Innovation Data (3rd edition). The Measurement of Scientific and Technological Activities. Paris: OECD Publishing.

Parker, R. (2001).The myth of the entrepreneurial economy: Employment and innovation in small firms. Work, Employment and Society, 15 (2), 239-53.

Pavlin, S. and Svetlik, I. (2011). The World of Work and the Demand for Competences. In: J. Allen, S. Pavlin and R. Van der Velden (eds.), Competencies and Early Labour Market Careers of Higher education Graduates in Europe. University of Ljubljana: Faculty of Social Sciences, 73-106.

Payne, J. (1995). Options at 16 and Outcomes at 24: a Comparison of Academic and Vocational Education and Training Routes. Youth Cohort Report 35, Department for Education and Employment, Sheffield.

Phelps, E.S. (1972). The Statistical Theory of Racism and Sexism. American Economic Review, 62, 659-61.

Piore, M.J. and Sabel, C.F. (1984). The Second Industrial Divide: Possibilities for Prosperity. New York: Basic Books.

Pollert, A. (1988). The "Flexible Firm": Fixation or Fact? Work, Employment and Society, 2, 281-316.

Pollmann-Schult, M. (2005). Crowding-out of Unskilled Workers in the Business Cycle: Evidence from West Germany. European Sociological Review, 21, 467-80.

Pouliakas, K. and Theodossiou, I. (2010). Measuring the Utility Cost of Temporary Employment Contracts Before Adaptation: A Conjoint Analysis Approach. Economica, 77, 688-709.

Ramsay, H. (1996). Managing Sceptically: A Critique of Organisational Fashion. In: S.R. Clegg and G. Palmer (eds.), The Politics of Management Knowledge. New York: Russell Sage Foundation, 155-72.

Reich, R.B. (1992). The Work of Nations: Preparing Ourselves for 2/st-CenturyCapitalism. New York: Knopf.

Revelt, D. and Train, K. (1998). Mixed Logit With Repeated Choices: Households' Choices Of Appliance Efficiency Level. Review of Economics and Statistics, 80 (4), 647-57.

ROA (2011). Maastricht University graduate survey (UM Scanner), Research Centre for Education and the Labour Market. Available at: http://www.roa.unimaas.nl/projects/umscanner/umscanner.htm (October 2013) 
Roberts, B., Caspi, A. and Moffit, T., (2001). The Kids Are Alright: Growth and Stability in Personality Development From Adolescence to Adulthood. Journal of Personality and Social Psychology, 81 (4), 67083.

Rosen, S. (2002). Markets and Diversity. American Economic Review, 92, 1-15.

Rossi, P., McCulloch, R. and Allenby, G. (1996). On the Value of Household Purchase History Information in Target Marketing. Marketing Science, 15, 321-40.

Ryan, M. (2004). Discrete choice experiments in health care. British Medical Journal, 328, 360-61.

Ryan, P. (2001). The School-to-Work Transition: A Cross-National Perspective. Journal of Economic Literature, 39, 34-92.

Rychen, D.S. and Salganik, L.H. (eds.) (2003). Key Competencies for a Successful Life and a Well-Functioning Society, Göttingen: Hogrefe and Huber.

Sattinger, M. (1993). Assignment models of the distribution of earnings. Journal of Economic Literature, 31, 831-80.

Sawtooth Software (2000). An Overview and Comparison of Design Strategies for Choice-Based Conjoint Analysis. Research Paper Series, Sawtooth Software.

Schmid, G. (1998). Transitional Labor Markets: A new European Employment Strategy. WZB Discussion Paper FS / 98-206. Berlin:WZB.

Schultz, T. W. (1975). The Value of the Ability to Deal with Disequilibria. Journal of Economic Literature, $13(3), 872-76$.

Semlinger, K. (1992). Small Firms in Big Subcontracting. In: N. Altmann, C. Koehler and P. Meil (eds.), Technology and Work in German Industry. London, New York: Routledge, 342-58.

Shavit, Y., Arum, R. and Gamoran, A. with Menahem, G. (eds.) (2007), Stratification in Higher Education: A Comparative Study. Stanford, California: Stanford University Press.

Silva, O. (2007). The Jack-of-all-trades entrepreneur: innate talent or acquired skill? Economics Letters, 97 (3), 118-23.

Sloane, P. (2003). Much Ado About Nothing? What Does the Overeducation Literature Really Tell Us? In: F. Büchel, A. de Grip and A. Mertens (eds.), Over-education in Europe: Current issues in theory and policy. Cheltenham: Edward Elgar.

Spence, M. (1973). Job Market Signaling. Quarterly Journal of Economics, 87 (3), 355-74.

Stone, K.V.W. (2006). Thinking and Doing: The Regulation of Workers' Human Capital in the United States. Socio-Economic Review, 4, 121-38.

Teulings, C. and Koopmanschap, M. (1989). An econometric model of crowding out of lower education levels. European Economic Review, 33, 1653-64.

Thurow, L.C. (1975). Generating Inequality. Basic Books, New York.

Tokar, D. M., Fischer, A.F. and Subich, M.L. (1998). Personality and Vocational Behavior: A Selective Review of the Literature (1993-1997). Journal of Vocational Behavior, 53 (2), 115-53.

Train, K. (2009). Discrete Choice Models with Simulation. Cambridge books, Cambridge: Cambridge University Press.

Trow, M. (2000). From Mass Higher Education to Universal Access: the American Advantage. Minerva, 37 (4), 303-28.

Turner, S.E. and Bowen, W.G. (1999). The Changing (Unchanging) Gender Gap. Industrial and Labor Relations Review, 52 (2), 289-313.

Van Beek, K.W.H., Koopmans, C.C. and Van Praag, B.M.S. (1997). Shopping at the labour market: A real tale of fiction. European Economic Review, 41 (2), 295-317. 
Van Berkel, K. (1999). Steekproef voor schoolloopbaan onderzoek VOCL'99. Heerlen: Statistics Netherlands.

Van der Velden, R. (2011). De effecten van betrouwbaarheid van onderwijsdiploma's op arbeidsproductiviteit: toepassing van een simulatiemodel. In: J.Dronkers (ed), Goede bedoelingen in het onderwijs: Kansen en missers. Mens en Maatschappij, 27-49.

Van der Velden, R. and Wolbers, M. (2003). The Integration of Young People into the Labour Market: The Role of Training Systems and Labour Market Regulation, In: W. Mülller and M. Gangl (eds.), Transitions from Education to Work in Europe. The Integration of Youth into EU Labour Markets, Oxford: Oxford University Press, 186-211.

Van der Velden, R.K.W. and Van Smoorenburg M.S.M. (1997). The Measurement of Overeducation and Undereducation: Self-Report vs. Job-Analyst Method, Research Centre for Education and the Labour Market Research Memorandum 1997/2E, Maastricht.

Van Dijk, J. (2005). The Deepening Divide. Inequality in the Information Society. London: Sage Publications. Van Ours, J.C. and Ridder, G. (1995) Job matching and job competition: Are lower educated workers at the back of job queues? European Economic Review, 39, 1717-31.

Van Smoorenburg, M.S.M. and Van der Velden, R.K.W. (2000). The training of school-leavers: Complementarity or substitution? Economics of Education Review, 19, 207-17.

Venkataraman, S. (1997). The distinctive domain of entrepreneurship research: An editor's perspective. In J. Katz and R. Brockhaus (eds.), Advances in entrepreneurship, firm emergence and growth: Vol. 3, Greenwich, CT: JAI Press, 119-38.

Verhaest, D. and Van der Velden, R. (2013). Cross-country Differences in Graduate Overeducation. European Sociological Review, 29 (3), 642-53.

Verluyten, P. (2001). Intercultural Communication in Business and Organisations. An Introduction. Leuven, Leusden, London: Acco.

Wagner, J. (2003). Testing Lazear's Jack-of-all-trades view of entrepreneurship with German microdata. Applied Economics Letters, 10 (11), 687-89.

Wagner, J. (2006). Are nascent entrepreneurs Jacks-of-all-trades? A test of Lazear's theory of entrepreneurship with German microdata, Applied Economics, 38, 2415-419.

Weimer, S. (1992). Small Firms in Big Subcontracting. In: N. Altmann, C. Koehler and P. Meil (eds.), Technology and Work in German Industry. London, New York: Routledge, 313-22.

Wickramasinghe, N. and Von Lubitz, D. (2007). Knowledge-Based Enterprise. Theories and Fundamentals. Hershey: IGI Publishing.

Wieling, M. and Borghans, L. (2001). Discrepancies between supply and demand and adjustment processes in the labour market. Labour, 15 (1), 33-56.

Williams, K., Cutler, T., Williams, J. and Haslam, C. (1987). The end of mass production? Economy and Society, 16 (3), 405-39.

Wiswall, M. and Zafar, B. (2013). Determinants of College Major Choice: Identification Using an Information Experiment. Federal Reserve Bank of New York Staff Reports, no. 500.

Zafar, B. (2009). College Major Choice and the Gender Gap. Federal Reserve Bank of New York StaffReports, no. 364 



\section{BIOGRAPHY}

Martin Humburg studied International Relations (Economics, Law, Political Sciences and History) in Dresden, Lille, Berlin and Paris, and received his Master's degree from the Free University of Berlin in 2006. After graduation, Martin worked as a research associate at the Central Evaluation and Accreditation Agency Hannover (ZEvA). He joined the Research Centre for Education and the Labour Market (ROA) at Maastricht University in 2008 where he was first employed as research assistant and later as $\mathrm{PhD}$ candidate and researcher. Since April 2014 Martin has been working for ICF International in its Brussels office. 



\section{ROA DISSERTATION SERIES}

1. Lex Borghans (1993), Educational Choice and Labour Market Information, Maastricht, Research Centre for Education and the Labour Market.

2. Frank Cörvers (1999), The Impact of Human Capital on International Competitiveness and Trade Performance of Manufacturing Sectors, Maastricht, Research Centre for Education and the Labour Market.

3. Ben Kriechel (2003), Heterogeneity Among Displaced Workers, Maastricht, Research Centre for Education and the Labour Market.

4. Arnaud Dupuy (2004), Assignment and Substitution in the Labour Market, Maastricht, Research Centre for Education and the Labour Market.

5. Wendy Smits (2005), The Quality of Apprenticeship Training, Conflicting Interests of Firms and Apprentices, Maastricht, Research Centre for Education and the Labour Market.

6. Judith Semeijn (2005), Academic Competences and Labour Market Entry: Studies Among Dutch Graduates, Maastricht, Research Centre for Education and the Labour Market.

7. Jasper van Loo (2005), Training, Labor Market Outcomes and Self-Management, Maastricht, Research Centre for Education and the Labour Market.

8. Christoph Meng (2005), Discipline-Specific or Academic? Acquisition, Role and Value of Higher Education Competencies, Maastricht, Research Centre for Education and the Labour Market.

9. Andreas Ammermüller (2007), Institutional Effects in the Production of Education: Evidence from European Schooling Systems, Maastricht, Research Centre for Education and the Labour Market.

10. Bart Golsteyn (2007), The Ability to Invest in Human Capital, Maastricht, Research Centre for Education and the Labour Market

11. Raymond Montizaan (2010), Pension Rights, human capital development and wellbeing, Maastricht, Research Centre for Education and the Labour Market. 
12. Annemarie Nelen (2012), Part-Time Employment and Human Capital Development, Maastricht, Research Centre for Education and the Labour Market.

13. Jan Sauermann (2013), Human Capital, Incentives, and Performance Out- comes, Maastricht, Research Centre for Education and the Labour Market.

14. Harald Ulrich Pfeifer (2013), Empirical Investigations of Costs and Benefits of Vocational Education and Training, Maastricht, Research Centre for Education and the Labour Market.

15. Charlotte Büchner (2013), Social Background, Educational Attainment and Labor Market Integration: An Exploration of Underlying Processes and Dynamics, Maastricht, Research Centre for Education and the Labour Market.

16. Martin Humburg (2014), Skills and the Employability of University Graduates, Maastricht, Research Centre for Education and the Labour Market. 